RAHUL RAJ

\title{
Prognostic Models in Traumatic Brain Injury
}

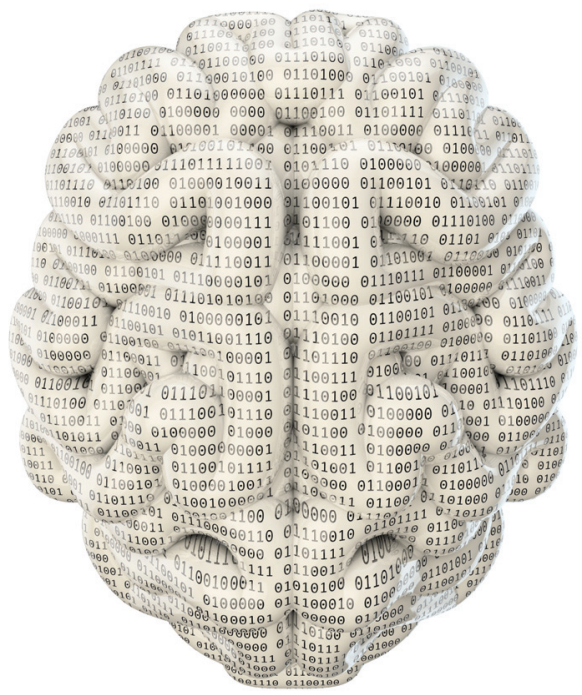

DEPARTMENT OF NEUROSURGERY

DEPARTMENT OF INTENSIVE CARE

HELSINKI UNIVERSITY CENTRAL HOSPITAL AND

FACULTY OF MEDICINE

DOCTORAL PROGRAMME IN CLINICAL RESEARCH UNIVERSITY OF HELSINKI 
Department of Neurosurgery

Department of Anesthesiology and Intensive Care

Helsinki University Central Hospital

Helsinki, Finland

$\&$

Faculty of Medicine and Doctoral School of Health Science

Doctoral Programme in Clinical Research

University of Helsinki

Helsinki, Finland

\title{
Prognostic Models in Traumatic Brain Injury
}

\author{
Rahul Raj
}

ACADEMIC DISSERTATION

To be presented,

with the permission of the Faculty of Medicine of the University of Helsinki, for public examination in Lecture Hall 1, of Töölö Hospital on 19 December 2014, at 12 noon.

Helsinki 2014 
Supervisors Associate Professor Jari Siironen, $\mathrm{MD}, \mathrm{PhD}$

Department of Neurosurgery

Helsinki University Central Hospital

Helsinki, Finland

Associate Professor Markus B. Skrifvars, MD, PhD, EDIC, FCICM

Department of Anaesthesiology and Intensive Care

Helsinki University Central Hospital

Helsinki, Finland

Reviewers Professor Juha Öhman, $\mathrm{MD}, \mathrm{PhD}$

Department of Neurosurgery

Tampere University Hospital

Tampere, Finland

Associate Professor Patrik Finne, MD, PhD

Department of Medicine, Division of Nephrology

Helsinki University Central Hospital

Helsinki, Finland

Opponent Professor Andrew Maas, MD, $\mathrm{PhD}$

Department of Neurosurgery

Antwerp University Hospital

Antwerp, Belgium

(C) Rahul Raj

Illustrations (C) Rahul Raj, except where indicated

Original Cover Image (c) Grandeduc| Dreamstime.com

ISBN 978-951-51-0129-7 (paperback)

ISSN 2342-3161 (print)

ISBN 978-951-51-0130-3 (PDF)

ISSN 2342-317X (online)

Hansaprint

Helsinki, 2014

Finland 


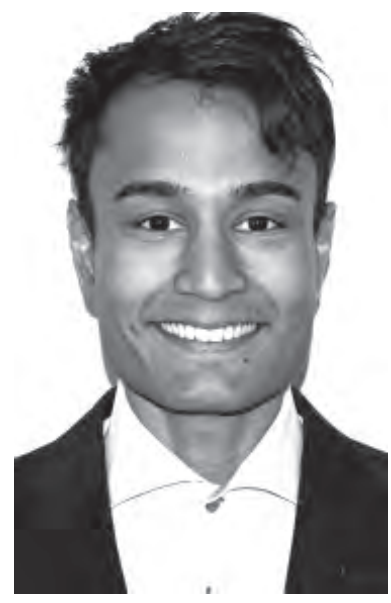

Author's contact information

\section{Rahul Raj}

Department of Neurosurgery

Helsinki University Central Hospital

Topeliuksenkatu 5

FI-00260, Helsinki

Finland

Mobile: +358443191190

E-mail: rahul.br.raj@icloud.com 

To my Mother \& Father 


\section{Table of Contents}

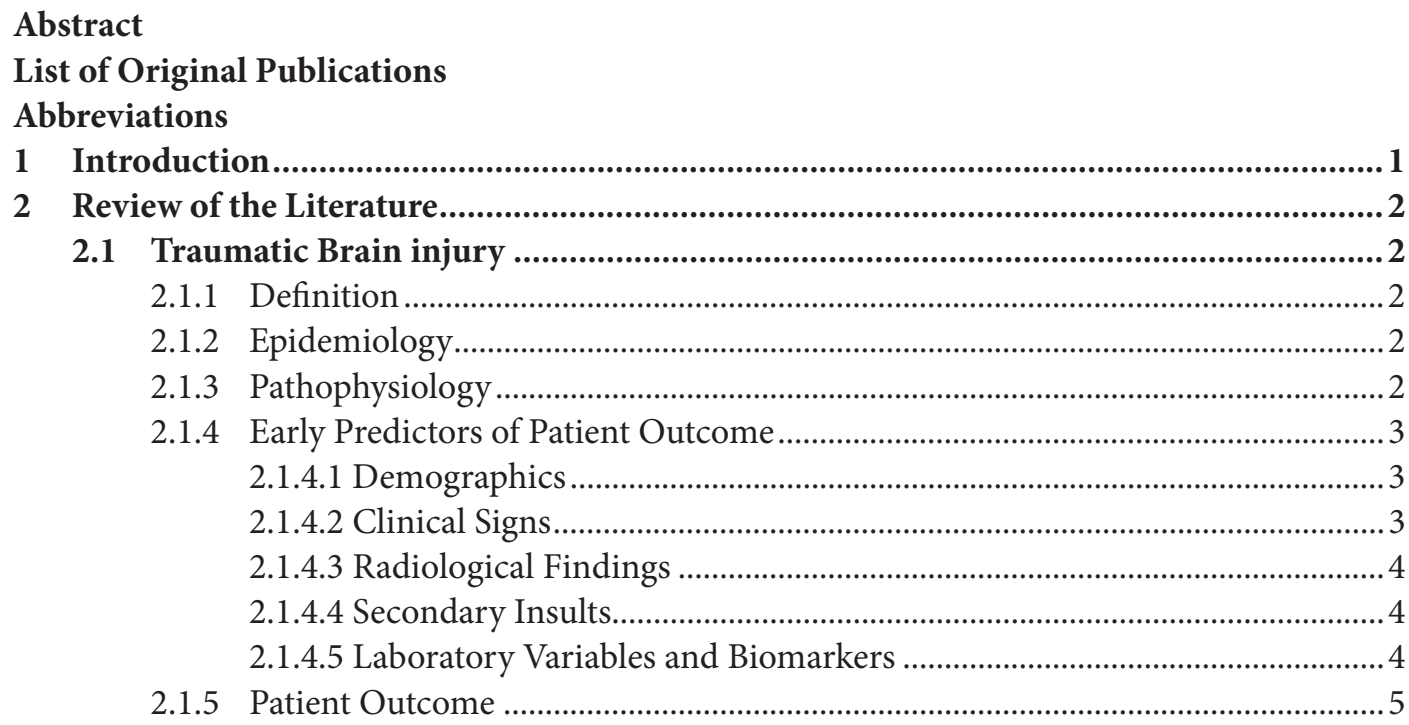

2.2 Prognostic Models .............................................................................................. 5

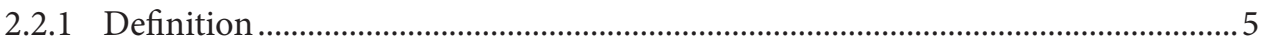

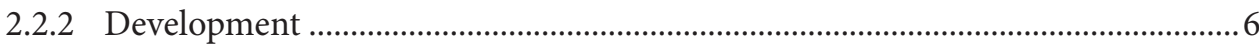

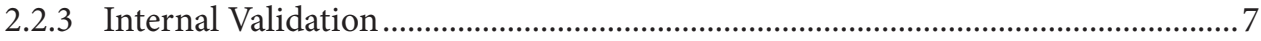

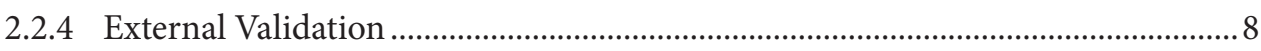

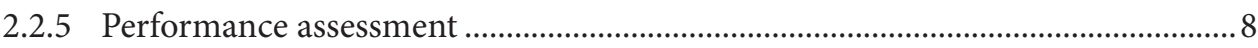

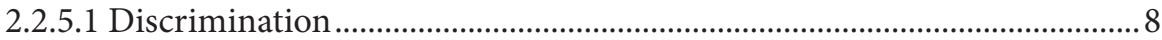

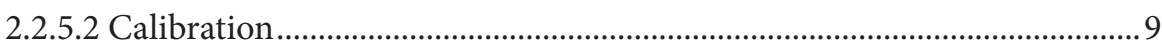

2.2.5.3 Overall performance measures..................................................................... 10

2.2.5.4 Net Reclassification Index .................................................................... 10

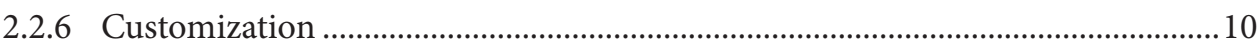

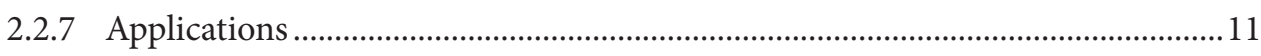

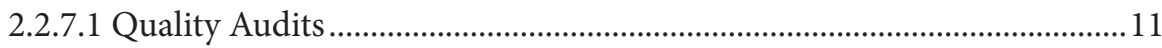

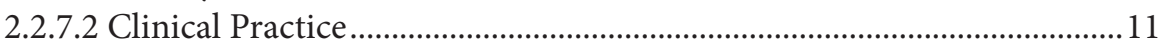

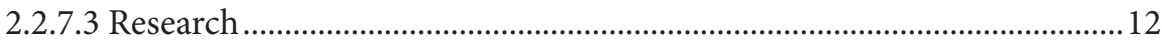

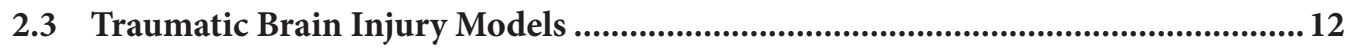

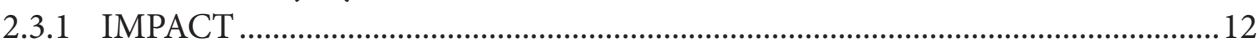

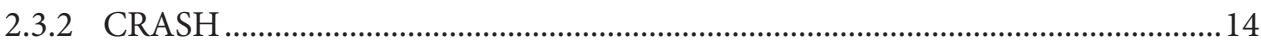

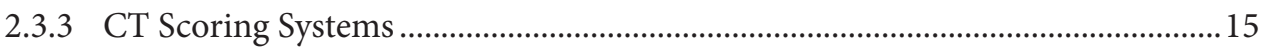

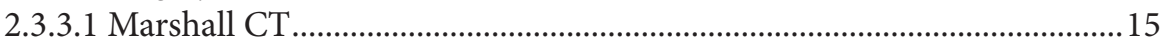

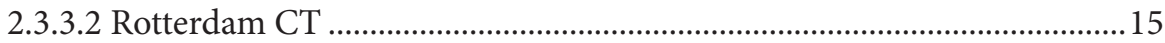

2.4 Trauma Scoring Systems ............................................................................ 16

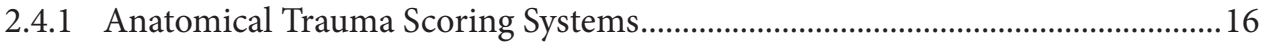

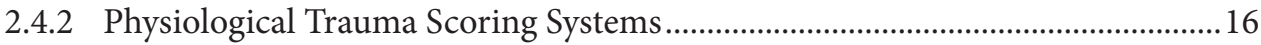

2.4.3 Combined Anatomical and Trauma Scores.......................................................... 16

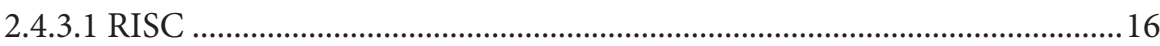

2.5 Intensive Care Scoring Systems..................................................................... 18

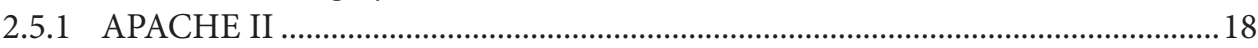

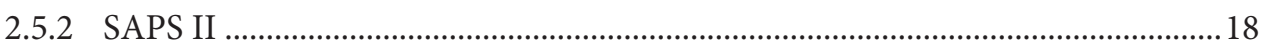

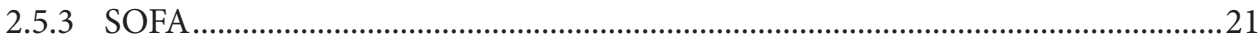




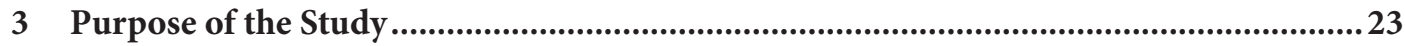

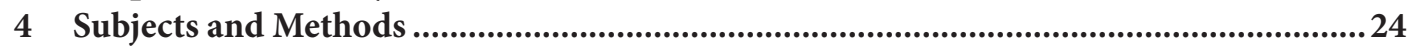

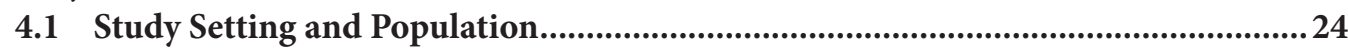

4.1.1 Traumatic Brain Injury Models (I-III) .............................................................24

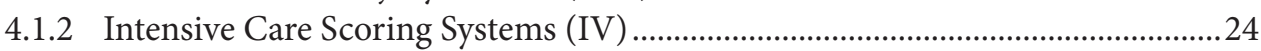

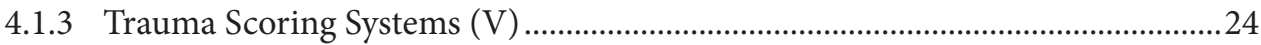

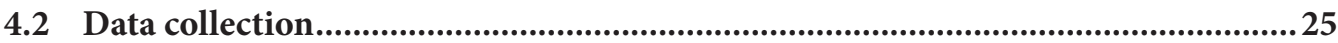

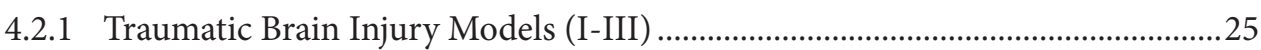

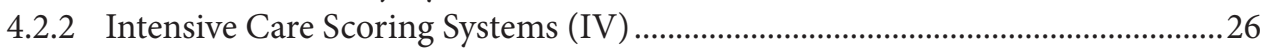

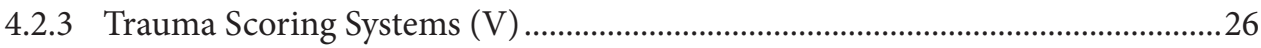

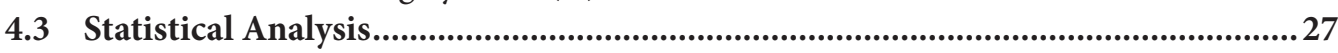

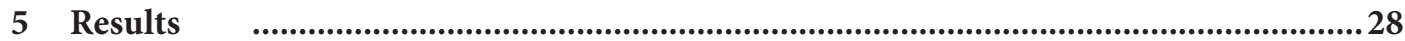

5.1 Study Characteristics and Patient Outcome .....................................................28

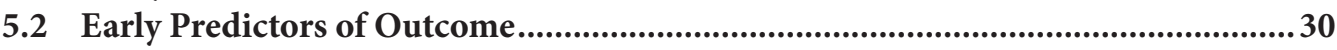

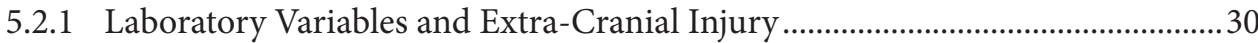

5.2.2 Computerized Tomography Abnormalities ......................................................... 31

5.3 Comparison of Different Types of Prognostic Models ............................................ 31

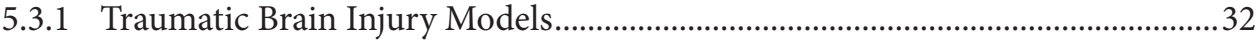

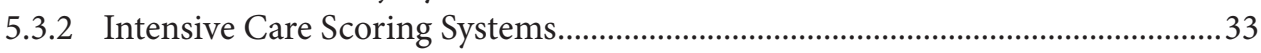

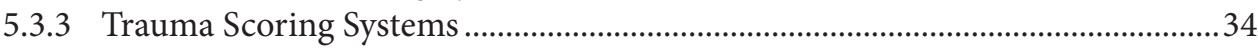

5.4 Novel Prognostic Models.........................................................................................36

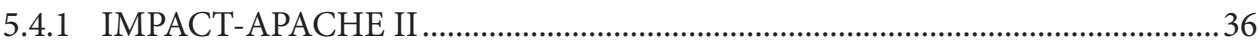

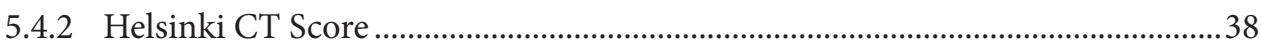

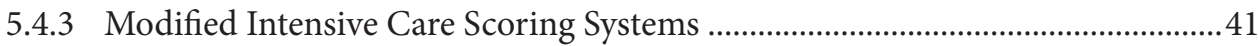

6 Discussion ..........................................................................................................4 44

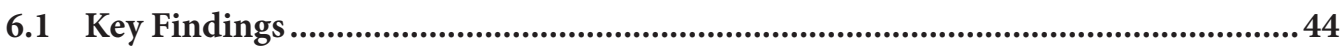

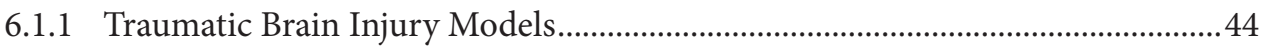

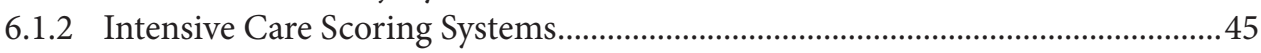

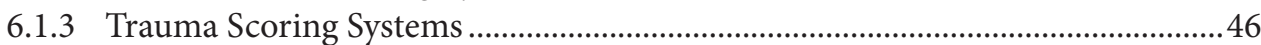

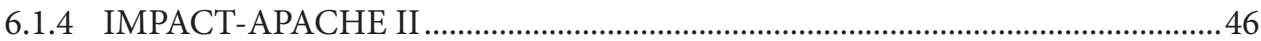

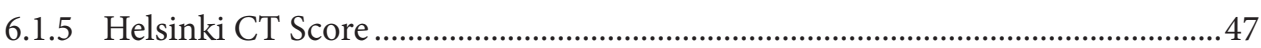

6.2 Early Predictors of Outcome after TBI ..........................................................47

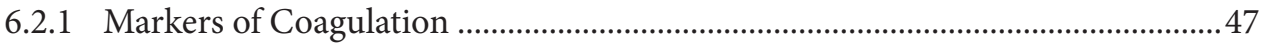

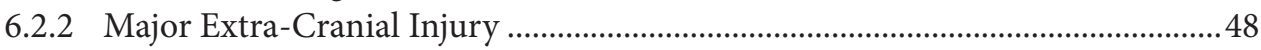

6.2.3 Early Computerized Tomography Characteristics ..............................................48

6.3 Statistical Considerations ...............................................................................49

6.4 Patient Outcome after Traumatic Brain Injury .................................................5 50

6.4.1 Outcome Assessment After TBI........................................................................... 51

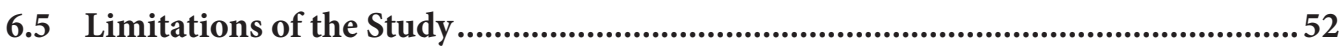

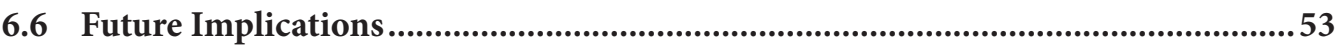

6.6.1 Which Model To Use And For What? ....................................................................53

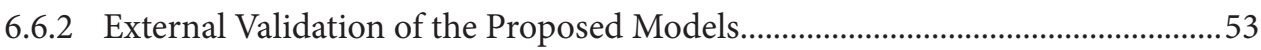

6.7 Practical Examples of Prognostic Models in TBI Research ................................. 54

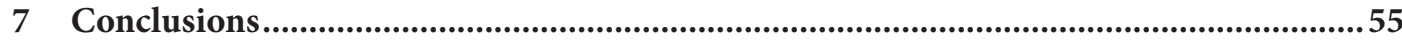

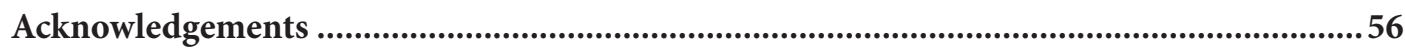

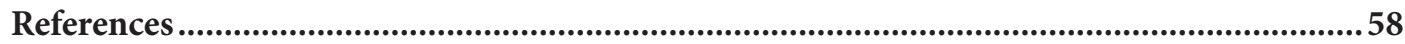




\section{Abstract}

Background: Prognostic models are important tools for heterogeneity adjustment in traumatic brain injury (TBI). Prognoses after TBI have been particularly challenging to predict, with limited availability of robust prognostic models. TBI patients are by definition trauma patients, and often treated in the intensive care unit (ICU). Several prognostic models for ICU and trauma patients have been developed, although their applicability in patients with TBI is uncertain. Recently, however, some new prognostic models specifically designed for patients with TBI were introduced. Still, the optimal type of prognostic model in TBI remains unknown.

Aim: To investigate the applicability of different types of prognostic models in patients with TBI and to develop novel models with enhanced performance to previous models, focusing on longterm outcome prediction.

Methods: Four patient databases of patients with TBI treated in the ICU were used to validate three TBI specific models, two computerized tomography (CT) scoring systems, one trauma scoring system, and three intensive care scoring systems. Models were validated by assessing their discrimination using area under the curve (AUC), calibration, and explanatory variation. Logistic regression was used for model customization and development. Models were internally validated using a resample bootstrap technique or a split-sample technique. Primary outcome was six-month mortality and unfavorable neurological outcome by the Glasgow Outcome Scale. 30-day in-hospital mortality was used for the trauma scoring system.

Results: Study populations ranged from 342 to 9,915 patients. The TBI models showed the best performance with AUCs between 0.80 and 0.85 , followed by the intensive care scoring systems and the CT scores with AUCs between 0.68 to 0.80 and 0.63 to 0.70 , respectively. Most models showed poor calibration, although good calibration was achieved following customization. The trauma scoring system exhibited modest to good discrimination (AUC 0.76-0.89) for short-term mortality prediction, but poor calibration. Several new prognostic models, with statistically significant superior performance to previous models were created, among them a combined TBI-ICU model ('IMPACT-APACHE') and a novel CT scoring system ('The Helsinki CT score'). Using a TBI specific model, based on admission characteristics, up to $40 \%$ of the patient's final long-term outcome could be predicted.

Conclusion: The TBI models showed superior predictive performance to the intensive care and trauma scoring systems, showing that TBI patients are a highly specific population in the trauma and ICU setting. Thus, the use of a TBI specific model is advocated in the setting of TBI. The newly proposed models were found to be significant improvements over previous models, but require external validation to show generalizability. 


\section{List of Original Publications}

This thesis is based on the following publications:

I Raj R, Siironen J, Kivisaari R, Hernesniemi J, Tanskanen P, Handolin L, Skrifvars MB. External Validation of the International Mission for Prognosis and Analysis of Clinical Trials Model and the Role of Markers of Coagulation, Neurosurgery, 2013;73(2):305311

II Raj R, Kivisaari R, Siironen J, Skrifvars MB. Predicting Outcome After Traumatic Brain Injury: Development of Prognostic Scores Based on the IMPACT and the APACHE II, Journal of Neurotrauma, 2014;31(20):1721-1732

III Raj R, Siironen J, Skrifvars MB, Lappalainen J, Hernesniemi J, Kivisaari R. Predicting Outcome in Traumatic Brain Injury: Development of a Novel Computerized Tomography Classification Systems (The Helsinki CT Score), Neurosurgery;75(6):632-647

IV Raj R, Skrifvars MB, Bendel S, Selander T, Kivisaari R, Siironen J, Reinikainen M. Predicting Six-month Mortality of Patients with Traumatic Brain Injury: Usefulness of Common Intensive Care Severity Scores, Critical Care, 2014;18:R60

V Raj R, Brinck T, Skrifvars MB, Kivisaari R, Siironen J, Lefering R, Handolin L. Validation of the Revised Injury Severity Classification Score in Patients With Moderate-toSevere Traumatic Brain Injury, Injury, 2014 (In Press)

The publications are referred to in the text by their roman numerals. The original publications have been reprinted with the permission of the copyright holders. 


\section{Abbreviations}

AIS, Abbreviated Injury Severity

APACHE, Acute Physiology and Chronic Health Evaluation

AUC, Area Under the Curve

AUROC, Area Under the Receiver Operating Characteristic Curve

BAC, Blood Alcohol Concentrations

CER, Comparative Effectiveness Research

CRASH, Corticosteroid Randomization After Significant Head Injury

CT, Computerized Tomography

DTI, Diffusor Tension Imaging

EDH, Epidural Hematoma

FICC, Finnish Intensive Care Consortium

GCS, Glasgow Coma Scale

GiViTI, Gruppo Italiano per la Valutaione degli Interventi in Terapia Intensive

GoF, Goodness of Fit

GOS, Glasgow Outcome Scale

H-L, Hosmer-Lemeshow Ĉ statistic test

ICD-10, International Classification of Diseases and Related Health Problems $10^{\text {th }}$ Edition

ICH, Intracerebral Hemorrhage

ICU, Intensive Care Unit

IMPACT, International Mission for Prognosis and Analysis of Clinical Trials

ISS, Injury Severity Score

MRI, Magnetic Resonance Imaging

IVH, Intraventricular Hemorrhage

NISS, New Injury Severity Score

PT, Thromboplastin Time

PTT, Partial Thromboplastin Time

RCT, Randomized Controlled Trial

RISC, Revised Injury Severity Classification

ROC, Receiver Operator Characteristic

SAPS, Simplified Acute Physiology Score

SDH, Subdural Hematoma

SOFA, Sequential Organ Failure Assessment

TARN, Trauma Audit \& Research Network

TBI, Traumatic Brain Injury

TR-DGU, Trauma Registry of the German Society for Trauma Surgery ${ }^{\circledast}$

TRISS, Trauma Score - Injury Severity Score

TR-THEL, Trauma Registry of Helsinki University Hospital

tSAH, Traumatic Subarachnoid Hemorrhage 


\section{Introduction}

Traumatic brain injury (TBI) is a global health care and socioeconomic problem. ${ }^{1-7}$ Each year, about 1 in 200 Europeans and Americans will sustain some form of TBI. Of all TBIs approximately $10-20 \%$ are moderate or severe in nature, requiring intensive care unit (ICU) treatment. ${ }^{4,8}$ Of these patients one in two dies or is left with severe lifelong disabilities, demonstrating the cruel prognosis of TBI. ${ }^{9,10}$ Establishing an early and reliable prognosis in patients with TBI has previously proved particularly challenging. ${ }^{11,12}$ However, advances in statistical modeling and large patient databases enable more accurate prognoses. ${ }^{13-16}$ Prognostic models, which generally characterize prognostic research, are statistical models that use two or more variables to calculate the probability of a pre-defined outcome. ${ }^{15}$ Prognostic models are broadly applicable to areas such as study design improvement, clinical audits, comparative effectiveness research (CER), disease characterization, support treatment decisions, resource allocation, and family counseling. ${ }^{17-19}$ In intensive care and trauma research, prognostic models have served for decades to evaluate and improve quality of care..$^{20-24}$ Although trauma and intensive care populations include patients with TBI, similar exploitations of prognostic models in TBI research have been scarce, possibly because previous models for TBI have suffered from poor quality. ${ }^{11,12}$ An accurate prognostic model for TBI patients remains challenging, mainly because of the wide disease heterogeneity, including differences in cause, pathophysiology, treatment, and outcome..$^{7,17}$

In 2008, prognostic research in TBI showed a marked advance after the introduction of two major new TBI prognostic models., ${ }^{9,10}$ The novel models offer great potential in TBI research in terms of adjusting for heterogeneity and increasing study power. ${ }^{18,25,26}$ However, the novel TBI models do not yet enjoy the same widespread use as some of the intensive care or trauma prognostic models routinely used around the world. ${ }^{22,27,28}$ In theory, these already implemented intensive care and trauma models could also be used in the TBI population, as TBI patients are trauma and intensive care patients as well. However, the applicability of the intensive care and trauma models in the setting of TBI is unknown. Furthermore, most intensive care and trauma models are designed to predict short-term outcomes, something that significantly underestimates the long-term consequences of $\mathrm{TBI}^{29}$ Accordingly, the aim was to investigate the applicability of some of the most widely used intensive care and trauma models in patients with TBI and compare them to TBI specific prognostic models, with focus on long-term outcome prediction. A secondary goal was to create novel prognostic models with enhanced performance compared to previous models. 


\section{Review of the Literature}

\subsection{Traumatic Brain injury}

\subsubsection{Definition}

TBI is not just one disease, but includes a wide spectrum of different pathologies and is characterized by a broad heterogeneity in terms of etiology, mechanism, pathology, and severity. The term 'head injury' is often used synonymously with TBI, but may refer to injury of the skull only with no pathological abnormalities in the brain. Accordingly, in this thesis, the term 'traumatic brain injury' or its abbreviation 'TBI' is used.

As of today, there is no diagnostic test for TBI. Thus, TBI is defined as "an alteration in brain function, or other evidence of brain pathology, caused by an external force." ${ }^{30}$ Symptoms of TBI vary by patient but may include disorientation, confusion, headache, nausea and vomiting, drowsiness, loss of memory, decreased level of or loss of consciousness, and neurological deficits (weakness, loss of balance, change in vision, sensory loss, paresis or paralysis).

\subsubsection{Epidemiology}

TBI is often referred to as 'the silent epidemic'. In Europe, it is estimated approximately 2.5 million people suffer from some form of TBI annually, leading to 1 million hospitalizations, causing 75,000 deaths. This is further associated with economic costs exceeding 33 billion euros. ${ }^{6,31}$ Similarly, in the US, about two million emergency department visits and almost 300,000 hospitalizations occur annually due to TBI, with associated costs reaching 76.5 billion dollars. ${ }^{8}$ The majority of all TBIs are mild in nature, but up to $10 \%$ to $20 \%$ are considered moderate or severe, depending on the population and

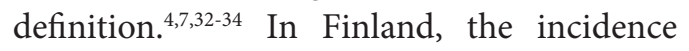
of hospitalized TBI is approximately $100 / 100,000$ with a mortality rate of
$18 / 100,000 . .^{35}$ By comparison, a systematic review of the epidemiology of TBI showed an overall incidence of 235/100,000 in Europe, $103 / 100,000$ in USA, 226/100,000 in Australia, $344 / 100,000$ in Asia, and 160/100,000 in India. ${ }^{4}$ One study found an incidence as high as 790/100,000 in New Zealand. ${ }^{33}$ However, rather than actual differences in incidence, these wildly different figures probably instead reveal national variations in healthcare and registration systems.

The most common mechanisms leading to TBI are fall accidents, traffic accidents, and assault related incidents. ${ }^{36}$ In low-andmiddle income countries traffic accidents dominate, while by contrast high-income countries show an increasing frequency of fall accidents. ${ }^{37}$ The World Health Organization (WHO) forecasts that by 2030, TBI will become a leading cause of disability and death globally. ${ }^{38}$ This growth is primarily due to the rising frequency of traffic accidents in developing countries, but is also fueled by the developed world's aging population and consequent increased susceptibility to fall accidents..$^{37,38}$ Noteworthy also is that up to half of all TBI patients are under the influence of alcohol at the time of injury, something that seems to be a particular problem in Finland due to the traditional drinking pattern 'low frequency and high quantity.',39-41

\subsubsection{Pathophysiology}

The pathological mechanism of TBI is traditionally divided into two phases: primary and secondary brain injury. The primary injury is the mechanical damage that occurs to the brain parenchyma (tissue, vessels) at the time of injury. The primary injury evolves over time, reaching its ictus in the succeeding hours and overlapping with the early phases of secondary brain injury. The secondary brain injury, originally initiated by the primary 
injury, takes place in the ensuing hours and days. Secondary brain injury processes include: hypoxic-ischemic injury, cerebral edema, metabolic dysfunction, alterations in vascular permeability, diminished blood flow, diffuse axonal injury, vasospasm, hydrocephalus, and the consequences of intracranial hypertension. ${ }^{7,42,43}$ Secondary injury is further exacerbated by systemic insults, such as: coagulopathy, hypoxemia, hypotension, hypertension, hyperthermia, hypoglycemia, hyperglycemia, hypocapnia, hypercapnia, anemia, hypernatremia, and acid-base disorders. ${ }^{42,44,45}$ Hence, TBI treatment focuses on inhibiting the progression of primary brain injury and preventing or even reversing secondary brain injury. ${ }^{42,46-48}$

\subsubsection{Early Predictors of Patient Outcome}

\subsubsection{Demographics}

Age is one of the strongest predictors of outcome after TBI,with a proposed linear relationship. ${ }^{49-53}$ Ethnic origin and gender may also be associated with outcome in TBI patients. A meta-analysis found slightly poorer quality of life in female compared to male TBI survivors, ${ }^{54}$ although this remains controversial, as the contrary has also been reported. ${ }^{55}$ Besides, men are more susceptible to TBI than women. ${ }^{4,49,53}$ Reports on gender differences in outcome after TBI have raised interest in possible hormonal influences of estrogen and progesterone. A recent Cochrane meta-analysis found evidence for the neuroprotective properties of progesterone on outcome after TBI, and there is currently a phase III trial investigating the effect of progesterone (ProTECT III, ClinicalTrials.gov Identifier: NCT00822900) and a phase II trial investigating the effect of estrogen on outcome after TBI (RESCUE - TBI, ClinicalTrials.gov Identifier: NCT00973674). ${ }^{56}$ Ethnic origin and outcome after TBI is also a controversial topic. A recent meta-analysis found black patients to have poorer outcomes compared to Caucasian and Asian patients, probably due to genetic differences. ${ }^{53}$ Thus, there is certainly a multifaceted age-gender-ethnic relationship affecting outcome after TBI, though its specific dynamics remain largely unknown.

\subsubsection{Clinical Signs}

Level of consciousness after injury is a major determinant of TBI severity and often assessed by the Glasgow Coma Score (GCS). ${ }^{57}$ The GCS is traditionally used to classify TBI into mild (GCS 13-15), moderate (GCS 9-12), and severe (GCS 3-8). Although debate exists over whether GCS 13 should be classified as moderate or mild, this stratification system has been used for the last 40 years. ${ }^{58,59}$ The GCS was introduced in 1974 as a tool for "repeated bedside assessment" to detect "changing states" and measuring "duration of coma" in the first 24 hours of observation in neurosurgical units. ${ }^{57}$ The GCS consists of three components: eye response, verbal response, and motor response, which are added together for a score from 3 to 15 (Table 1). The abbreviation 'GCS' is used inconsistently in the literature, as it may refer to both the individual components of the GCS (Glasgow Coma Scale) and the total score (Glasgow Coma Score)..$^{59}$ The scale is probably more useful for the individual patient and the score to summarize large groups of patients. Notably, GCS was never intended to be used in trauma or emergency medicine or even for its three components to be added together into a sum; despite the authors' objections, it has been used in those manners ever since its introduction. ${ }^{59,60}$ However, the strong relationship between GCS and outcome after TBI and its simplicity still favors its use, ${ }^{59,61}$ although some contrary conclusions have been proposed. ${ }^{62}$ 
Pupillary size and light reactivity is vital to neurologic assessment of patients with a history of head trauma. An acute dilation of the pupil and unresponsiveness to light is considered a neurological emergency and is strongly associated with poor prognosis. ${ }^{61}$ Acute abnormal pupillary findings after TBI may be the result of third cranial nerve compression and subsequent brain stem compression, uncal herniation (transtentorial herniation of the medial temporal lobe), or reduced blood flow to the brain stem. ${ }^{63,64}$

Extra-cranial injuries are common in patients with TBI, with up to one third sustaining a major extra-cranial injury. ${ }^{65}$ However, the effect of those injuries on outcome in patients with TBI is controversial, with some studies suggesting no effect and some showing significantly higher risk of poor outcome with concomitant extra-cranial and intracranial injuries. ${ }^{65-67}$

Table 1: The Glasgow Coma Scale

\begin{tabular}{|c|c|c|}
\hline Component & Response & Score \\
\hline \multirow[t]{4}{*}{ Eye response } & Spontaneous & 4 \\
\hline & To speech & 3 \\
\hline & To pressure & 2 \\
\hline & None & 1 \\
\hline \multirow[t]{5}{*}{ Verbal response } & Oriented & 5 \\
\hline & Confused & 4 \\
\hline & Words & 3 \\
\hline & Sounds & 2 \\
\hline & None & 1 \\
\hline \multirow[t]{6}{*}{ Motor response } & Obeying commands & 6 \\
\hline & Localizing & 5 \\
\hline & $\begin{array}{l}\text { Normal flexion (with- } \\
\text { drawal) }\end{array}$ & 4 \\
\hline & Abnormal flexion & 3 \\
\hline & Extension & 2 \\
\hline & None & 1 \\
\hline Total & & 3-15 \\
\hline
\end{tabular}

Table reproduced from Teasdale et al. Lancet Neurol 2014;13:844-54 with changes in terminology from Teasdale et al., Lancet 1974 13;2(7872):81-4 with the permission from Elsevier ${ }^{\circ}$

\subsubsection{Radiological Findings}

Radiological research in TBI has focused mainly on abnormalities detected by CT imaging. The most readily identifiable intracranial bleedings detected by conventional non-contrast computerized tomography (CT) imaging are: subdural hematoma $(\mathrm{SDH})$, epidural hematoma (EDH), intracerebral hemorrhage (ICH or contusion), traumatic subarachnoid hemorrhage (tSAH), intraventricular hemorrhage (IVH), and diffuse axonal injury (DAI, although this is more readily detected by magnetic resonance imaging [MRI] than by CT). Lesions most strongly associated with poor outcome after TBI are: bleeding type, status of basal cisterns, midline shift, and $\mathrm{tSAH}$, with $\mathrm{tSAH}$ and complete obliteration of the basal cisterns likely being the strongest individual predictors. ${ }^{68,69}$ Novel radiological techniques such as MRI and diffusion tensor imaging (DTI) are under increasing investigation at present, although their role in outcome prediction remains undefined. ${ }^{70,71}$

\subsubsection{Secondary Insults}

In the pre-hospital period, approximately one in five TBI patients suffer from some form of secondary insult. ${ }^{72-76}$ TBI patients are subject to several secondary insults, of which hypoxia and hypotension are the most frequently encountered and also most deleterious..$^{72,73}$

\subsubsection{Laboratory Variables and Biomarkers}

Several laboratory variables associate with outcome after TBI, among them blood glucose levels, ${ }^{77,78}$ hemoglobin concentrations, ${ }^{78,79}$ sodium levels, ${ }^{78}$ and markers of coagulation. ${ }^{78,80-83}$ Hyperglycemia, low hemoglobin levels, hyponatremia and hypernatremia, and coagulopathy are accordingly strongly predictive of poor outcome. $^{78}$ 
Identifying laboratory abnormalities as predictors of outcome is important, as these can often be corrected. Confronting the question of causality however, is crucial before actively correcting abnormal laboratory values. For example, high levels of blood glucose concentrations independently predict poor outcome after TBI. ${ }^{77,78}$ However, recent evidence suggest that early hyperglycemia after TBI might be a beneficial stress response, and thus, actively lowering blood glucose levels in early phases may reduce brain glucose availability and increase secondary brain injury. ${ }^{84-87}$

As of today, there is no accurate biomarker of $\mathrm{TBI},{ }^{88,89}$ though interest in biomarkers has been increasing in recent years. An accurate biomarker for mild TBI to establish diagnosis or for moderate to severe TBI to determine extent of injury would be of great clinical use, although no such biomarker has yet been identified. ${ }^{88,89}$ Promising biomarkers for detecting brain injury include glial fibrillary acidic protein (GFAP), ubiquitin C-terminal hydrolase-L1 (ICH-L1), alfa-II spectric breakdown product (SBDP145), and S100B and neuron specific enolase, although few of these are routinely used in the clinical setting. ${ }^{90,91}$

\subsubsection{Patient Outcome}

Outcome after severe TBI is poor; about one in three patients dies and most survivors are left with severe lifelong disabilities. ${ }^{9,29,43,52}$ Furthermore, survivors of severe TBI face prolonged rehabilitation times, causing significant patient and family suffering as well as enormous economic costs. ${ }^{5,6,8,31} \mathrm{~A}$ recent large meta-analysis, including more than 140,000 patients from over 200 case series and a time period of almost 125 years (1885-2006), showed a general improvement in outcome after TBI. ${ }^{92}$ Notably, though, the improvement stagnated in 1990, suggesting no advances in patient outcome over the last quarter-century. Nonetheless, several studies after 1990 have reported improvements in patient outcome as a result of, for instance, TBI care guideline development ${ }^{93,94}$ and aggressive neurointensive treatment regimes. ${ }^{95-98}$

A common and biased interpretation of improved patient outcome appears when comparing outcomes from recent randomized controlled trials (RCTs) with older observational studies. Such comparisons should be interpreted with great caution. Observational studies tend to have much broader inclusion criteria than RCTs, where patients with the most extreme prognosis (e.g. bilaterally dilated pupils, GCS 3, elderly patients) are often excluded. Thus, it is natural that patient outcome is better in RCTs than observational studies. However, the epidemiological shift of TBI patients towards older and sicker populations might, on the other hand, increase rates of poor outcome in observational studies. ${ }^{37}$ Hence, there are often substantial differences in patient casemix between observational studies and RCTs, confounding inter-study comparisons.

\subsection{Prognostic Models}

\subsubsection{Definition}

A prognostic model is a statistical model, or a mathematical equation, that includes two or more prognostic factors, or variables, to calculate the probability of a pre-defined outcome. In medical research, the outcome is often dichotomized; examples include predicting the probability of being alive or dead at a certain time point, a tumor being benign or malign, or the risk of an adverse event occurring.

Different terms for 'prognostic models' may be used, like 'prediction model,' 'scoring system,' or simply 'score, often depending on the term used in the originating paper. In the present study, original terms are used when discussing individual models, but for general discussion the term 'prognostic model' or simply 'model' is used. 


\subsubsection{Development}

Ideally, the factors used to create a prognostic model should all individually be statistically and clinically associated with the outcome, although this is not always the case. Thus, included variables should be chosen carefully; it is recommended to start with selected candidate variables, known from previous studies, after which variables from the own population are added. ${ }^{99}$ Generally, a higher number of variables improve the model's explanatory effect, but using more variables also increases the risk of overfitting and decreases clinical applicability. Accordingly, more than one researcher has suggested that a good model should include no more than five to seven predictors. ${ }^{99,100}$

To create a prognostic model, complex statistical techniques are often necessary.
The most commonly used statistical method is logistic regression, ${ }^{99,101}$ but others include: discriminant analysis, artificial neural networks, and recursive partitioning. Logistic regression, however, has some key advantages over the other techniques, as it does not require variables to be normally distributed, linearly related, or to have equal within-group variances. Furthermore, logistic regression handles both categorical variables and continuous variables, and gives us easily interpretable outputs in the form of regression coefficients and odds ratios. Recursive partitioning, on the other hand, has the advantage of being easy to grasp visually, facilitating clinical applicability, but suffers from problems of overfitting and categorization of continuous data. ${ }^{102}$ Neural networking mimics the information processing of neurons in the brain and

Table 2: Recommendation for developing and validating prognostic models in traumatic brain injury

\begin{tabular}{|ll|}
\hline Model & Recommendation \\
\hline Study population & Large sample size \\
& Reflects the inherent heterogeneity (in terms of injury type and severity) of the disease \\
& Representative of current practice \\
Predictors & Plausible, based on previous research or expert opinion \\
& Precisely defined \\
& Measurable with little inter-observer variability \\
& Readily obtainable \\
Outcome & Assessed at a fixed time-point \\
& Relevant to the disease (e.g. mortality/Glasgow Outcome Scale/neuropsychological mea- \\
& sures/quality of life) \\
& Precisely defined \\
& Measurable with little inter-observed variability \\
Development & Use of appropriate statistical techniques for selection of predictors and estimation of \\
& prognostic effects \\
& Presentation in a readily applicable format \\
Internal validation with efficient procedures, for example with bootstrapping \\
Validation
\end{tabular}

Table reprinted from N.A. Mushkudiani et al. J Clin Epidem 61 (2008) 331-343 with permission from Elsevier 
produces prognostic models. These models are possibly superior to models created by logistic regression, in terms of statistical performance, but are also more complex. ${ }^{103}$ The complexity of neural networking is also its weakness, limiting its use. By combining neural networking with logistic regression, model complexity can be reduced while maintaining predictive accuracy, although this technique has yet to gain popularity. ${ }^{103-105}$

Still, more important than the statistical method is the selection of predictors. ${ }^{11,15,99,106,107}$ A systematic review of methodological improvements for prognostic models in TBI established recommendations for their development and validation (Table $2)^{99}$.

\subsubsection{Internal Validation}

Internal validation refers to testing the model for reproducibility in a dataset similar to the one used to develop the model. All prognostic models should be at least internally validated before introduction in order to adjust for optimism, ${ }^{15}$ which is the term applied when the model performs worse than expected in a new dataset. ${ }^{106}$ Split-sample, cross-validation, jackknifing, and bootstrapping are the most common statistical techniques for internal validation. ${ }^{108}$

The split-sample technique is probably the most simple and straightforward method for internal validation. ${ }^{109}$ The dataset is randomly divided into two groups, making the groups similar but independent; one group is used for the development of the model (development set) and the other group is used for validation of the model (validation set). In this way the model is tested on similar but still independent data. The split-sample technique, however, heavily depends on sample size and requires adequately large patient groups. Furthermore, splitting data always results in lost data, and thus, reduces the statistical power of the model. ${ }^{108}$
The cross-validation technique is an extension of the split-sample technique, where patients are again randomly divided into two parts, one for model development and the other for validation. ${ }^{110}$ In cross-validation, this procedure is, however, repeated with the model now developed in the other dataset and validated in the original development dataset. The average of these two stages is taken as an estimate of performance. The cross-validation technique can further be extended to taking $90 \%$ of the data for model development and $10 \%$ for validation. The procedure is repeated for a total of ten iterations and the average represents the performance estimate. The most extreme variation of the cross-validation technique is the jackknife technique, where one patient is left out at a time, and the test is repeated hundreds or thousands of times. ${ }^{111}$

The bootstrap technique has been recognized as the most statistically robust method of internal validation. ${ }^{108}$ Bootstrapping is a computer-intensive resampling technique that draws random samples with replacements from the original dataset. ${ }^{111,112}$ Bootstrapping follows the logic of 'the population is to the sample as the sample is to the bootstrap samples.'113 The bootstrap technique may be applied to a variety of performance measures, including the AUC, calibration slopes, and Nagelkerke R2 (see below). To assess the internal validity of a model using the bootstrap technique, an optimism-corrected performance is calculated as follows: ${ }^{114}$

\section{Optimism corrected performance}

= apparent performance in sample-

optimism, where optimism

= bootstrap performance-test performance 


\subsubsection{External Validation}

A prognostic model generally performs better on the dataset from which it was derived than on new data. ${ }^{115}$ External validation aims to assess the performance of a prognostic model in a different, but plausibly related, population. External validation is essential to support the generalizability of prognostic models and to provide evidence that the model does in fact accurately predict outcomes. ${ }^{115,116}$ There are several types of external validation variations, whether methodological (temporal, geographical, fully independent) or characteristic (prospective testing with more recent patients, multi-site testing, other investigators at another site). ${ }^{115-}$ 118

\subsubsection{Performance assessment}

\subsubsection{Discrimination}

Discrimination refers to a model's ability to distinguish patients with a particular outcome from patients without it (e.g. survivors and non-survivors). ${ }^{101}$ A good discriminating model predicts high probabilities of patients having the outcome and low probabilities of patients not having the outcome. Discrimination includes accuracy, sensitivity, and specificity and is often measured (for prognostic models with a binary outcome) by the area under the receiver operator characteristic curve (AUC, also called the C-statistic for models with a binary outcome). ${ }^{119,120}$ The receiver operator curve is a plot of the sensitivity versus specificity calculated at consecutive intervals of the predicted outcome (Figure 1).
The AUC shows the likelihood that a randomly chosen patient with the outcome will have a higher probability than a randomly chosen patient without the outcome. An AUC of 0.5 indicates the predictive value of the model to be no better than mere chance, while an AUC of 1.0 is perfect (100\% sensitivity and specificity). Perfect discrimination is achieved when the probabilities for all cases with the outcome are higher than the probabilities without the outcome with no overlap. Generally, one strives for an AUC $>0.75$ to $>0.80 .{ }^{119}$ Other commonly used cutoffs are $>0.90$ for 'excellent', $>0.80$ for 'good,' $>0.70$ for 'satisfactory' or 'modest', and $<0.70$ for 'poor.'101

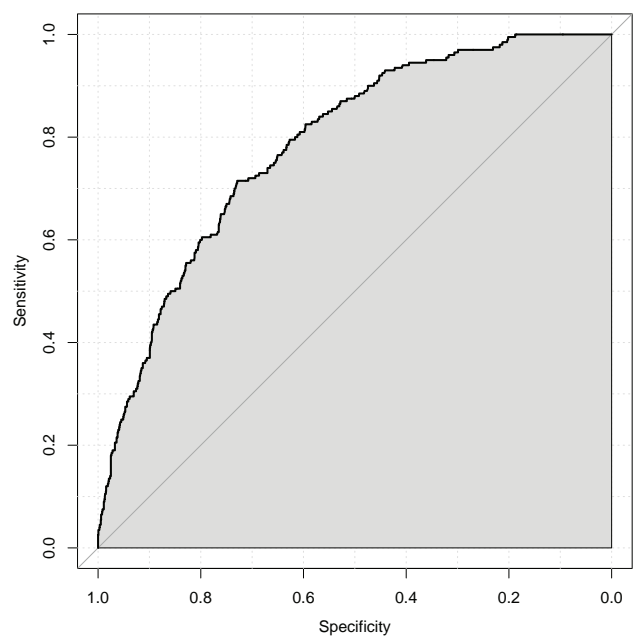

Figure 1: An example of the area under the receiver operator characteristic curve (AUC) defined by the grey area. The Y-axis demonstrates model sensitivity and the $X$-axis model specificity 


\subsubsection{Calibration}

Model calibration refers to the concordance between predicted and observed outcomes over the whole risk spectra. ${ }^{101}$ Calibration testing is often overlooked in prognostic research, where many studies focus mainly on discrimination measures. ${ }^{121}$ Discrimination is considered more important when predicting outcome for the individual patient, but for risk stratification and trial enrollment, calibration is more important than discrimination. ${ }^{121,122}$

Calibration is traditionally assessed by either the Hosmer-Lemeshow (H-L) goodness-of-fit (GoF) test or by calibration slope and intercept. ${ }^{120,123}$ Most studies refer to the H-L GoF test as one test, although in reality the $\mathrm{H}-\mathrm{L}$ GoF encompasses two different tests: the H-L $\hat{\mathrm{C}}$ and the H-L $\hat{\mathrm{H}}$ test. The former divides patients into equally sized groups (commonly of ten) independent of risk, whereas the latter divides patients into groups of equal risk interval (often 0-10, 11-20, etc.) independent of patient size and calculates a chi-square $\left(\chi^{2}\right)$ between the predicted and observed risk for each group (Figure 2a). A p-value $<0.05$ (statistical significant deviation between the observed and predicted outcome) is considered poor calibration and $\mathrm{p}>0.05$ (no statistical significant deviation between the observed and predicted outcome) good calibration.

However, the H-L tests have been criticized for relying heavily on sample size and neglecting the individual patients allocated to the different groups. ${ }^{124,125}$ To avoid this problem, the GiViTI (Gruppo Italian per la Valuation deli Intervention in Terraria Intensive) calibration belt was developed, ${ }^{126}$ in which the relationship between the predicted and observed outcome is calculated by fitting a logistic function between the outcome and the logit transformation of the predicted probability. Thus, the GiViTI test creates a calibration belt consisting of the $80 \%$ and 95\% confidence intervals (CI) that are based on every single patient. In contrast to the H-L GoF test, a statistically significant deviation between the predicted and observed outcome

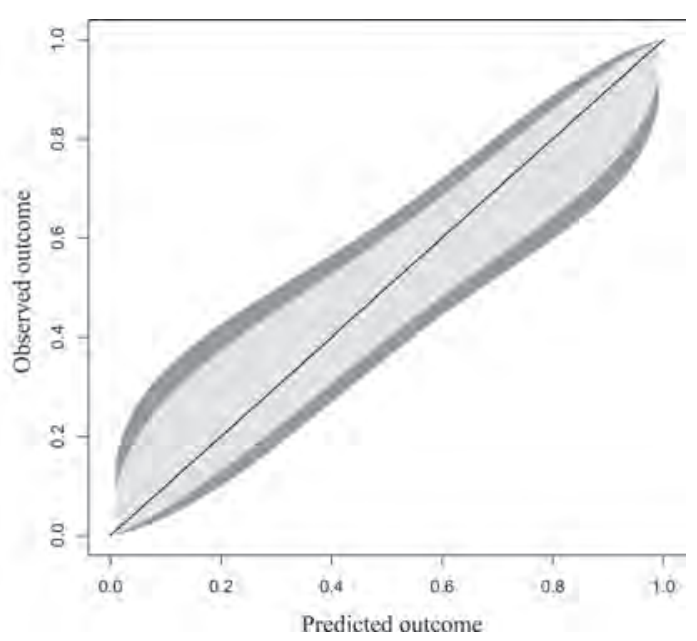

Figure 2: a) an example of the Hosmer-Lemeshow $\hat{C}$ test with the observed outcome of the Y-axis and the predicted outcome on the X-axis. In the $\hat{C}$ test patients are divided into ten equally sized groups for which the difference between predicted outcome and observed outcome is tested for each group; $b$ ) an example of the GiViTI calibration belt with observed outcome on the Y-axis and predicted on the X-axis. The black bisector lines represent perfect calibration; the light grey area represent the $80 \%$ confidence interval (CI) and the dark grey area the 95\% CI. This is an example of good calibration because the 95\% CI does not cross the black bisector line 
occurs when the 95\% CIs do not overlap the bisector line, indicating perfect calibration (Figure 2b). In this sense it is possible to identify visually areas of poor calibration and determine its direction (model overprediction or underprediction).

The calibration slope is the regression coefficient $\beta$ in a logistic regression model with the linear predictor as the only covariate: observed $=\alpha+\beta$ linear predictor, where $\beta$ is the intercept. ${ }^{127}$ Well calibrated models have a slope $(\alpha)$ of 1 and an intercept $(\beta)$ of $0 .{ }^{128}$ Overpredicting models have a slope under 1 , with the model tending to underestimate the incidence of outcome in low-risk patients and overpredict it in high-risk patients. Conversely, if the slope is greater than 1 , the predicted risks are not sufficiently differentiated across the risk strata. ${ }^{120}$ An intercept under 0 indicates that the predicted risks are systematically too high and an intercept over 0 indicates that the predicted risks are systematically too low.

\subsubsection{Overall performance measures}

The explanatory variation is considered an overall measure of model performance, including both discrimination and calibration. In linear regression, the $\mathrm{R}^{2}$ summarizes the grade of explanation of the dependent variables (or covariates) with the independent variable (the outcome). Larger values indicate a higher degree of explanation, with an $\mathrm{R}^{2}$ of 1.0 indicating that the model explains for $100 \%$ of the outcome, and an $\mathrm{R}^{2}$ of 0.0 meaning that the model explains for $0 \%$ of the outcome. In logistic regression, however, it is not possible to calculate a single $\mathrm{R}^{2}$ that has all the characteristics of the $\mathrm{R}^{2}$ in the linear regression. This has led to the development of several 'pseudo $\mathrm{R}^{2}$ ' measures, of which the Nagelkerke $\mathrm{R}^{2}$ test is probably the most frequently used. ${ }^{129,130}$ The Nagelkerke $\mathrm{R}^{2}$ is a variation of the earlier Cox and Snell $\mathrm{R}^{2}$ test for logistic regression, but in contrast to it, the Nagelkerke $\mathrm{R}^{2}$ ranges from 0 to $1(0-100 \%)$, to better mimic the 'real' linear regression $R^{2}{ }^{129}$

\subsubsection{Net Reclassification Index}

The added value of a variable to a prognostic model is often measured by comparing differences in AUC. Yet, for a model's AUC to increase significantly, the independent association between the new variable and the outcome has to be very strong. In other words, a predictor may be significant without improving AUC, which might lead to neglecting important variables. ${ }^{121,131}$ In response, Pencina et al. introduced the Net Reclassification Index (NRI). ${ }^{132}$ The NRI is a novel, more sensitive, statistical technique to measure the added value of a predictor when added to a prognostic model by reclassification tables (which require a priori meaningful risk categories) or a continuous test. The NRI show how many patients are better classified because of the added predictor, with an associated p-value.

\subsubsection{Customization}

All prognostic models become outdated over time. ${ }^{15,114}$ To improve the performance of a prognostic model and make it applicable to new settings, it may be customized. Customization aims to improve the performance of a particular prognostic model in a plausibly related but different population from the original development population. There are two methods for model customization, known as first and second level customization. ${ }^{133-135}$

First level customization involves fitting a new logistic regression equation with the observed outcome as the dependent variable and the logit-transformed original prediction as the independent variable. The influence of the individual variables does not change; rather, they recalibrate their joint effects on outcome. 
Second level customization involves fitting all the original predictors into a logistic regression model with the outcome as the dependent variable, and has been shown to be more effective than the first level variety. Thus, given sufficient sample size, second level customization is preferable. ${ }^{134}$ In general, customization does not affect discrimination but instead improves calibration. ${ }^{134,135}$

\subsubsection{Applications}

\subsubsection{Quality Audits}

It is impossible to improve results that are unknown; the aim of quality management is the delivery of improved care by monitoring clinical performance. Since the 1980s, riskadjusted mortality rates have served as an important measure of hospital care quality. ${ }^{19,23}$ Comparing the observed outcome with the expected outcome has been shown to be a feasible method for improving quality of trauma and intensive care. ${ }^{22,136-139}$ For example, the Trauma Audit \& Research Network (TARN) in the UK annually presents casemix adjusted survival rates (often referred to as SMR for Standardized Mortality Rate) from their participating hospitals publicly at https://www.tarn.ac.uk/. Public comparisons of adjusted survival rates are, however, not without problems and it is important to know the limitation of such comparisons. Two things are absolutely vital for adjusted survival rates: 1) an accurate prognostic model and 2) a proper outcome measure. ${ }^{140,141}$ In TBI, trauma, and intensive care research, hospital mortality is the most commonly used outcome measure (and also in the TARN database). ${ }^{22,142-145}$ Hospital mortality, however, is known to underestimate mortality rates substantially in severely ill patients and is thus a source of biased results. ${ }^{142,143}$ This is a particular problem in patients with moderate to severe TBI, because as many as one third of hospital survivors die within six months following hospital discharge. ${ }^{29,50}$ Moreover, differences in discharge policies vary not only between countries but also within them, and adjusting for those differences with a fixedtime outcome measure is absolutely essential, lest hospitals feel pressured to discharge severely ill patients more rapidly to avoid them from dying to keep up their stats. ${ }^{140,143}$ Furthermore, using mortality rates as the primary outcome measure after TBI neglects important aspects of patient outcome, such as functional and neurological recovery and quality of life.

\subsubsection{Clinical Practice}

Prognostic models aim to aid, not replace, clinicians in estimating patient prognosis. Prognoses provided by a good prognostic model are probably more accurate than the predictions of an individual clinician. ${ }^{146}$ Prognostics estimation is a natural feature of every clinical environment when making treatment decisions (e.g. 'will this patient benefit from craniotomy?'), allocating resources (e.g. 'will this patient benefit from intensive care?'), and informing relatives. Decision making should, however, never be based solely upon a prognostic model. ${ }^{19}$

The value of prognosis estimation in the management of TBI was already demonstrated 30 years ago. ${ }^{147}$ In a survey, the vast majority of neurosurgeons thought that prognosis estimation was especially important when deciding which patients need decompressive craniectomy, intensive care, ICP monitoring and aggressive ICP treatment, and when treatment should be withdrawn. ${ }^{148}$ Moreover, Murray and Teasdale ${ }^{149}$ showed that computer-based prognosis estimation of patients with TBI increased the rate of intubation and ventilation, ICP monitoring, and osmotic administration in those with an estimated good prognosis but reduced them in patients with an estimated poor prognosis. It is important to note that the predictions did not alter decisions to provide or restrict 
treatment and did not affect outcomes. Thus, using prognostic models as a part of the routine clinical evaluation of TBI is not only reasonable and practical but also becoming increasingly important in the era of personalized medicine, where decisions are deeply connected with individual patient characteristics.

\subsubsection{Research}

The gold standard of modern evidencebased medicine is RCTs. RCTs are, however, increasingly hard to conduct in TBI research. For example, it might be considered unethical to randomize TBI patients who require intensive care to ordinary ward care, just for research purposes. Moreover the nature of TBI (a life-threatening event with unconsciousness) makes patient consent as a rule impossible to obtain, leaving that decision to the families.

The failure of numerous clinical trials in TBI has been attributed to the broad heterogeneity of TBI. $^{150}$ To limit heterogeneity, clinical trials often apply strict enrollment criteria that decrease result generalizability and thus weaken statistical power. Study generalizability and statistical power can, however, be improved by using prognostic models. ${ }^{26}$ This can be achieved by: baseline characteristic selection, prognostic targeting, and covariate adjustment. Of these methods covariate adjustment has proven most robust. ${ }^{151}$ Pre-specified covariate adjustment has in simulation studies increased statistical efficiency by $30 \%$ in observational studies and $16 \%$ in RCTs. ${ }^{151,152}$ Moreover, the use of prognostic models also allows for more sophisticated statistical analyses, such as the sliding dichotomy and proportional odds approaches, further increasing statistical power up to $50 \%$ when combined with prespecified covariate adjustment. ${ }^{26,153,154}$ Increased study power also provides significant benefits from the financial perspective in terms of shortened study duration and, thus, study costs.

RCTs are, however, not the only way to produce scientific evidence, especially in TBI. ${ }^{25}$ In fact, modern clinical practice in TBI is largely based on guideline development and results from observational studies rather than results from RCTs. ${ }^{25}$ Accordingly, there is currently a re-orientation of TBI research from RCTs towards more international observational collaboration studies and comparative effectiveness research (CER). ${ }^{18,25,155}$ CER is designed to inform healthcare decisions by providing evidence of effectiveness, benefits, and harms of different treatment strategies. ${ }^{156}$ The Institute of Medicine (IOM) defines CER as "the generation and synthesis of evidence that compares the benefits and harms of alternative methods to prevent, diagnose, treat, and monitor for a clinical condition or to improve delivery of care". In contrast to an RCT, where the main goal is to assess the efficacy of a specific intervention on patient outcome, CER aims to assess the effectiveness of different treatment strategies by measuring differences in patient outcome. CER generally allows much broader patient inclusion criteria than RCTs, making them more applicable to bedside medicine. Still, an accurate prognostic model is essential for proper CER in order to adjust for heterogeneity. ${ }^{18,25}$

\subsection{Traumatic Brain Injury Models}

\subsubsection{IMPACT}

The International Mission for Prognosis and Analysis of Clinical Trials (IMPACT) study is the result of pooled data from eight RCTs and three observational studies conducted between 1984 and 1997 (Table 11). ${ }^{157,158}$ The IMPACT prognostic models (simply IMPACT below) were introduced in 2008 and are freely available online (http://www. tbi-impact.org/?p=impact/calc). IMPACT 
uses patient admission characteristics to predict probability of six-month outcomes. IMPACT has three levels of complexity, from the simplest core model to the extended and the most complex laboratory model. The core model consists of age, the motor score component of the GCS, and pupillary light reactivity. The addition of hypoxia (defined as oxygen saturation $<90 \%$ at any time in the pre-hospital setting), hypotension (defined as systolic blood pressure $<90 \mathrm{mmHg}$ at any time in the pre-hospital setting), and head CT scan characteristics (epidural hematoma, traumatic subarachnoid hemorrhage, Marshall CT classification) makes up the extended model. For the laboratory model, blood hemoglobin and glucose concentrations are also added (Table 3). ${ }^{9}$ Naturally, model performance improves with increasing numbers of variables.

IMPACT has been externally validated in selected patients from the CRASH megatrial (see below). However, due to data incompleteness, only the core model and a variant of the extended model were externally validated with good results (AUC 0.780.80). ${ }^{9}$ Since then, IMPACT has been widely externally validated in independent datasets, with AUCs ranging from 0.65 to $0.90 .{ }^{159-162}$

\section{TABLE EXPLANATIONS}

Sum scores can be calculated for the core model (age, motor score, pupillary reactivity), the extended model (core + hypoxia + hypotension + CT characteristics), and a lab model (core + hypoxia + hypotension + CT + glucose $+\mathrm{Hb})$. The probability of 6 mo outcome is defined as $1 /\left(1+\mathrm{e}^{-\mathrm{LP}}\right)$, where LP refers to the linear predictor in a logistic regression model. Six LPs were defined as follows:

$\mathrm{LP}_{\text {core, mortality }}=-2.55+0.275$ * sum score core

$\mathrm{LP}_{\text {core, unfavorable }}^{\text {core, mortality }}=-1.62+0.299 *$ sum score core

$\mathrm{LP}_{\text {extended, mortality }}=-2.98+0.256^{*}$ sum score extended

$\mathrm{LP}_{\text {extended, unfavorable }}=-2.10+0.276^{*}$ sum score extended

$\mathrm{LP}_{\text {lab, mortality }}^{\text {extended, unfavorable }}=-3.42+0.216^{*}$ sum score lab

$\mathrm{LP}_{\text {lab, unfavorable }}=-2.82+0.257^{\star}$ sum score core lab

Table reproduced rom Steyerberg et al., PLoS Medicine 5(8):5165
Table 3: The International Mission for Prognosis and Analysis of Clinical Trials in TBI (IMPACT) model

\begin{tabular}{|c|c|c|}
\hline Characteristic & Value & Score \\
\hline \multirow[t]{6}{*}{ Age } & $<30$ & 0 \\
\hline & $30-39$ & 1 \\
\hline & $40-49$ & 2 \\
\hline & $50-59$ & 3 \\
\hline & $60-69$ & 4 \\
\hline & $\geq 70$ & 5 \\
\hline \multirow[t]{5}{*}{ Motor score } & None/extension & 6 \\
\hline & Abnormal flexion & 4 \\
\hline & Normal flexion & 2 \\
\hline & Localizes/obeys & 0 \\
\hline & Untestable/missing & 3 \\
\hline \multirow[t]{3}{*}{ Pupillary reactivity } & Both reacted & 0 \\
\hline & One reacted & 2 \\
\hline & None reacted & 4 \\
\hline \multicolumn{3}{|c|}{ SUM SCORE CORE MODEL } \\
\hline \multirow[t]{2}{*}{ Hypoxia } & Yes or suspected & 1 \\
\hline & No & 0 \\
\hline \multirow{2}{*}{$\begin{array}{l}\text { Hypotension } \\
\text { Yes or suspected }\end{array}$} & & 2 \\
\hline & No & 0 \\
\hline \multirow[t]{4}{*}{ CT classification } & I & -2 \\
\hline & II & 0 \\
\hline & III/IV & 2 \\
\hline & $\mathrm{V} / \mathrm{VI}$ & 2 \\
\hline \multirow{2}{*}{$\begin{array}{l}\text { Traumatic sub- } \\
\text { arachnoid hemor- } \\
\text { rhage }\end{array}$} & Yes & 2 \\
\hline & No & 0 \\
\hline \multirow[t]{2}{*}{ Epidural hematoma } & Yes & -2 \\
\hline & No & 0 \\
\hline \multicolumn{3}{|c|}{ SUB SCORE CT } \\
\hline \multicolumn{3}{|c|}{ SUM SCORE EXTENDED MODEL } \\
\hline \multirow[t]{5}{*}{ Glucose $(\mathrm{mmol} / \mathrm{l})$} & $<6$ & 0 \\
\hline & $6-8.9$ & 1 \\
\hline & $9-11.9$ & 2 \\
\hline & $12-14.9$ & 3 \\
\hline & $\geq 15$ & 4 \\
\hline \multirow[t]{4}{*}{ Hemoglobin (g/dl) } & $<9$ & 3 \\
\hline & $9-11.9$ & 2 \\
\hline & $12-14.9$ & 1 \\
\hline & $\geq 15$ & 0 \\
\hline \multicolumn{3}{|l|}{ SUB SCORE LAB } \\
\hline \multicolumn{3}{|c|}{ SUM SCORE LAB MODEL } \\
\hline
\end{tabular}




\subsubsection{CRASH}

The Corticosteroid Randomization After Significant Head Injury (CRASH) prognostic model is the result of the MRCCRASH meta-trial investigating the role of corticosteroids in patients with TBI. ${ }^{10,163}$ The CRASH model was developed on 10,008 TBI patients enrolled from 1994 to 2004, when the trial was shut down (Table 11). ${ }^{51} \mathrm{CRASH}$ debuted in 2008 and is also freely available online (http://www.trialscoordinatingcentre. lshtm.ac.uk/Riskcalculator/index.html). Like IMPACT, CRASH is based upon admission characteristics to predict probabilities of 14-day mortality and 6-month neurological outcome on the Glasgow Outcome Scale. CRASH has two levels of complexity, a basic

Table 4: The Corticosteroid Randomization After Significant Head Injury (CRASH) model

\begin{tabular}{|c|c|c|c|c|}
\hline & \multicolumn{2}{|c|}{ Mortality at 14 days } & \multicolumn{2}{|c|}{ Death or severe disability at 6 months } \\
\hline $\begin{array}{l}\text { Prognostic } \\
\text { variables }\end{array}$ & $\begin{array}{l}\text { High-income } \\
\text { contrives }\end{array}$ & $\begin{array}{l}\text { Low-middle income } \\
\text { countries }\end{array}$ & $\begin{array}{l}\text { High-income } \\
\text { countries }\end{array}$ & $\begin{array}{l}\text { Low-middle income } \\
\text { countries }\end{array}$ \\
\hline \multicolumn{5}{|c|}{ Multivariate basic predictive model shown as odds ratio (95\% confidence interval), $z$ score } \\
\hline $\mathrm{Age}^{\dagger}$ & $\begin{array}{l}1.72(1.62-1.83) \\
14.08\end{array}$ & 1.47 (1.40-1.54), 14.10 & $\begin{array}{l}1.73(1.64-1.82) \\
15.99\end{array}$ & $1.70(1.63-1.77), 18.58$ \\
\hline $\mathrm{GCS}^{*}$ & $\begin{array}{l}1.24(1.19-1.29) \\
10.22\end{array}$ & $1.39(1.35-1.42), 25.60$ & $\begin{array}{l}1.22(1.18-1.25), \\
12.84\end{array}$ & $1.42(1.39-1.45), 30.64$ \\
\hline \multicolumn{5}{|l|}{$\begin{array}{l}\text { Pupillary } \\
\text { reactivity: }\end{array}$} \\
\hline Both & 1 & 1 & 1 & 1 \\
\hline One & $2.57(1.65-4.00), 4.17$ & $1.91(1.53-2.39), 5.69$ & $2.43(1.62-3.66), 4.26$ & $2.01(1.59-2.56), 5.81$ \\
\hline None & $5.49(3.70-8.15), 8.45$ & $3.92(3.14-4.90), 12.07$ & $3.28(2.20-4.89), 5.85$ & $4.54(3.38-6.11), 10.03$ \\
\hline \multicolumn{5}{|l|}{$\begin{array}{l}\text { Major extra- } \\
\text { cranial injury: }\end{array}$} \\
\hline No & 1 & 1 & 1 & 1 \\
\hline Yes & $1.53(1.11-2.09), 2.62$ & $1.15(0.99-1.34), 1.78$ & $1.62(1.26-2.07), 3.82$ & 1.73 (1.51-1.99), 7.76 \\
\hline \multicolumn{5}{|c|}{ Multivariate predictive model with computerized tomography, shown as odds ratio (95\% confidence interval), $z$ score } \\
\hline Age $^{\dagger}$ & $\begin{array}{l}1.73(1.62-1.84) \\
13.33\end{array}$ & $1.46(1.39-1.54), 12.54$ & $\begin{array}{l}1.73(1.63-1.83) \\
14.94\end{array}$ & $1.72(1.64-1.81), 17.74$ \\
\hline $\mathrm{GCS}^{\ddagger}$ & $1.18(1.12-1.23), 6.87$ & 1.27 (1.24-1.31), 16.68 & 1.18 (1.14-1.22), 9.83 & $1.34(1.30-1.37), 22.32$ \\
\hline \multicolumn{5}{|l|}{ Pupil reactivity: } \\
\hline Both & 1 & 1 & 1 & 1 \\
\hline One & $2.00(1.25-3.20), 2.88$ & 1.45 (1.14-1.86), 2.97 & 2.12 (1.39-3.24), 3.47 & 1.54 (1.20-1.99), 3.35 \\
\hline None & $4.00(2.58-6.20), 6.21$ & $3.12(2.46-3.97), 9.31$ & 2.83 (1.84-4.35), 4.73 & $3.56(2.60-4.87), 6.03$ \\
\hline \multicolumn{5}{|l|}{$\begin{array}{l}\text { Major extra- } \\
\text { cranial injury }\end{array}$} \\
\hline No & 1 & 1 & 1 & 1 \\
\hline Yes & 1.53 (1.10-2.13), 2.53 & 1.08 (0.91-1.28), 0.89 & 1.55 (1.20-1.99), 3.37 & $1.61(1.38-1.88), 6.03$ \\
\hline \multicolumn{5}{|l|}{$\begin{array}{l}\text { Findings on } \\
\text { computed } \\
\text { tomography: }\end{array}$} \\
\hline $\begin{array}{c}\text { Petechial } \\
\text { hemorrhages }\end{array}$ & 1.15 (0.83-1.59), 0.84 & $1.26(1.07-1.47), 2.82$ & 1.21 (0.95-1.55), 1.56 & 1.49 (1.29-1.73), 5.33 \\
\hline $\begin{array}{c}\text { Obliteration of } \\
3^{\text {rd }} \text { or basal cisterns }\end{array}$ & $4.46(2.97-6.68), 7.23$ & 1.99 (1.69-2.35), 8.25 & $2.21(1.49-3.30), 3.95$ & 1.53 (1.31-1.79), 5.30 \\
\hline $\begin{array}{l}\text { Subarachnoid } \\
\text { bleed }\end{array}$ & 1.48 (1.09-2.02), 2.51 & 1.33 (1.14-1.55), 3.60 & $1.62(1.26-2.08), 3.79$ & 1.20 (1.04-1.39), 2.49 \\
\hline Midline shift & $2.77(1.82-4.21), 4.77$ & 1.78 (1.44-2.21), 5.35 & 1.93 (1.30-2.87), 3.24 & $1.86(1.48-2.32), 5.42$ \\
\hline $\begin{array}{l}\text { Non-evacuated } \\
\text { hematoma }\end{array}$ & $2.06(1.49-2.84), 4.40$ & 1.48 (1.24-1.76), 4.43 & $1.72(1.33-2.22), 4.15$ & 1.68 (1.43-1.97), 6.34 \\
\hline
\end{tabular}

${ }^{\star}$ Excluding data from computerized tomography, $†$ Per 10 -year increase after 40 years, $¥$ Per decrease of each value of GCS.

Table reprinted from BMJ 2008 23;336(7641):425-9 with permission from BMJ Publishing Group Ltd 
model, and an extended version with CT scan characteristics. The basic model includes age, GCS, pupillary light reaction, and presence of major extra-cranial injury. CT scan characteristics added for the extended model are presence of petechial hemorrhage, status of third ventricle and basal cisterns, presence of tSAH, midline shift, and mass lesion. Moreover, CRASH is calibrated differently for patients from low-and-middle income countries and high-income countries (Table 4). Similar to IMPACT, external validation studies of CRASH have yielded good results. ${ }^{10,164-166}$

\subsubsection{CT Scoring Systems}

\subsubsection{Marshall CT}

Developed in 1991 by Marshall et al. the Marshall CT classification is the most extensively used CT classification system in TBI. ${ }^{167}$ The Marshall CT classification was developed from 746 patients admitted between 1984 and 1987 to the six American clinical centers that made up the Traumatic Coma Data Bank. Three main variables characterize the Marshall classification: presence of mass lesion, status of perimesencephalic cisterns, and degree of midline shift. There are six categories in all: diffuse injury I to IV, evacuated mass lesion, and non-evacuated mass lesion (Table 5). The differentiation between evacuated mass lesion and non-evacuated mass lesion is artificial and often used as one single class for patients with any mass lesion larger than $25 \mathrm{~cm}^{3}$ present. Originally, the Marshall CT classification was not intended as a prognostic model but rather as a descriptive tool. Thus, the predictive ability of the Marshall classification system varies among studies. ${ }^{69,168,169}$

\subsubsection{Rotterdam CT}

In 2005 Maas et al. refined the Marshall CT classification, using 2,269 patients from the Tirilazad trials in Europe and North America, to develop the Rotterdam CT score (Table 6). ${ }^{69}$ While the Marshall CT classification was designed as a descriptive tool for TBI classification, the Rotterdam CT score was explicitly intended for six-month mortality outcome prediction in TBI. Since its introduction, several studies have shown good performance of the Rotterdam CT score in predicting outcome after TBI. ${ }^{69,168,170,171}$

Table 5: The Marshall CT classification

\begin{tabular}{|ll|}
\hline Marshall CT class & Definition \\
\hline Diffuse injury I & No visible intracranial pathology seen on CT scan \\
Diffuse injury II & $\begin{array}{l}\text { Cisterns present with midline shift of } 0-5 \mathrm{~mm} \text { and/or lesions densities } \\
\text { present; no high or mixed density lesions }>25 \mathrm{~cm}^{3} \text { may include bone } \\
\text { fragments and foreign bodies }\end{array}$ \\
& $\begin{array}{l}\text { Cisterns compressed or absent with midline shift of } 0-5 \text { mm; no high or } \\
\text { mixed density lesions }>25 \mathrm{~cm}^{3}\end{array}$ \\
Diffuse injury III & Midline shift $>5 \mathrm{~mm}$; no high or mixed density lesions $>25 \mathrm{~cm}^{3}$ \\
Diffuse injury IV & Any lesion surgically evacuated \\
Evacuated mass lesion & High of mixed density lesion $>25 \mathrm{~cm}^{3}$; not surgically evacuated \\
Non-evacuated mass lesion &
\end{tabular}

Table reprinted from Marshall et al., J Neurosurg 1991 7(S1):S14-S20 with permission from the JNS Publishing Group 
Table 6: The Rotterdam CT score

\begin{tabular}{|lc|}
\hline Variable & Score \\
\hline Basal cisterns & \\
Normal & 0 \\
Compressed & 1 \\
Absent & 2 \\
Midline shift & \\
$\quad$ No shift or $\leq 5 \mathrm{~mm}$ & 0 \\
Shift $>5 \mathrm{~mm}$ & 1 \\
Epidural mass lesion & \\
$\quad$ Present & 0 \\
$\quad$ Absent & 1 \\
Intraventricular blood or traumatic & \\
subarachnoid hemorrhage & \\
Absent & \\
Present & 0 \\
Sumscore & 1 \\
\hline
\end{tabular}

Table reprinted from Maas et al., Neurosurgery 2005 57(6):1173-82

\subsection{Trauma Scoring Systems}

\subsubsection{Anatomical Trauma Scoring Systems}

The Injury Severity Score (ISS) and the New Injury Severity Score (NISS) are anatomical scoring systems providing an overall indicator of patient injury severity. ${ }^{172,173}$ In both systems the body is divided into six regions (head, face, chest, abdomen, extremities, and external) and each body region injury is assigned a score based on injury severity from 0 (no injury) to 6 (unsurvivable injury) on the Abbreviated Injury Scale (AIS). ${ }^{174}$ The ISS and NISS both use a range from 0 to 75 . A patient with an AIS of 6 in any body region automatically gets a total ISS of 75; otherwise ISS is calculated by the sum of squares of the single highest AIS in each of the three most severely injured body regions. The NISS is a modification of the ISS and calculated by the sum of squares of the patient's three most severe AIS injuries, regardless of body region.

\subsubsection{Physiological Trauma Scoring Systems}

The Trauma Score (TS) was first introduced in 1981 by Champion et al. and later revised in 1989 into the Revised Trauma Score (RTS). ${ }^{175,176}$ The TS and the RTS are physiological scores giving points for abnormal physiologic patient characteristics - the more abnormal the value, the lower the score and the higher the risk of death. The TS includes five variables (respiratory rate, respiratory effort, systolic blood pressure, capillary refill, GCS), while the RTS uses only three (respiratory rate, systolic blood pressure, and GCS). Normal physiological measures (e.g. systolic blood pressure $>90 \mathrm{mmHg}$ ) give a score of 4 - the more abnormal the value, the closer the assigned score is to 0 (e.g. GCS 3 gives 0 points). Accordingly, the TS ranges from 0-20, and the RTS from 0-12.

\subsubsection{Combined Anatomical and Trauma Scores}

The recognition of the close connection between anatomical injury severity and physiological response made way for new prognostic models that combine these two scoring systems. Since its introduction, the Trauma Score-Injury Severity Score (TRISS) has been considered the gold standard of injury severity classification for general trauma patients. ${ }^{20,175,177}$ The TRISS uses values from the ISS, the RTS, patient age, and injury type (blunt vs. penetrating) to quantify the probability of survival.

\subsubsection{RISC}

In recent years, the TRISS approach for outcome prediction in trauma patients has been discussed critically. ${ }^{178,179}$ The TRISS has been cited for not considering adequately the importance of age and head injury in trauma patients. ${ }^{180}$ 
The establishment of the Trauma Registry of the German Society for Trauma Surgery (TraumaRegister DGU ${ }^{\oplus}$, TR-DGU) in 1993 led to the development of a trauma prediction model targeted explicitly at German trauma patients. Accordingly, in 2009 Lefering introduced the Revised Injury
Severity Classification (RISC), based upon 2,008 severely injured patients (of whom 551 had a severe head injury) from the TR-DGU during the years 1993 to 2000 (Table 11).

The RISC combines 11 different components: age, NISS, head injury, pelvic injury, GCS, PTT (partial thromboplastin

Table 7: The Revised Injury Severity Score (RISC) model

\begin{tabular}{|c|c|c|c|c|}
\hline Characteristic & Value & Coefficient & Replacement strategy & Comment \\
\hline \multirow[t]{4}{*}{ Age, years } & $<55$ & 0 & None & Compulsory variable \\
\hline & $55-64$ & -1.0 & & \\
\hline & $65-74$ & -2.0 & & \\
\hline & $\geq 75$ & -2.3 & & \\
\hline NISS & $1-75$ & -0.03 & None & Compulsory variable \\
\hline \multirow[t]{3}{*}{ AIS-Head } & $0-3$ & 0 & None & Compulsory variable \\
\hline & 4 & -0.5 & & \\
\hline & $5-6$ & -1.8 & & \\
\hline \multirow[t]{2}{*}{ AIS-Extremities } & $0-4$ & 0 & None & Compulsory variable \\
\hline & 5 & -1.0 & & \\
\hline \multirow[t]{2}{*}{$\mathrm{GCS}^{*}$} & $6-15$ & 0 & GCS $\dagger$ & $\begin{array}{l}\text { Use standard category if no GCS is } \\
\text { available }\end{array}$ \\
\hline & $3-5$ & -0.9 & & \\
\hline \multirow[t]{2}{*}{ PTT $\dagger$ (seconds) } & $<40$ & 0 & PT & $\begin{array}{l}\text { If PTT and PT are missing, double the } \\
\text { points for indirect bleedings signs; no } \\
\text { replacement if bleedings signs are missing }\end{array}$ \\
\hline & $40-49$ & -0.8 & $50-79 \%$ & \\
\hline \multirow[t]{2}{*}{$50-79$} & & -1.0 & $30-49 \%$ & \\
\hline & $\geq 80$ & -1.2 & Below 30\% & \\
\hline \multirow[t]{2}{*}{$\begin{array}{l}\text { Base excess } \dagger \\
(\mathrm{mmol} / \mathrm{l})\end{array}$} & $\begin{array}{l}-9.0 \text { to } \\
-19.0\end{array}$ & -0.8 & $\begin{array}{l}\text { Choose the worse of } \\
\text { platelets }<100^{\star} 10^{9} \text { or } \\
\text { cardiac arrest } \dagger\end{array}$ & Use standard category if no data available \\
\hline & $\begin{array}{l}\text { Under } \\
-20.0\end{array}$ & -2.7 & & \\
\hline $\begin{array}{l}\text { Relevant } \\
\text { bleeding signs: }\end{array}$ & None & & & \\
\hline $\begin{array}{l}\text { Systolic BP }<90 \\
\mathrm{mmHg}^{*}\end{array}$ & 1 & -0.4 & Blood pressure $\dagger$ & $\begin{array}{l}\text { No replacement if neither blood pressure } \\
\text { is available }\end{array}$ \\
\hline $\begin{array}{l}\text { Hemoglobin }<9 \\
\mathrm{mg} / \mathrm{dl} \dagger\end{array}$ & 2 & -0.8 & Blood pressure $\dagger$ & $\begin{array}{l}\text { No replacement in both values were } \\
\text { missing }\end{array}$ \\
\hline $\begin{array}{l}\text { Transfusion }>9 \\
\text { units of pROC } \dagger\end{array}$ & 3 & -1.6 & Standard category & $\begin{array}{l}\text { Hemodynamic data suggest that cases with } \\
\text { missing data were not transfused }\end{array}$ \\
\hline \multirow[t]{2}{*}{ Cardiac arrest ${ }^{\star}$} & No & 0 & $\begin{array}{l}\text { Blood pressure }{ }^{\star}=0 \text { or } \\
\text { cardiac arrest } \dagger\end{array}$ & Use standard category if no data available \\
\hline & Yes & -2.5 & & \\
\hline CONSTANT & 5.0 & & & \\
\hline
\end{tabular}

${ }^{*}$ Preclinical values, †First assessment in hospital, Abbreviations: NISS, New Injury Severity Score; AIS, Abbreviated Injury Severity; GCS, Glashow Coma Score; PTT, Partial Thromboplastin Time; PT, Thromboplastin Time; pRBC, packed Red Blood Cells. Table reprinted from Lefering R, Eur J Trauma Emerg Surg 2009;35(5):43747 with permission from Springer 
time), base excess, cardiac arrest, and relevant signs of bleeding (Table 7). ${ }^{180}$ With the exception of NISS, all the variables are categorical. According to the original methodology of the RISC, missing values are substituted, so that, for example, missing partial thromboplastin values are replaced by thromboplastin. The value of each predictor is associated with a given coefficient. For an individual patient, the point weights are subtracted from a constant of 5.0, resulting in the final score $\mathrm{X}$, which is transformed into a probability of hospital survival (Ps) with the logistic function: $\mathrm{P}(\mathrm{s})=1 /\left(1+\mathrm{e}^{-\mathrm{X}}\right)=\mathrm{e}^{\mathrm{X}} /\left(1+\mathrm{e}^{\mathrm{X}}\right)$. The RISC predicts in-hospital mortality and serves as the prediction model for one of the largest trauma databases in Europe (TRDGU). It is noteworthy that the RISC has not been externally validated in independent populations outside Germany.

\subsection{Intensive Care Scoring Systems}

ICU scoring system-based models are among the most widely used prognostic models in healthcare. ${ }^{22,27}$ The first intensive care scoring systems were introduced over 30 years ago, with the introduction of the Acute Physiology and Chronic Health Evaluation (APACHE ${ }^{181}$ ) in 1981 and the Simplified Acute Physiology Score (SAPS ${ }^{182}$ ) in 1984. Since debuting, APACHE has been revised three times (APACHE II, ${ }^{183}$ APACHE III, ${ }^{184}$ APACHE IV $^{185}$ ) and the SAPS twice (SAPS II, ${ }^{186}$ SAPS $\left.3^{187,188}\right)$. Moreover, although not originally developed as a prognostic tool, the Sequential Organ Failure Assessment (SOFA $^{189-}$ ${ }^{191}$ ) score is frequently used for outcome prediction in ICU patients. Nevertheless, although routinely used in most ICUs in the world, the role of the intensive care scoring systems in the neurotrauma population is controversial. ${ }^{17,192,193}$

\subsubsection{APACHE II}

APACHE II is based on 5,815 patients, with various critical illnesses, admitted to 13 ICUs in North America during 1979-1982 (Table 11). The APACHE II score consists of three major blocks: 1) the acute physiology score, consisting of the most abnormal values of 12 different physiological parameters measured during the first 24 hours of ICU admission; 2) the age score; and 3) the chronic health score (Table 8). ${ }^{183}$ Each parameter yields a sub-score (Acute Physiology Score [APS], age points [B], chronic health evaluation [C], see Table 8) that add up to the total APACHE II score, ranging from 0 to 71 - the higher the score, the more severe the disease and the higher the risk of death. The relation between risk of death and APACHE II score is not linear but rather sigmoid-shaped and largely dependent on admission diagnosis.

The development cohort of APACHE II included 120 head injury patients $(+517$ possible patients belonging to the multiple trauma and neurologic sub-groups). Despite the relatively low number of TBI patients, previous studies have shown APACHE II to be a poor to good predictor of short-term mortality after TBI. ${ }^{194-196}$

\subsubsection{SAPS II}

SAPS II is based on 13,152 patients admitted to 137 ICUs in 12 countries in 1991 and 1992 (Table 11). Like the APACHE II score, SAPS II is calculated with 12 physiological parameters from the first 24 hours of ICU admission and three disease-related variables (Table 9). ${ }^{186}$ SAPS also uses the most abnormal physiological value measured during the first 24 hours of ICU admission. The points of the 15 variables are added together to yield the total score for SAPS II, which ranges from 0 to 163 - the higher the score, the more severe the disease and the higher the risk of death. 


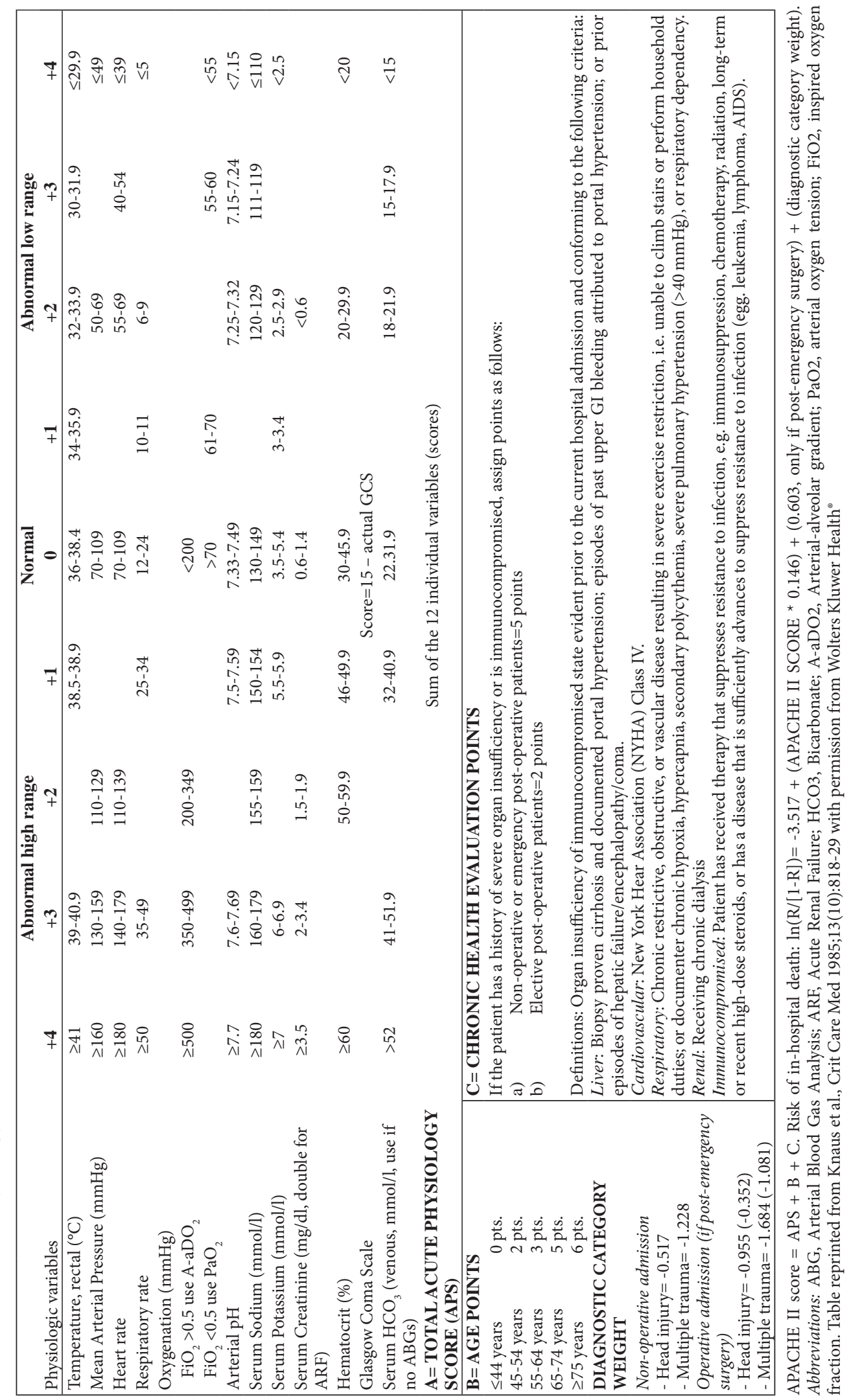




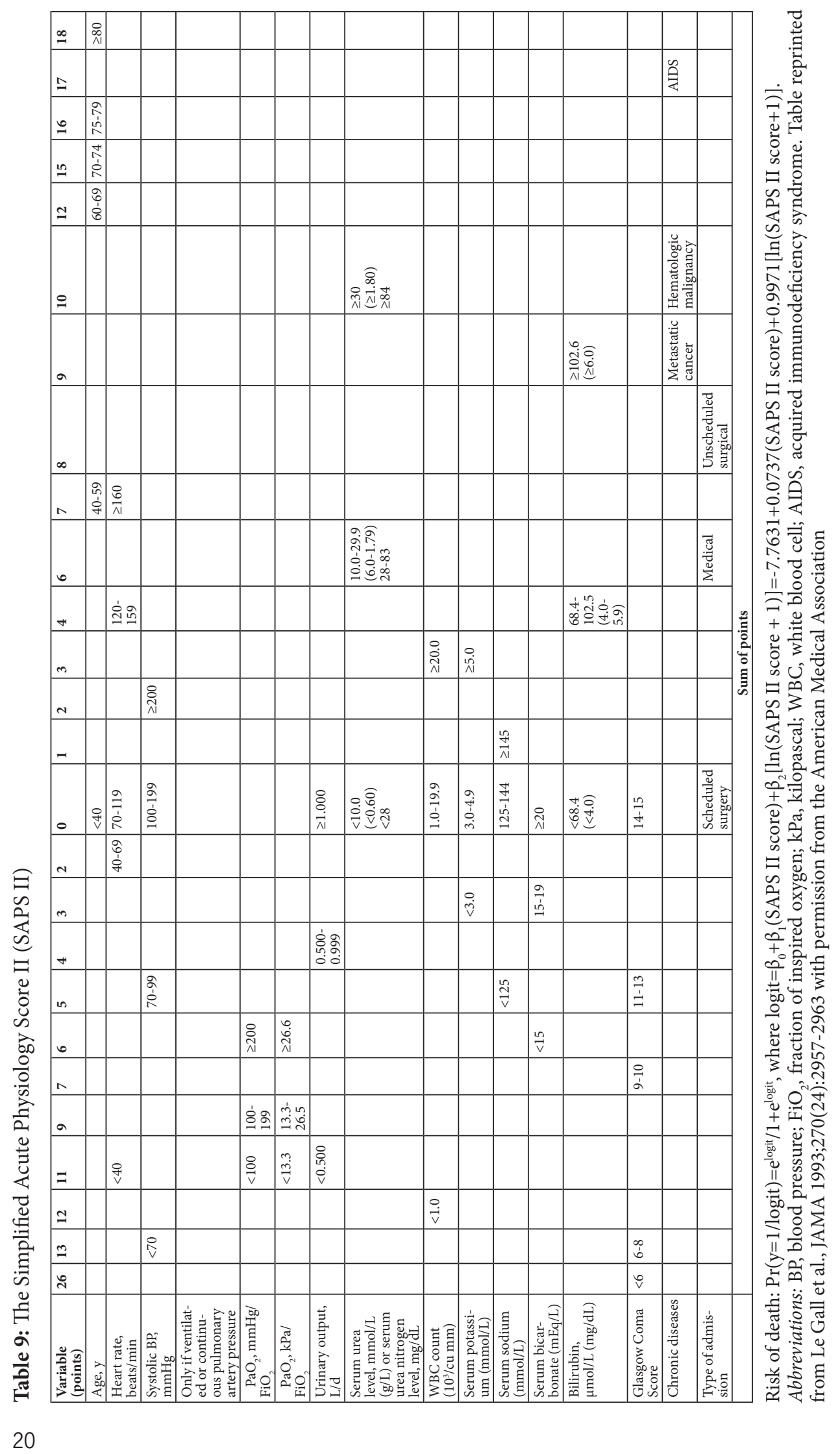


In contrast to APACHE II, SAPS II does not account for admission diagnosis. In spite of this, SAPS II has been found to be of good predictive value for short-term mortality prediction in patients with TBI. ${ }^{195-197}$

\subsubsection{SOFA}

The SOFA score was developed in a cohort of 1,449 patients admitted to 40 ICUs in 16 countries in May 1995 (Table 11), and was initially developed as a scoring system to describe objectively the degree of organ dysfunction in septic patients over time. ${ }^{198}$ However, shortly after its introduction it was discovered that SOFA scores also apply well to non-septic patients. ${ }^{199}$ Unlike APACHE II and SAPS II, the SOFA score was not designed to predict outcome; rather, it is a measure of the degree of multi-organ failure. The SOFA score is calculated based upon six variables, each representing an organ system (respiration, coagulation, liver, cardiovascular, central nervous system, renal). Each organ receives a sub-score ranging from 0 (normal) to 4 (high degree of dysfunction/failure) (Table 10). ${ }^{198}$ The worst sub-score (i.e. highest point) is collected every 24 hours during the ICU stay to show organ dysfunction development. The SOFA score ranges from 0 to $24-$ the higher the score, the higher the degree of organ dysfunction. Although not designed to predict mortality, a rough prediction can be made based upon score trend or maximal score. ${ }^{189,198}$

Table 10: The Sequential Organ Failure Assessment (SOFA) score

\begin{tabular}{|c|c|c|c|c|}
\hline SOFA score & 1 & 2 & 3 & 4 \\
\hline $\begin{array}{l}\text { Respiration } \\
\mathrm{PaO}_{2} / \mathrm{FiO}_{2}, \mathrm{mmHg}\end{array}$ & $<400$ & $<300$ & $\begin{array}{l}<200 \\
\text { (With respiratory } \\
\text { support) }\end{array}$ & $\begin{array}{l}<100 \\
\text { (With respiratory } \\
\text { support) }\end{array}$ \\
\hline $\begin{array}{l}\text { Coagulation } \\
\text { Platelets }{ }^{*} 10^{3} / \mathrm{mm}^{3}\end{array}$ & $<150$ & $<100$ & $<50$ & $<20$ \\
\hline $\begin{array}{l}\text { Liver } \\
\text { Bilirubin, mg/dl ( } \mu \mathrm{moll} / \mathrm{l})\end{array}$ & $\begin{array}{l}1.2-1.9(20- \\
32)\end{array}$ & $2.0-5.9(33-101)$ & $6.0-11.9(102-204)$ & $>12.0(>204)$ \\
\hline $\begin{array}{l}\text { Cardiovascular } \\
\text { Hypotension }\end{array}$ & $\begin{array}{l}\mathrm{MAP}<70 \\
\mathrm{mmHg}\end{array}$ & $\begin{array}{l}\text { Dopamine } \leq 5 \\
\text { Or doputa- } \\
\text { mine }^{\star}\end{array}$ & $\begin{array}{l}\text { Dopamine }>5 \\
\text { Or Epinephrine } \leq 0.1 \\
\text { Or Norepinephrine } \\
\leq 0.1\end{array}$ & $\begin{array}{l}\text { Dopamine }>15 \\
\text { Or Epinephrine }>0.1 \\
\text { Or Norepinephrine } \\
>0.1\end{array}$ \\
\hline $\begin{array}{l}\text { Central nervous system } \\
\text { Glasgow Coma Scale }\end{array}$ & $13-14$ & $10-12$ & $6-9$ & $<6$ \\
\hline $\begin{array}{l}\text { Renal } \\
\text { Creatinine, } \mathrm{mg} / \mathrm{dl}(\mu \mathrm{mol} / \mathrm{l}) \text { or urine } \\
\text { output }\end{array}$ & $\begin{array}{l}1.2-1.9(110- \\
170)\end{array}$ & $\begin{array}{l}2.0-3.4(171- \\
299)\end{array}$ & $\begin{array}{l}3.5-4.9(300-440) \\
\text { Or }<500 \mathrm{ml} / \text { day }\end{array}$ & $\begin{array}{l}>5.0(>440) \\
\text { Or }<200 \mathrm{ml} / \text { day }\end{array}$ \\
\hline
\end{tabular}

* Doputamine at any dose, Adrenergic agents administered for at least $1 \mathrm{~h}$ (doses given are in $\mu \mathrm{g} / \mathrm{kg}$ * $\mathrm{min}$, Risk of ICU death $=\mathrm{e}-4.0473+0.2790$ * TMS $/ 1+\mathrm{e}-4.0473+0.2790 *$ TMS, TMS= total maximum SOFA score during the ICU stay. Table reprinted from Vincent et al., Crit Care Med 1998;26(11):1793-800 with permission from Wolters Kluwer Health ${ }^{\oplus}$ 
Table 11: Prognostic model development

\begin{tabular}{|c|c|c|c|c|c|}
\hline & Released & Patients & Patients, TBI & Enrollement & Outcome \\
\hline \multicolumn{6}{|l|}{ TBI models } \\
\hline IMPACT & 2008 & 8,509 & $\begin{array}{l}\text { 8,509 (core), } \\
\text { 6,999 (extended), } \\
3,554 \text { (lab) }\end{array}$ & $1985-1997$ & $\begin{array}{l}\text { 6-month } \\
\text { mortality } \\
\text { 6-month GOS }\end{array}$ \\
\hline CRASH & 2007 & 10,008 & 10,008 & $1999-2004$ & $\begin{array}{l}\text { 14-day mortality } \\
\text { 6-month GOS }\end{array}$ \\
\hline \multicolumn{6}{|l|}{ CT models } \\
\hline $\begin{array}{l}\text { Marshall CT } \\
\text { classification }\end{array}$ & 1991 & 746 & 746 & 1984-1987 & NA \\
\hline Rotterdam CT score & 2005 & 2,269 & 2,269 & 1991-1994 & 6-month outcome \\
\hline \multicolumn{6}{|l|}{ ICU models } \\
\hline APACHE II & 1985 & 5,815 & $105(+517)$ & $1979-1982$ & $\begin{array}{l}\text { In-hospital } \\
\text { mortality }\end{array}$ \\
\hline SAPS II & 1993 & 13,152 & Unknown & 1991-1992 & $\begin{array}{l}\text { In-hospital } \\
\text { mortality }\end{array}$ \\
\hline SOFA & 1996 & 1,449 & $181^{*}$ & 1995 & In-ICU mortality \\
\hline \multicolumn{6}{|l|}{ Trauma models } \\
\hline RISC & 2009 & 2,008 & 551 & $1993-2000$ & $\begin{array}{l}\text { In-hospital or 30- } \\
\text { day mortality }\end{array}$ \\
\hline
\end{tabular}

Abbreviations: TBI, Traumatic Brain Injury; IMPACT, International Mission for Prognosis and Analysis of Clinical Trials in TBI; CRASH, Corticosteroid Randomization After Significant Head Injury; APACHE II, Acute Physiology and Chronic Health Evaluation II; SAPS II, Simplified Acute Physiology Score II; SOFA, Sequential Organ Failure Assessment; RISC, Revised Injury Severity Classification, ${ }^{*}$ General trauma patients 


\section{$3 \quad$ Purpose of the Study}

The purpose of this study is to validate different types of prognostic models for patients with TBI and to develop novel models with enhanced predictive performance, with focus on long-term outcome prediction. The following specific aims were addressed:

1. To investigate the predictive accuracy of TBI specific models (I-III), general intensive care scoring systems (IV), and general trauma scoring systems (V) for outcome prediction in patients with TBI.

2. To create new prognostic models with enhanced performance compared to previous models (II, III, IV). 


\section{$4 \quad$ Subjects and Methods}

\subsection{Study Setting and Population}

\subsubsection{Traumatic Brain Injury Models (I-III)}

Studies I, II, and III investigate TBI models and are based on patients with TBI admitted to the ICUs of Töölö Hospital (Helsinki University Central Hospital [HUCH]) from January 2009 to December 2012 (Table 12). Located in Helsinki, Finland, Töölö Hospital is the $\mathrm{HUCH}$ trauma unit and the only Level I trauma center in The Hospital District of Helsinki and Uusimaa (HUS), a joint authority encompassing 24 municipalities and approximately two million inhabitants. The Department of Neurosurgery in Helsinki is the largest neurosurgical unit in Finland and one of the largest in Europe, performing more than 3,200 neurosurgical operations annually.

TBI was defined as a discharge ICD-10 (International Classification of Diseases and Related Health Problems, 10 ${ }^{\text {th }}$ Edition) diagnosis of S06.1-S06.9, caused by an external force. ${ }^{30}$ Only blunt injury mechanism TBI and adult patients ( $\geq 14$ years for I and III, $\geq 16$ years for II) were included. Patients with a history of head trauma but no intracranial pathological findings by CT imaging during the hospital stay and those with subacute injuries ( $>24$ hours) were excluded.

Study I includes 342 patients with moderate to severe TBI (admission GCS 3-12) admitted from January 2009 to December 2010 .

Studies II and III include patients with mild complicated TBI (defined as admission GCS 13-15 requiring ICU admission) and moderate to severe TBI (admission GCS 3-12) admitted from January 2009 to December 2012; there were totals of 890 (II) and 869 patients (III).

\subsubsection{Intensive Care Scoring Systems (IV)}

Study IV includes patients with moderate to severe TBI admitted to one of five university hospitals participating in the Finnish Intensive Care Consortium (FICC) database from January 2003 to December 2012 (Table 12).

The FICC database is a multi-center database consisting of prospectively collected data from ICUs in 22 different hospitals (of which 5 are university hospitals). The FICC database was established in 1994 as a co-operative benchmarking project to improve the quality of intensive care in Finland. Data from patient monitors, laboratory systems, and ventilators are automatically collected. ${ }^{200}$ Specially trained ICU personnel manually enter specific types of other data, such as co-morbidities and outcomes. All data are stored in a central database maintained by Tieto Healthcare \& Welfare Ltd. (Kuopio, Finland). Patients with TBI were identified by their APACHE III ${ }^{184}$ diagnosis. Moderate to severe TBI was defined as a worst GCS of 3 to 13 in the first ICU day, ${ }^{57}$ leading to the inclusion of 1,625 patients in the study.

\subsubsection{Trauma Scoring Systems (V)}

Study V encompasses severely injured patients with moderate to severe TBI admitted to the TR-DGU and the Trauma Register of Helsinki University Hospital (TR-THEL) (Table 12). Moderate to severe traumatic brain injury was defined as head-region AIS of three or higher. Patients were further divided based on the severity of extra-cranial injuries into isolated TBI (no other body part AIS $\geq 2$ ) and polytrauma TBI (at least one other body part AIS $\geq 2$ ). For comparison reasons, mild TBI (AIS-head=1-2) and no TBI (AIS-head=0) were also defined.

The TR-DGU (TraumaRegister DGU of the German Trauma Society) began in 
1993 with five trauma units in Germany. Since then, the TR-DGU has grown to be one of Europe's largest databases, entering over 30,000 patients annually from over 600 hospitals, more than $90 \%$ of which are in Germany. Inclusion criteria are admission via the emergency department with subsequent ICU care, or admission with vital signs but death before ICU admission. Data for the TR-DGU is gathered prospectively in a central web-based database hosted by the Akademie der Unfallchirurgie $\mathrm{GmbH}$ of the DGU. Scientific data analyses are approved by a peer-reviewed process by the Committee of Emergency Medicine, Intensive Care, and Trauma Management of the German Trauma Society (Sektion NIS). Study V was registered as TR-DGU Project ID: 2012-053 II.

The Trauma Registry of Helsinki University Hospital (TR-THEL) is a singlecenter trauma registry consisting of patients with severe trauma (defined as an ISS >15) admitted to Töölö Hospital. The TR-THEL was founded in 2006 as a benchmarking project for improving the quality of trauma care in the region. Data is collected according to the Utstein recommendations. ${ }^{201}$ From 2006 to 2011, 400 to 450 patients were entered into the database annually.

\subsection{Data collection}

\subsubsection{Traumatic Brain Injury Models (I-III)}

Patient admission characteristics were recorded by emergency department physicians and were retrieved from electronic records. Two authors co-operatively classified all admission head-CT images by Marshall CT classification, Rotterdam CT score, and by a set of pre-defined characteristics:

- Mass lesion type (SDH, EDH, ICH [contusion])

- Mass lesion volume ( $\geq 25 \mathrm{~cm} 3,<25$ $\mathrm{cm} 3$ )
- Presence, location, and thickness of tSAH (basal, cortical, both; thin, thick)

- $\quad$ Presence of IVH (yes or no)

- Status of suprasellar cisterns (normal, compressed, obliterated)

- Status of ambiens cisterns (normal, compressed, obliterated)

- Status of fourth ventricle (normal, abnormal)

- Midline shift (in mm)

- Cortical sulci effacement (no effacement, unilateral effacement, bilateral effacement)

Patients scheduled for acute mass lesion evacuation were classified as Marshall class $\mathrm{V}$ (evacuated mass lesion). Mass lesion was defined as any $\mathrm{SDH}, \mathrm{EDH}$, or $\mathrm{ICH}$ of any size, with ICH referring to both contusion and intracerebral hemorrhage, as no clear distinction between the two exists. Mass lesion volume was measured using the $\mathrm{ABC} / 2$ method, which is accurate for both intra-parenchymal and extra-parenchymal hemorrhage volume assessment, with little inter-observer variability. ${ }^{202-204}$

Laboratory values were measured on admission and retrieved from electronic hospital records. The international normalized ratio (INR) and platelet count were used as markers of coagulation, while ISS indicated extra-cranial injury. ${ }^{172}$ The ISS was calculated by an independent accredited nurse using the AIS 2005 revision. ${ }^{174}$ Hypotension and hypoxia were defined according to the Brain Trauma Foundation guidelines as a systolic blood pressure $<90 \mathrm{mmHg}$ and an oxygen saturation $<90 \%$, respectively, at any time prior to hospital admission. ${ }^{47}$ The APACHE II variables were extracted from the ICU software (PICIS, Anesthesia Manager ${ }^{\circledast}$ ) at five-minute intervals to pinpoint the most abnormal physiological and laboratory values measured during the first 24 hours in the ICU. 
Missing baseline data were infrequent and, thus, handled by case exclusion. There were no patients with unavailable baseline data in Study I, while 33 patients were excluded from Study II due to missing baseline data, and two patients were excluded from Study III due to missing head CT data.

Data on mortality were retrieved from the Finnish population register center, which is available for $100 \%$ of Finnish patients. Neurological outcome was dichotomized into favorable and unfavorable outcome based on the Glasgow Outcome Scale (GOS). ${ }^{205}$ Unfavorable outcome was defined as GOS 1-3 (1, death; 2, vegetative state; 3 , severe disability) and favorable outcome as GOS 4-5 (4, moderate disability; 5, low disability/ full recovery). Two independent authors retrospectively adjudicated six-month GOS based on outpatient clinic follow-up records with a neurosurgeon or neurologist. Discrepancies in GOS evaluation were resolved by discussion; GOS agreement was good among the authors, with a kappa of 0.90
(95\% CI 0.86-0.95). It was not possible to assess the GOS for 13 patients in Study I, 48 patients in Study II, and 54 patients in Study III.

\subsubsection{Intensive Care Scoring Systems (IV)}

All variables according to APACHE II, ${ }^{183}$ SAPS II, ${ }^{186}$ and SOFA ${ }^{206}$ were extracted from the FICC database. ${ }^{200}$ The primary outcome was six-month mortality, with a secondary outcome of hospital mortality. Patients with missing outcome data were excluded $(n=897)$. Moreover, seven patients with missing baseline data were excluded from the analyses.

\subsubsection{Trauma Scoring Systems (V)}

Patients with major trauma (defined as ISS >15) entered from 2006 to 2011 into the TR-DGU and TR-THEL databases were extracted and combined into a joint database. For the TR-DGU, only major Level

Table 12: Study populations

\begin{tabular}{|c|c|c|c|}
\hline Characteristic & Studies I-III & Study IV & Study V \\
\hline Patient source & Helsinki & FICC & $\begin{array}{l}\text { TR-THEL + TR- } \\
\text { DGU }\end{array}$ \\
\hline $\begin{array}{l}\text { Single or multi } \\
\text { center }\end{array}$ & Single & Multi & Multi \\
\hline Enrollment period & $\begin{array}{l}\text { 2009-2010 (I) } \\
2009-2012 \text { (II, III) }\end{array}$ & $2003-2012$ & 2006-2011 \\
\hline Age criteria (years) & $14-99$ (I), $\geq 16$ (II), $\geq 14$ (III) & $\geq 16$ & $\geq 16$ \\
\hline Clinical severity & $\begin{array}{l}\text { GCS } 3-12 \\
\text { GCS } 3-15^{*}\end{array}$ & GCS $3-13 \dagger$ & AIS-head $\geq 3$ \\
\hline Exclusion criteria & $\begin{array}{l}\text { Penetrating head injury, subacute injury } \\
\text { ( }>24 \mathrm{~h}) \text {, dead on arrival, death before ICU } \\
\text { admission or CT imaging, normal admis- } \\
\text { sion head-CT scan (III) }\end{array}$ & $\begin{array}{l}\text { Patients treated at } \\
\text { non-neurosurgical } \\
\text { unit }\end{array}$ & $\begin{array}{l}\text { Not primary trans- } \\
\text { fer, Penetrating } \\
\text { non-head injury }\end{array}$ \\
\hline Outcome & Six-month mortality and GOS & $\begin{array}{l}\text { Six-month mor- } \\
\text { tality }\end{array}$ & $\begin{array}{l}\text { 30-day in-hospital } \\
\text { mortality }\end{array}$ \\
\hline
\end{tabular}

Age showed as median (IQR), ${ }^{\star}$ All patients requiring ICU admission, †Worst measured GCS in the first day in the ICU, $\$ 30$ day mortality or death before discharge. Abbreviations: AIS, Abbreviated Injury Scale; GCS, Glasgow Coma Scale; GOS, Glasgow Outcome Scale; CT, Computerized Tomography; FICC, Finnish Intensive Care Consortium; TR-THEL, Trauma Registry of Helsinki University Hospital; TR-DGU ${ }^{\bullet}$, TraumaRegister $\mathrm{DGU}^{\oplus}$ 
I trauma centers located in Germany treating more than 50 trauma cases annually were included $(n=85)$. Patients under the age of 16 , indirectly admitted patients, and patients with penetrating non-head injuries were excluded.

All RISC variables were extracted from the joint database. The ISS and AIS were classified according to the 2005 revision. ${ }^{174}$ Patient outcome was measured as 30-day mortality or death before hospital discharge. Missing data were replaced according to the original RISC substitution strategy. ${ }^{180}$ Following substitution, RISC was not possible to calculate for $8 \%$ of patients $(n=1,367)$ and $1 \%(n=6)$ of patients in the TR-DGU and TR-THEL, respectively, and those patients were excluded.

\subsection{Statistical Analysis}

The statistical analyses employed IBM SPSS Statistics for Windows and Mac, Versions 20.0, 21.0, 22.0 (IBM, Armonk, NY), Analyze-it for Windows Microsoft Excel Versions 2.30, 3.50 (Microsoft, Seattle, WA), and R: A Language Environment for Statistical Computing (R-Foundation for Statistical Computing, Vienna, Austria). In R, the 'PredictABEL,' ${ }^{207}$ 'pROC,'208 'GiViTI,'126 and 'rms'209 packages were predominantly used.

Statistical differences in categorical variables between patient groups were tested using the chi-squared test (two-tailed) and the Fisher's exact test (when the expected number was less than five). Continuous data were tested for skewness; the Mann-Whitney U-test was used for skewed data and the Student's t-test used for normally distributed data. Categorical data is presented as absolute numbers (with percentages), parametric data as means (with standard deviations [SD]), and nonparametric data as medians (with interquartile range $[\mathrm{IQR}]$ ), unless otherwise noted.

Association between variables and outcome was assessed by logistic regression analysis, by assessing gain in AUC, by assessing gain in explanatory variation (Nagelkerke $\mathrm{R}^{2}$ ), and by NRI testing. Improvements in AUC, NRI, or both with an associated p-value under 0.05 were considered statistically significant.

Prognostic model performance was tested by assessing discrimination (by AUC), calibration (by H-L, calibration slopes, and GiViTI), re-classification statistics (by NRI), and explanatory variation (by Nagelkerke $\left.\mathrm{R}^{2}\right) .{ }^{120,126,210,211}$ Differences in AUC were tested using the DeLong test ${ }^{212}$ or the Venkatraman test. ${ }^{213}$ Models were internally validated using a split-sample technique ${ }^{109}$ or a re-sample optimism-corrected bootstrapping technique, ${ }^{108,114,214}$ except for the RISC (V), which was internally validated in the original dataset (TR-DGU) and externally validated in an independent cohort (TR-THEL).

Logistic regression analysis was used for customization of the prediction models to make them fit the underlying study population. ${ }^{114,133-135} \mathrm{New}$ prognostic models were developed using logistic regression. Backward stepwise logistic regression was used to identify significant predictors for the Helsinki CT score (III). In the Helsinki CT score, regression coefficients were transformed and rounded to whole numbers to make the model more clinically applicable. ${ }^{215}$ Predicted probabilities are calculated by the following equation: 1/ $\left(1+\mathrm{e}^{-\operatorname{logit}}\right)$, where logit is defined as $\beta_{0}+\beta_{1} \chi_{1}$ $+\beta_{2} x_{2}+\beta_{m} x_{m}$. 


\section{$5 \quad$ Results}

\subsection{Study Characteristics and Patient Outcome}

The study populations were 342 (I), 890 (II), 896 (III), 1,625 (IV), and 9,915 (V) (Table 13). Median patient age ranged from 46 years (V) to 58 years (II).

Table 13: Study baseline characteristics

\begin{tabular}{|llllll|}
\hline Characteristic & Study I & Study II & Study III & Study IV & Study V \\
\hline No. of patients & 341 & 890 & 869 & 1,625 & $809+9,106$ \\
Age, years & $57(43-65)$ & $58(44-68)$ & $57(43-68)$ & $55(38-66)$ & $46(29-64)+47(30-61)$ \\
Six-month outcome & & & & & \\
$\quad$ Mortality (\%) & 32 & 23 & 25 & 33 & $26 \dagger$ \\
Unfavorable $\left.^{*} \%\right)$ & 57 & 47 & 48 & NA & NA \\
\hline
\end{tabular}

Age showed as median (IQR), ${ }^{\star}$ Defined as Glasgow Outcome Scale $1-3, \dagger 30$ day mortality or death before discharge

14-day mortality or hospital mortality was $11 \%$ (II), $16 \%$ (I), and $21 \%$ (IV). 30-day mortality was reported in two studies: $15 \%$ (II) and $26 \%(\mathrm{~V})$. Six-month mortality ranged between $23 \%$ (II) and 33\% (IV). The rate of six-month unfavorable outcome was between $47 \%$ (II) and 57\% (I) (Figure 3). The use of short-term mortality endpoints (14-day, 30-day) notably underestimated mortality rates (mean 14-day mortality 16\% [I, II, IV], mean 30 -day mortality $21 \%$ [II, V], mean sixmonth mortality 27\% [II-IV]). Furthermore, mortality continued to increase following the six-month follow up (Figure 4).

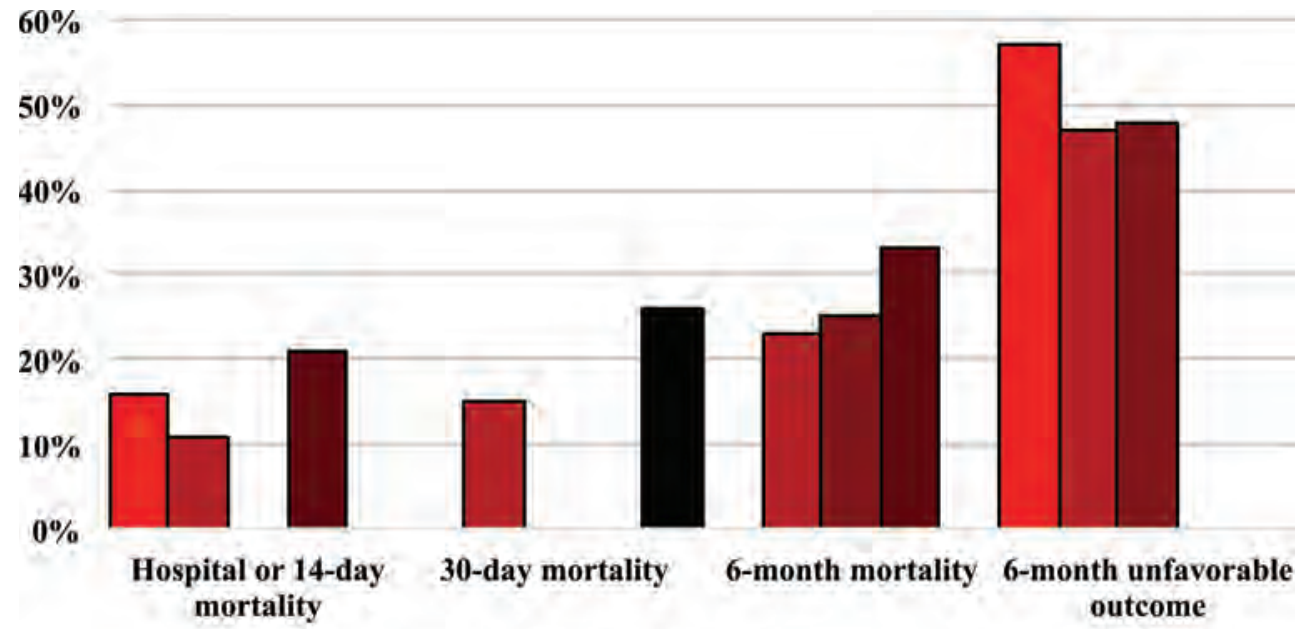

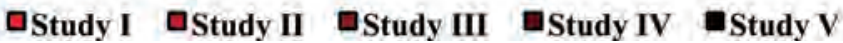

Figure 3: Incidence of outcome in studies I-V. Mean 14-day mortality was 16\%, mean 30-day mortality $21 \%$, and mean six-month mortality $27 \%$ 


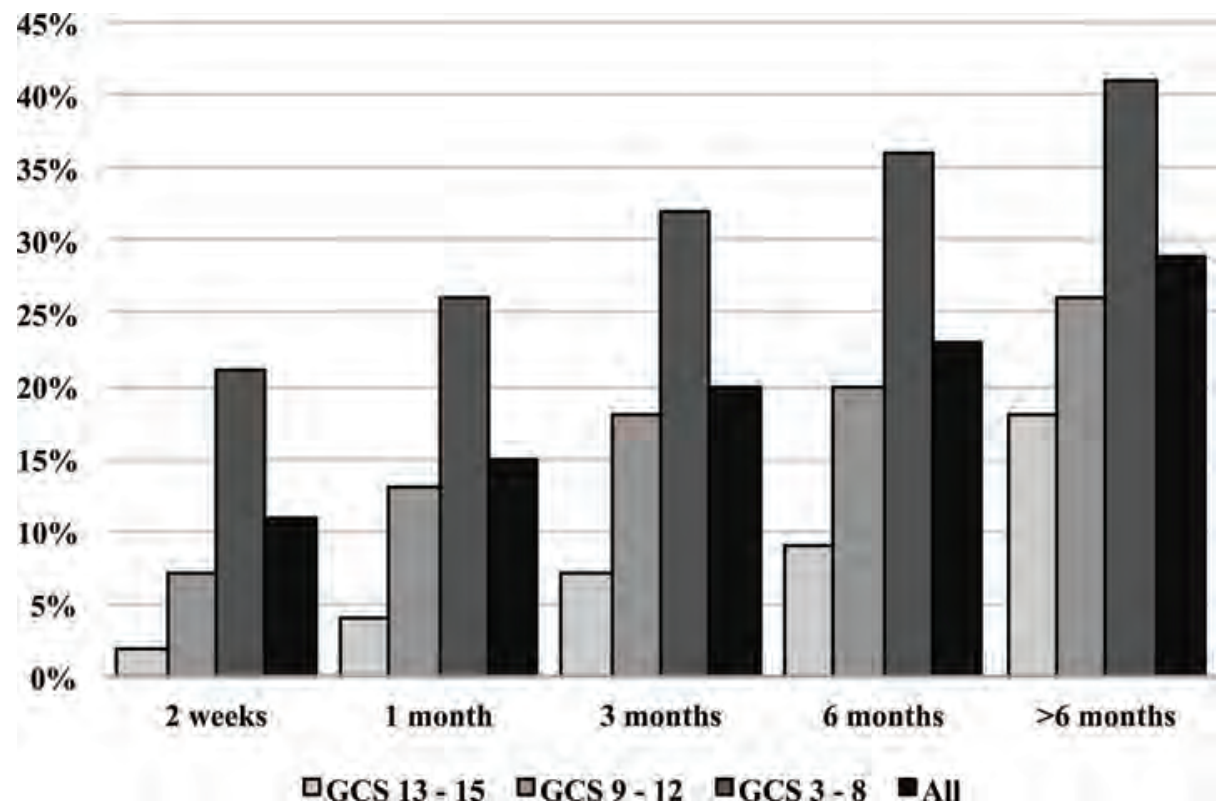

Figure 4: Cumulative mortality of 890 patients from Study II by TBI severity according to admission Glasgow Coma Scale (GCS). Mortality steadily increased during the whole six-month follow-up time and continued to do so even after six-months from injury for all TBI severity groups 


\subsection{Early Predictors of Outcome}

\subsubsection{Laboratory Variables and Extra-Cranial Injury}

The role of coagulation markers and extra-cranial injury severity markers were investigated by multivariate logistic regression analysis, AUC comparison, and NRI testing.

In logistic regression analysis, INR independently predicted six-month mortality (OR 2.23, 95\% CI 1.20-4.17, $\mathrm{p}=0.012$ ), but not six-month unfavorable outcome $(p=0.116$; Table 14). The addition of INR to IMPACT significantly increased AUC from 0.85 to 0.87 (AUC $+0.02, p=0.034$ ) for sixmonth mortality prediction, but not for sixmonth unfavorable outcome (AUC +0.00, $\mathrm{p}=0.721$ ). Similarly, NRI testing found the addition of INR to significantly improve six-month mortality prediction (NRI 0.28 , 95\% CI 0.08-0.48, p=0006), but again, not unfavorable outcome prediction (NRI -0.05, 95\% CI -0.25-[-0.16], $\mathrm{p}=0.658$ ).

Platelet count was insignificant in logistic regression analysis for both sixmonth mortality $(\mathrm{OR}=1.00, \mathrm{p}=0.578)$ and unfavorable outcome prediction (OR 1.00, $\mathrm{p}=0.169)$, with no increases in AUC ( $\mathrm{p}>0.05)$.

ISS was used as a marker of extra-cranial injury severity and dichotomized to $>15$ vs. $\leq 15$ and to $>25$ vs. $\leq 25$. Logistic regression analysis revealed ISS to be statistically insignificant after adjusting for IMPACT covariates $(p>0.05)$, with no gain in AUC $(\mathrm{AUC}+0.00, \mathrm{p}>0.05)$

Table 14: Gained prognostic value of markers of coagulation and markers of extra-cranial injury to the IMPACT model

\begin{tabular}{|c|c|c|c|c|c|}
\hline Prognostic model & AUC (95\% CI) & Gain in AUC & P-Value* & OR (95\% CI) & P-Value $\dagger$ \\
\hline & \multicolumn{5}{|c|}{ Six-month mortality } \\
\hline IMPACT-lab & $0.85(0.81-0.89)$ & Reference & Reference & & \\
\hline+ INR & $0.87(0.83-0.91)$ & +0.02 & 0.034 & $2.23(1.20-4.17)$ & 0.012 \\
\hline + Platelet count & $0.85(0.81-0.89)$ & 0.00 & 0.944 & $1.00(1.00-1.01)$ & 0.578 \\
\hline+ ISS $>15$ & $0.85(0.81-0.89)$ & 0.00 & 0.777 & $1.26(0.33-4.76)$ & 0.735 \\
\hline \multirow[t]{2}{*}{+ ISS $>25$} & $0.85(0.81-0.90)$ & 0.00 & 0.334 & $1.13(0.63-2.02)$ & 0.683 \\
\hline & \multicolumn{5}{|c|}{ Six-month unfavorable outcome } \\
\hline IMPACT-lab & $0.81(0.76-0.86)$ & Reference & Reference & & \\
\hline+ INR & $0.81(0.77-0.86)$ & 0.00 & 0.721 & $0.52(0.23-1.18)$ & 0.116 \\
\hline + Platelet count & $0.81(0.76-0.86)$ & 0.00 & 0.764 & $1.00(1.00-1.01)$ & 0.169 \\
\hline+ ISS $>15$ & $0.81(0.76-0.86)$ & 0.00 & 0.819 & $0.96(0.38-2.47)$ & 0.937 \\
\hline+ ISS $>25$ & $0.81(0.76-0.86)$ & 0.00 & 0.841 & $1.03(0.59-1.77)$ & 0.929 \\
\hline
\end{tabular}

The addition of INR significantly improved the AUC of the IMPACT model with +0.02 units for mortality prediction. NRI testing confirmed the relationship between INR and mortality. In contrast, INR was not significant for neurological outcome prediction by either method, showing that one cannot expect the same variables to predict mortality and neurological outcome. Platelet count and ISS were not significant by either test for either outcome measure. Abbreviations: IMPACT, International Mission for Prognosis and Analysis in Clinical Trials for TBI; AUC, Area Under the Receiver Characteristic Curve; INR, International Normalized Ratio; ISS, Injury Severity Score

${ }^{*}$ Significance tested for gain in AUC compared to the reference AUC

$\dagger$ Significance for the independent effect of the variable adjusted for the IMPACT lab

¥IMPACT lab includes: age, motor score, pupillary reactivity, hypoxia, hypotension, Marshall CT class, presence of epidural hematoma, presence of traumatic subarachnoid hemorrhage, glucose concentration and hemoglobin concentration. The IMPACT lab model was first level customized 
When investigating the strength of individual laboratory predictors on outcome hemoglobin (Nagelkerke $\mathrm{R}^{2} \quad$ 0.072-0.083) displayed the highest explanatory variation, followed by glucose (Nagelkerke $\mathrm{R}^{2} 0.017$ 0.037), and INR (Nagelkerke $R^{2} 0.016-0.019$ ) (Table 15).

Table 15: The individual apparent univariate explanatory variation for individual laboratory values

\begin{tabular}{|lll|}
\hline Laboratory variable & \multicolumn{2}{c|}{ Nagelkerke $\mathbf{R}^{2}$} \\
\hline Hemoglobin & 0.072 & Unfavorable \\
\cline { 2 - 3 } Glucose & 0.037 & 0.084 \\
INR & 0.019 & 0.017 \\
Platelet count & 0.011 & 0.016 \\
Base excess & 0.011 & 0.016 \\
Bicarbonate & 0.005 & 0.001 \\
Sodium & 0.000 & 0.000 \\
\hline
\end{tabular}

Table showing the explanatory variation of individual admission laboratory values for six-month mortality and unfavorable outcome from patients in study II $(\mathrm{n}=890)$. Hemoglobin had the highest explanatory variation, explaining $7-8 \%$ of the patients final outcome, while sodium had a very low explanatory variation, explaining $0-1 \%$ of the final outcome

\subsubsection{Computerized Tomography Abnormalities}

Admission CT images were classified by an a priori defined set of characteristics. In univariate analysis, the presence of any of SDH $(p<0.001), \operatorname{ICH}(p=0.016), t S A H$ in basal cisterns $(p<0.001)$, IVH $(p<0.001)$, mass lesion volume $\geq 25 \mathrm{~cm}^{3} \quad(\mathrm{p}<0.001)$, compressed or absent suprasellar compressed ( $\mathrm{p}<0.001 ; \mathrm{p}<0.001)$, compressed or absent ambiens cisterns compressed $\quad(p<0.001$; $\mathrm{p}<0.001)$, midline shift $5-10 \mathrm{~mm}(\mathrm{p}<0.001)$, or $>10 \mathrm{~mm}(\mathrm{p}<0.001)$, unilateral $(\mathrm{p}<0.001)$, or bilateral $(\mathrm{p}<0.001)$ cortical sulci effacement or an abnormal fourth ventricle $(\mathrm{p}<0.001)$ was significantly associated with an increased likelihood of unfavorable outcome (Table 16). The presence of EDH was, on the other hand, associated with an increased likelihood of favorable outcome (OR 3.85, 95\% CI 2.276.67, $\mathrm{p}<0.001)$.

After adjusting for age, GCS motor score, and pupillary light reactivity only mass lesion volume $\geq 25 \mathrm{~cm}^{3}(\mathrm{p}=0.020), \mathrm{SDH}$ $(\mathrm{p}=0.001), \mathrm{ICH}(\mathrm{p}<0.001), \mathrm{tSAH}$ in basal cisterns $(p=0.003), \operatorname{IVH}(\mathrm{p}=0.001)$, abnormal fourth ventricle $(p=0.012)$, absent suprasellar cisterns $(\mathrm{p}<0.001)$, absent ambiens cisterns $(\mathrm{p}=0.001)$, and bilateral cortical sulci effacement $(p=0.036)$ remained significant predictors of unfavorable outcome.

\subsection{Comparison of Different Types of Prognostic Models}

Three TBI models (IMPACT core, extended, and laboratory), three intensive care scoring systems (APACHE II, SAPS II, and SOFA) and one trauma score (RISC) were investigated. The ability to predict six-month outcome was assessed for all models, with the exception of the trauma score. A comparison of the models' discrimination is summarized in Table 17 (note that the AUC for the outcome for the RISC is tested for 30-day hospital mortality).

Most models exhibited poor calibration before customization (Table 18). Accordingly, customization was attempted to improve model calibration. For IMPACT, three types of customization are possible, first level customization (using the IMPACT logit risk), and two types of second level customization. The first of the two types (type 1) uses the IMPACT score chart for customization (e.g. age 50 gives 3 points, see table 3 for IMPACT score chart), and the second type (type 2) uses the variable itself (e.g. age 50 years). The effect of customization on the IMPACT models is illustrated in Table 19. Type 2 second level customization resulted in slightly better performance, in terms of discrimination, calibration, and explanatory variation, than both first level customization and type 1 second level customization. 
Table 16: Multivariate analysis showing relationship between individual admission CT characteristics and six-month unfavorable outcome

\begin{tabular}{|c|c|c|c|c|}
\hline & \multicolumn{2}{|l|}{ Univariate analysis } & \multicolumn{2}{|c|}{ Multivariate analysis ${ }^{\star}$} \\
\hline & OR $(95 \% C I)$ & P-Value & OR $(95 \% C I)$ & $P$-Value \\
\hline Mass lesion volume $>25 \mathrm{~cm}^{3}$ & $2.90(2.19-3.85)$ & $<0.001$ & $1.49(1.07-2.10)$ & 0.020 \\
\hline Subdural hematoma & $3.46(2.51-4.77)$ & $<0.001$ & $1.71(1.18-2.49)$ & 0.001 \\
\hline Epidural hematoma & $0.26(0.15-0.44)$ & $<0.001$ & $0.59(0.32-1.09)$ & 0.091 \\
\hline Intracerebral hemorrhage & $1.39(1.06-1.82)$ & 0.016 & $2.15(1.53-3.01)$ & $<0.001$ \\
\hline \multicolumn{5}{|l|}{ Traumatic SAH } \\
\hline No & 1 & & 1 & \\
\hline Limited to cortical sulci & $1.05(0.78-1.43)$ & 0.733 & $1.19(0.83-1.71)$ & 0.345 \\
\hline Also in basal cisterns & $2.13(1.48-3.06)$ & $<0.001$ & $1.94(1.24-3.01)$ & 0.003 \\
\hline Intraventricular hemorrhage & $2.83(1.84-4.34)$ & $<0.001$ & $2.41(1.45-3.98)$ & 0.001 \\
\hline Abnormal fourth ventricle & $12.71(2.97-54.40)$ & $<0.001$ & $8.23(1.60-42.87)$ & 0.012 \\
\hline \multicolumn{5}{|l|}{ Suprasellar cisterns } \\
\hline Normal & 1 & & 1 & \\
\hline Compressed & $2.06(1.49-2.84)$ & $<0.001$ & $1.28(0.87-1.87)$ & 0.214 \\
\hline Absent & $6.97(4.44-10.95)$ & $<0.001$ & $2.91(1.62-5.25)$ & $<0.001$ \\
\hline \multicolumn{5}{|l|}{ Ambiens cisterns } \\
\hline Normal & 1 & & 1 & \\
\hline Compressed & $2.13(1.51-3.01)$ & $<0.001$ & $1.31(0.86-2.01)$ & 0.206 \\
\hline Absent & $5.62(3.72-8.48)$ & $<0.001$ & $2.47(1.43-4.27)$ & 0.001 \\
\hline \multicolumn{5}{|l|}{ Midline shift } \\
\hline$<5 \mathrm{~mm}$ & 1 & & 1 & \\
\hline $5-10 \mathrm{~mm}$ & $1.51(1.08-2.11)$ & $<0.001$ & $1.16(0.79-1.71)$ & 0.454 \\
\hline$>10 \mathrm{~mm}$ & $3.52(2.49-4.96)$ & $<0.001$ & $1.07(0.69-1.67)$ & 0.768 \\
\hline \multicolumn{5}{|l|}{ Cortical sulci effacement } \\
\hline No effacement & 1 & & 1 & \\
\hline Unilateral effacement & $1.83(1.33-2.53)$ & $<0.001$ & $1.25(0.86-1.82)$ & 0.248 \\
\hline Bilateral effacement & $3.40(2.38-4.83)$ & $<0.001$ & $1.61(1.03-2.50)$ & 0.036 \\
\hline
\end{tabular}

Table showing univariate and multivariate analysis of the association between admission CT characteristics and six-month unfavorable neurological outcome. In univariate analysis, all except traumatic SAH limited to cortical sulci were significantly associates with the outcome. In an enter type multivariate logistic regression analysis, epidural hematoma cortical sulci traumatic SAH, compressed ambiens cisterns, midline shift and unilateral cortical sulci effacement were found to be insignificant predictors of outcome. Data is from Study III, with a total patient number of 869. Abbreviations: SAH, subarachnoid hemorrhage.

*Multivariate analysis adjusted for age (continuous), GCS motor score (six categories) and pupillary light reactivity (normal, one reacts, no reaction)

\subsubsection{Traumatic Brain Injury Models}

IMPACT discrimination (by AUC) increased with rising model complexity from the core (AUC 0.81 ) to the laboratory model (AUC 0.85). The addition of INR significantly increased the laboratory model's AUC from 0.85 to 0.87 (AUC +0.02, p=0.034), which was the highest AUC achieved in the study. IMPACT discriminated in general better for six-month mortality than neurological outcome (mean AUC for mortality prediction 0.82, and mean AUC for unfavorable neurological outcome prediction 0.81 ).

In close relationship with the TBI models, two CT scoring systems were also investigated: the Marshall CT classification and the Rotterdam CT score. Both CT scores were of limited value for long-outcome prediction, with AUCs ranging from 0.64 to 0.70 (Table 17). 


\subsubsection{Intensive Care Scoring Systems}

APACHE II and SAPS II showed the best discrimination of the three investigated intensive care scoring systems, with AUCs between 0.79 and 0.80 . There was, however, no statistical significant difference in AUC between APACHE II and SAPS II (AUC 0.79 [95\% CI $0.75-0.82]$ vs. 0.80 [95\% CI
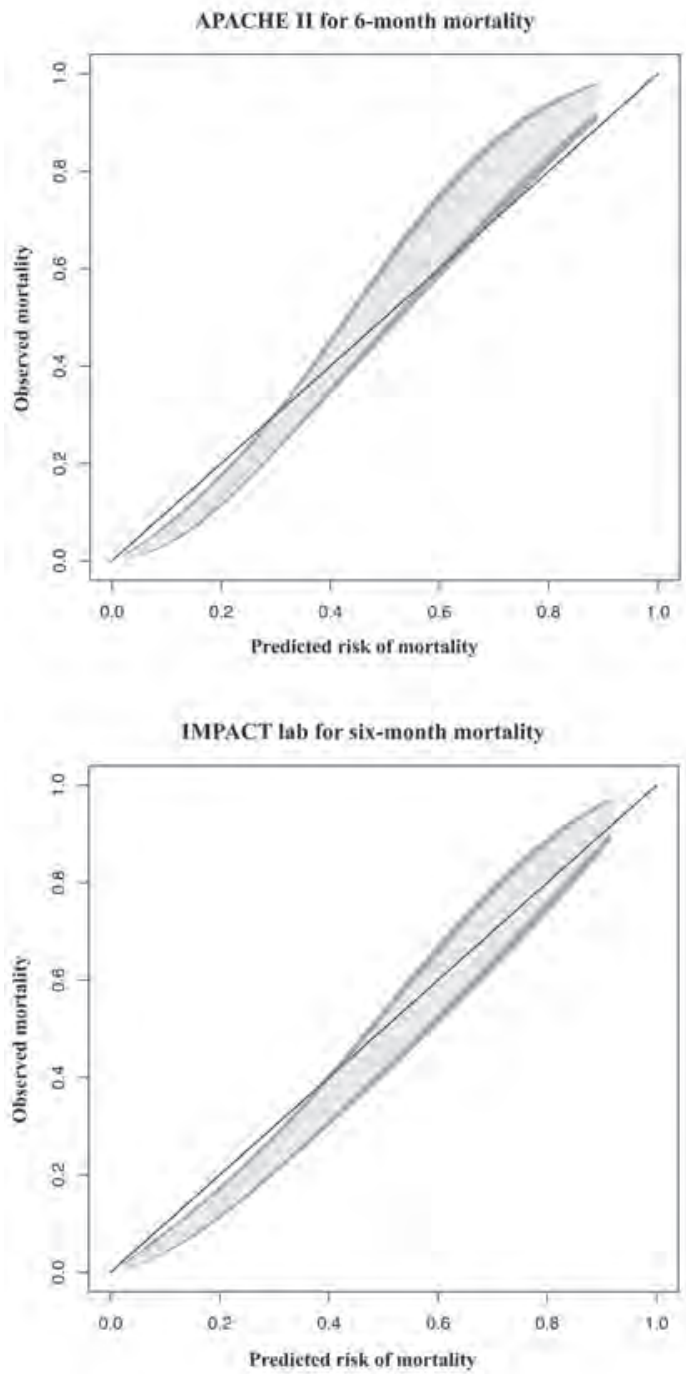

0.77-0.83], $\mathrm{p}>0.05)$ for six-month mortality prediction. In contrast, the SOFA score revealed significantly poorer discrimination compared to APACHE II (AUC 0.79 vs. 0.68 [95\% CI 0.64-0.72], $\mathrm{p}<0.001$ ) and SAPS II (AUC 0.80 vs. 0.68 [95\% CI 0.64-0.72], $\mathrm{p}<0.001)$. Moreover, APACHE II showed modest discrimination for six-month unfavorable neurological outcome prediction, with an AUC of 0.78 (95\% CI 0.74-0.82).
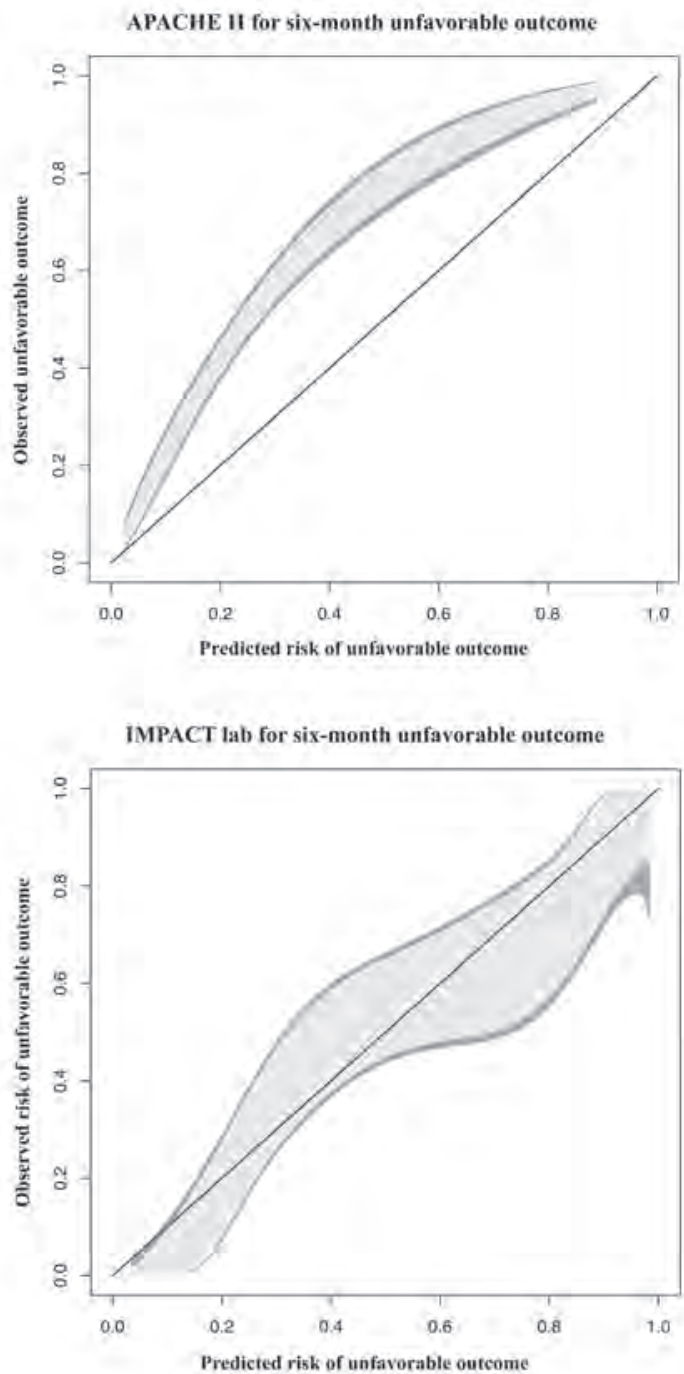

Figure 5: Calibration of the APACHE II and the IMPACT laboratory shown by the GiViTI calibration belt. Left: calibration for six-month mortality; Right: calibration for six-month unfavourable outcome. Comparable calibration between the IMPACT and APACHE II models are noted for six-month mortality prediction while calibration of the IMPACT is notably better for unfavourable outcome prediction than APACHE II (top right). Both IMPACT and APACHE II are uncustomized 
Comparing discrimination between IMPACT and APACHE II, for six-month mortality prediction, revealed no statistically significant differences in AUC between the models (AUC APACHE II 0.81 vs. IMPACT 0.81-0.82, $\mathrm{p}>0.05$ between all models). In contrast, for six-month unfavorable outcome prediction IMAPCT significantly outperformed APACHE II (AUC APACHE II 0.78 vs. IMPACT AUC 0.82-0.82, $\mathrm{p}<0.05$, between all models).

\subsubsection{Trauma Scoring Systems}

RISC showed good discrimination for predicting 30-day mortality in a mixed trauma population (AUC TR-THEL 0.89, TR-DGU 0.92). Likewise, in a mixed cohort of patients with moderate to severe TBI RISC exhibited good discrimination (AUC TR-THEL 0.84, TR-DGU 0.89). Discrimination of RISC was higher for TBI patients with polytrauma than for patients with isolated TBI in both datasets (AUC TR-THEL 0.89 vs. 0.76; AUC TR-DGU 0.90 vs. 0.87$)$.

Subgroup analysis revealed patients with isolated moderate to severe TBI to have the lowest AUC (0.76 in TR-THEL, 0.87 in TR-DGU). Moreover, RISC overpredicted risk of death for all TBI patients, particularly among high-risk TBI patients. Accordingly, RISC calibration was suboptimal for patients with isolated TBI in both datasets $(\mathrm{H}-\mathrm{L}$ $\chi^{2} 4366.7$ for TR-DGU and $\chi^{2} 111.6$ for TR-THEL), but still, worse for polytrauma TBI patients (H-L $\chi^{2} 449.0$ for TR-DGU and $\chi^{2} 49.1$ for TR-THEL).
Table 17: Comparison of discriminative power between prognostic models

\begin{tabular}{|c|c|c|}
\hline \multirow[t]{2}{*}{ Prognostic model } & \multicolumn{2}{|c|}{ Area Under the Curve } \\
\hline & Mortality & Unfavorable \\
\hline \multicolumn{3}{|l|}{ TBI Models } \\
\hline IMPACT core* & 0.81 & 0.81 \\
\hline IMPACT core $\ddagger$ & 0.83 & 0.81 \\
\hline IMPACT extended ${ }^{*}$ & 0.81 & 0.82 \\
\hline IMPACT lab* & 0.82 & 0.82 \\
\hline IMPACT lab $\dagger$ & 0.85 & 0.81 \\
\hline IMPACT lab + INRS & 0.87 & 0.81 \\
\hline \multicolumn{3}{|l|}{ CT Models } \\
\hline Marshall CT classification $\neq$ & 0.64 & 0.63 \\
\hline Rotterdam CT score $末$ & 0.70 & 0.68 \\
\hline Helsinki CT score & 0.75 & 0.75 \\
\hline \multicolumn{3}{|l|}{ TBI + CT Models } \\
\hline IMPACT core + Marshall CTS & 0.83 & 0.81 \\
\hline IMPACT core + Rotterdam CT\$ & 0.83 & 0.81 \\
\hline IMPACT core + Helsinki CT§ & 0.84 & 0.83 \\
\hline \multicolumn{3}{|l|}{ Intensive Care Scoring Systems } \\
\hline APACHE II $^{*}$ & 0.81 & 0.78 \\
\hline APACHE II $\dagger$ & 0.79 & NA \\
\hline SAPS II $\dagger$ & 0.80 & NA \\
\hline SOFA $\dagger$ & 0.68 & NA \\
\hline Adjusted SOFA§ & 0.79 & NA \\
\hline Reference§ & 0.77 & NA \\
\hline \multicolumn{3}{|l|}{ TBI + Intensive Care Models } \\
\hline IMPACTcore-APACHE II\$ & 0.84 & 0.83 \\
\hline IMPACText-APACHE IIऽ & 0.84 & 0.83 \\
\hline IMPACTlab-APACHE IIS & 0.85 & 0.83 \\
\hline \multicolumn{3}{|c|}{ Trauma Scoring Systems (Hospital Mortality) ๆ } \\
\hline \multicolumn{3}{|c|}{$R I S C^{*}(T R-D G U ®)$} \\
\hline Severe TBI & 0.89 & $N A$ \\
\hline Isolated severe TBI & 0.87 & $N A$ \\
\hline Polytrauma severe TBI & 0.90 & $N A$ \\
\hline \multicolumn{3}{|l|}{ RISC* (TR-THEL) } \\
\hline Severe TBI & 0.84 & $N A$ \\
\hline Isolated severe TBI & 0.76 & $N A$ \\
\hline Polytrauma severe TBI & 0.89 & $N A$ \\
\hline
\end{tabular}

The TBI, TBI + CT and TBI + Intensive Care Scoring Systems had the highest discriminative power of the models, followed by the Intensive Care and Trauma Scoring Systems in isolation. Mortality is defined as death within six months from injury unless other stated. Unfavorable outcome defined as Glasgow Outcome Scale 1-3 six months from injury (dead, vegetative state, severe disability). ${ }^{*}$ Not customized original models, †First level customized, $¥$ Second level customized, $₫ \mathrm{New}$ logistic regression based models, Predicts risk of 30-day mortality or death before discharge - not comparable to the other models predicting six-month outcome 
Table 18: Original model calibration for mortality prediction prior to customization

\begin{tabular}{|lll|}
\hline Prognostic model & $\mathbf{N}$ & H-L p-value \\
\hline TBI models (II) & & \\
IMPACT core & 890 & $<0.001$ \\
IMPACT extended & 890 & $<0.001$ \\
IMPACT lab & 890 & 0.054 \\
Intensive Care Scoring Systems (IV) & & \\
APACHE II & 1,625 & $<0.001$ \\
SAPS II & 1,625 & 0.002 \\
SOFA & 1,625 & $<0.001$ \\
Trauma models (V) (Hospital mortality) & & \\
RISC (TR-DGU) & 9,106 & $<0.001$ \\
RISC (TR-THEL) & 809 & $<0.001$ \\
\hline
\end{tabular}

Table showing the calibration of the original uncustomized models. Calibration was poor for every model prior to customization, except for the IMPACT lab, as indicated by the $\mathrm{H}-\mathrm{L}$ p-value $<0.05$ (meaning that there is a significant difference between predicted and observed outcome). As the $\mathrm{H}-\mathrm{L}$ test is largely sample size dependent patient number is shown (N). Abbreviations: H-L; Hosmer-Lemeshow $\hat{\mathrm{C}}$-statistic 
Table 19: Effect of difference strategies of customization on performance of the IMPACT models

\begin{tabular}{|c|c|c|c|}
\hline Customization & First level & Type 1 second level & Type 2 second level \\
\hline \multicolumn{4}{|l|}{ Area under the curve } \\
\hline \multicolumn{4}{|l|}{ Six-month mortality } \\
\hline IMPACT core & 0.80 & 0.80 & 0.82 \\
\hline IMPACT extended & 0.80 & 0.80 & 0.83 \\
\hline IMPACT lab & 0.81 & 0.80 & 0.83 \\
\hline \multicolumn{4}{|c|}{ Six-month unfavorable outcome } \\
\hline IMPACT core & 0.78 & 0.78 & 0.80 \\
\hline IMPACT extended & 0.79 & 0.79 & 0.81 \\
\hline IMPACT lab & 0.79 & 0.79 & 0.82 \\
\hline \multicolumn{4}{|l|}{ Calibration slope } \\
\hline \multicolumn{4}{|l|}{ Six-month mortality } \\
\hline IMPACT core & 1.005 & 1.001 & 0.960 \\
\hline IMPACT extended & 1.000 & 1.000 & 0.921 \\
\hline IMPACT lab & 1.000 & 1.006 & 0.913 \\
\hline \multicolumn{4}{|c|}{ Six-month unfavorable outcome } \\
\hline IMPACT core & 1.001 & 1.006 & 0.956 \\
\hline IMPACT extended & 1.002 & 1.000 & 0.914 \\
\hline IMPACT lab & 1.001 & 1.001 & 0.905 \\
\hline \multicolumn{4}{|l|}{ Nagelkerke $\mathbf{R}^{2}$} \\
\hline \multicolumn{4}{|l|}{ Six-month mortality } \\
\hline IMPACT core & 0.288 & 0.300 & 0.347 \\
\hline IMPACT extended & 0.295 & 0.306 & 0.356 \\
\hline IMPACT lab & 0.311 & 0.328 & 0.373 \\
\hline \multicolumn{4}{|c|}{ Six-month unfavorable outcome } \\
\hline IMPACT core & 0.269 & 0.299 & 0.353 \\
\hline IMPACT extended & 0.312 & 0.320 & 0.367 \\
\hline IMPACT lab & 0.313 & 0.327 & 0.378 \\
\hline
\end{tabular}

Patients from study II $(\mathrm{n}=890)$ were used for this demonstration of the effect of customization. All models were internally validated by a 500 resample bootstrap technique. The table shows that discrimination (AUC), calibration (calibration slope) and explanatory variation (Nagelkerke R2) increases with second level customization, as compared to first level customization. Furthermore, due to the score chart nature of the IMPACT, second level customization may be performed using (type 1) the score chart or (type 2) the individual predictor values. As shown, type 2 results in better performance. Abbreviations: IMPACT, International Mission for Prognosis and Analysis of Clinical Trials in TBI.

*First level customization is performed by fitting a new logistic regression with the observed outcome as the dependent variable and logit-transformed original prediction as the independent variable

$\dagger$ Type 1 second level customization is performed by fitting a new logistic regression model with the observed outcome as the dependent variable and the individual IMPACT predictors, using the score chart, as the independent variables.

¥Type 2 second level customization is performed by fitting a new logistic regression model with the observed outcome as the dependent variable and the individual IMPACT predictors as the independent variables. The IMPACT predictors are age, GCS motor score, pupillary light reactivity (IMPACT core) + hypoxia, hypotension, Marshall CT class, presence of epidural hematoma, and presence of traumatic subarachnoid hemorrhage (IMPACT extended) + glucose and hemoglobin concentrations (IMPACT lab).

§Unfavorable outcome defines as Glasgow Outcome Scale 1 (death), 2 (vegetative state) and 3 (severe disability)

\subsection{Novel Prognostic Models}

Three new sets of prediction models were created:

- The IMPACT-APACHE II models

- The Helsinki CT score

- The Modified Intensive Care Scoring Systems

\subsubsection{IMPACT-APACHE II}

To create the IMPACT-APACHE II models the scores of the individual IMPACT and APACHE II were added together. Similar to IMPACT the IMPACT-APACHE II models increase in complexity from a core model (age, GCS motor score, pupillary reactivity + 
APACHE II) to an extended model (addition of hypoxia, hypotension, EDH, tSAH, Marshall CT class + APACHE II) to the most complex laboratory model (addition of glucose, hemoglobin + APACHE II). Thus, the IMPACT-APACHE II models account for admission characteristics specific to TBI patients and early intensive care abnormalities detected by the APACHE II scoring system.

The IMPACT-APACHE II models showed significantly higher AUCs compared to the individual IMPACT and APACHE II for six-month mortality prediction (AUC $+0.03-0.04, \mathrm{p}<0.05$ ) (II: Figure 3). For sixmonth unfavorable neurological outcome prediction, however, AUC testing did not reveal any significant improvement in predictive performance of IMPACTAPACHE II over the individual IMPACT models (AUC +0.01-0.02, p>0.05). However, because AUC testing is a rather insensitive measure to improvements in predictive ability, NRI testing was conducted to investigate further the effect of combining APACHE II with IMPACT on neurological outcome prediction. Subsequently, NRI testing revealed significant improvements for the IMPACTcore-APACHE II $(\mathrm{p}=0.035)$ and IMPACText-APACHE II models $(\mathrm{p}=0.009)$ but not for the IMPACTlab-APACHE II model ( $\mathrm{p}=0.093$, Figure 6 ).

IMPACT-APACHE II calibration was good for both six-month mortality and unfavorable outcome prediction $(p>0.05)$. The internal validity of the IMPACT-APACHE II models was confirmed using both splitsample and resample bootstrap techniques, which showed similar results.

The risks of six-month mortality (Pmort) and unfavorable outcome (Pneuro) using the
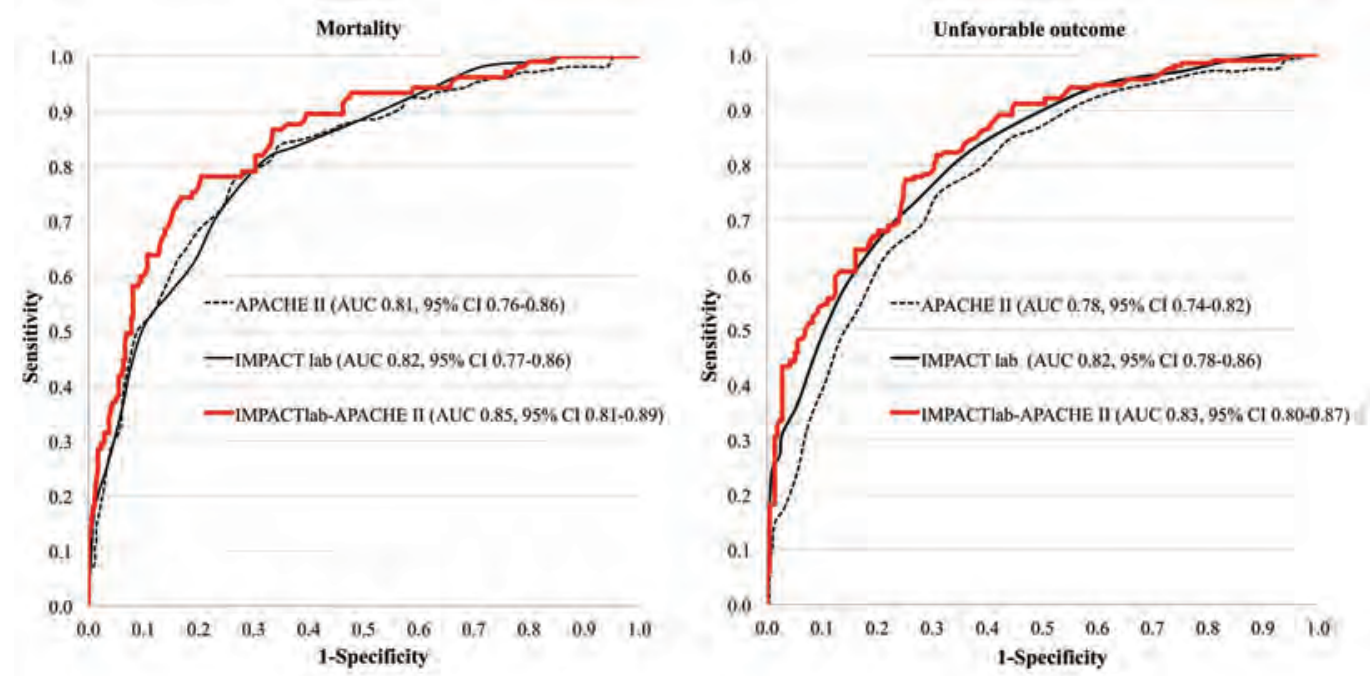

Figure 6: Area under the receiver operator characteristic curve (AUC) for the IMPACTlab-APACHE II for six-month mortality (left) and neurological outcome (right) prediction. The IMPACTlab-APACHE II was significantly superior to the individual IMPACT lab $(A U C+0.03, p=0.043)$ and APACHE II (AUC $+0.04, p=0.006)$ for six-month mortality prediction; for six-month unfavourable outcome prediction IMPACTlab-APACHE II was significantly superior to APACHE II (AUC +0.05, $p=0.002)$, but not to IMPACTlab (AUC +0.01, $p=0.448)$. Abbreviations: IMPACT, International Mission for Prognosis and Analysis of Clinical Trials; APACHE II, Acute Physiology and Chronic Health Evaluation II; CI, Confidence Interval 
IMPACT-APACHE II models are calculated as follows, using the split-sample technique:

- Pmort $_{\text {core }}=1 /\left(1+\mathrm{e}^{-(-6.004+\text { IMPACT core sumscore * }}\right.$ $0.234+$ APACHE II score ${ }^{*} 0.160$ )

- Pmort $_{\text {extended }}=1 /\left(1+\mathrm{e}^{-(-6.265+\text { IMPACT extended sum- }}\right.$ score ${ }^{\star} 0.193+$ APACHE II score $\left.{ }^{*} 0.158\right)$

- Pmort $_{\text {laboratory }}=1 /\left(1+\mathrm{e}^{-(-6.516}+\right.$ IMPACT extended sumscore ${ }^{*} 0.187+$ APACHE II score ${ }^{*} 0.149$ )

- Pneuro $_{\text {core }}=1 /\left(1+\mathrm{e}^{-(-3.363+\text { IMPACT core sumscore * }}\right.$ $0.198+$ APACHE II score ${ }^{\star} 0.113$ )

- Pneuro $_{\text {extended }}=1 /\left(1+\mathrm{e}^{-(-3.551+\text { IMPACT core sum- }}\right.$ score ${ }^{*} 0.175+$ APACHE II score $\left.{ }^{*} 0.105\right)$

- Pneuro $_{\text {laboratory }}=1 /\left(1+\mathrm{e}^{-(-3.732+\text { IMPACT core sum- }}\right.$ score ${ }^{*} 0.162+$ APACHE II score ${ }^{*} 0.099$ )

\subsubsection{Helsinki CT Score}

In univariate analysis 11 of the predefined CT characteristics were significantly associated with unfavorable six-month outcome. These variables were inserted into a backward stepwise logistic regression model to identify the strongest predictors. The stepwise model identified six statistically significant predictors: mass lesion volume $\geq 25 \mathrm{~cm}^{3}$, presence of $\mathrm{SDH}$, presence of $\mathrm{EDH}$, presence of $\mathrm{ICH}$, presence of IVH, and status of suprasellar cisterns (Figure 7). The variables' regression coefficients were rounded to even numbers and merged to create the Helsinki CT score (Table 20). Figure 8 demonstrates the concordance between predicted and observed outcome for the Helsinki CT score.

Risk of six-month mortality (Pmort) and unfavorable outcome (Pneuro) using the Helsinki CT score is calculated as follows:

- Pmort $=1 /\left(1+\mathrm{e}^{-\left(-2.666+\text { Helsinki CT score }{ }^{*} 0.287\right)}\right)$

- Pneuro $=1 /\left(1+\mathrm{e}^{-\left(-1.636+\text { Helsinki CT score }{ }^{*} 0.319\right)}\right)$
The Helsinki CT score demonstrated superior discrimination over the Rotterdam CT score and the Marshall CT classification in terms of six-month mortality prediction (Helsinki CT AUC 0.74 vs. Rotterdam CT AUC 0.70, p=0.006; Helsinki CT AUC 0.74 vs. Marshall CT AUC 0.64, p<0.001) and unfavorable outcome prediction (Helsinki CT AUC 0.75 vs. Rotterdam CT AUC 0.68, $\mathrm{p}<0.001$; Helsinki CT AUC 0.75 vs. Marshall CT AUC 0.63, p<0.001). Moreover, Helsinki CT had notably higher explanatory variation (Nagelkerke $\mathrm{R}^{2}$ 0.20-0.25) than Rotterdam CT (Nagelkerke $\mathrm{R}^{2}$ 0.15-0.16) and Marshall CT (Nagelkerke $\mathrm{R}^{2}$ 0.09, 0.09). However, compared to a clinical model based only on age, GCS motor score, and pupillary reactivity (i.e. IMPACT core), the Helsinki CT score alone exhibited lower overall performance (Nagelkerke $\mathrm{R}^{2} 0.20$-0.25 vs. 0.37; AUC 0.740.75 vs. $0.81-0.84$ ).

Adding three basic clinical variables (age, motor score, pupils) to the Helsinki CT score considerably increased its performance for six-month mortality prediction (AUC from 0.75 to 0.83 ; Nagelkerke $\mathrm{R}^{2}$ from 0.20 to 0.42 ) and for six-month unfavorable outcome prediction (AUC from 0.75 to 0.84 ; Nagelkerke $\mathrm{R}^{2}$ from 0.25 to 0.40 ). Likewise, addition of the Helsinki CT score to the clinical model (age, motor score, pupils) increased its predictive ability (AUC from 0.81-0.83 to $0.83-0.84$; Nagelkerke $\mathrm{R}^{2}$ from 0.37 to $0.40-0.41$ ), while in contrast addition of the Marshall CT or Rotterdam CT scores did not increase the predictive ability of the clinical model. 

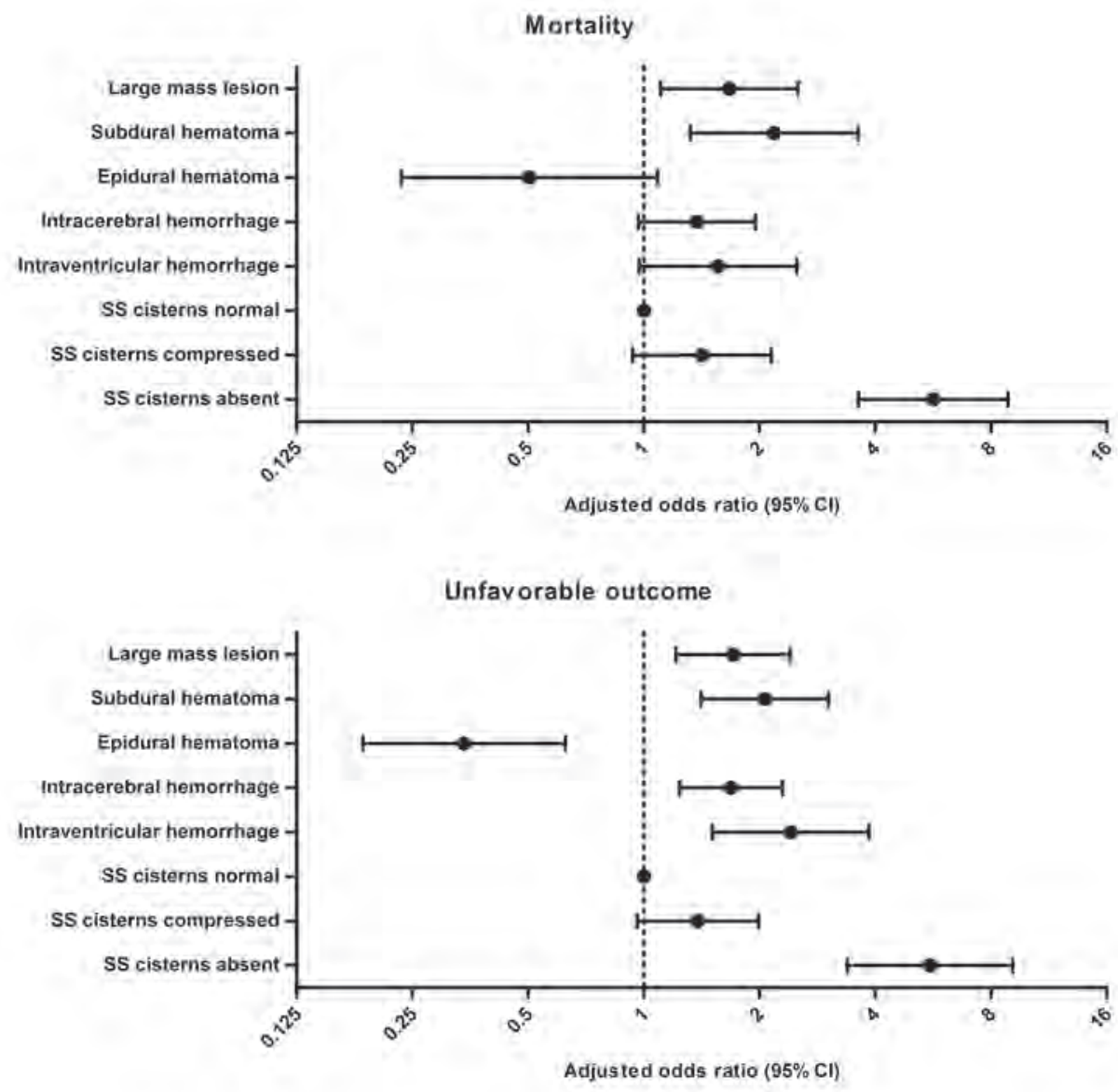

Figure 7: Multivariate logistic regression model showing the individual relationship between admission CT characteristics and six-month outcome (top: mortality; bottom: unfavourable outcome). An odds ratio over one indicates an increased likelihood of the outcome. The presence of a large mass lesion (defined as $\geq 25 \mathrm{~cm}^{3}$ ), subdural hematoma, intracerebral hemorrhage, intraventricular hemorrhage, and obliterated suprasellar cisterns significantly predicted risk of unfavourable six-month outcome. In contrast, presence of epidural hematoma was associated with an improved outcome. For mortality prediction, only large mass lesion, subdural hematoma, and obliterated suprasellar cisterns remained significant predictors. The Helsinki CT score was developed on significant predictors of unfavourable neurological outcome 

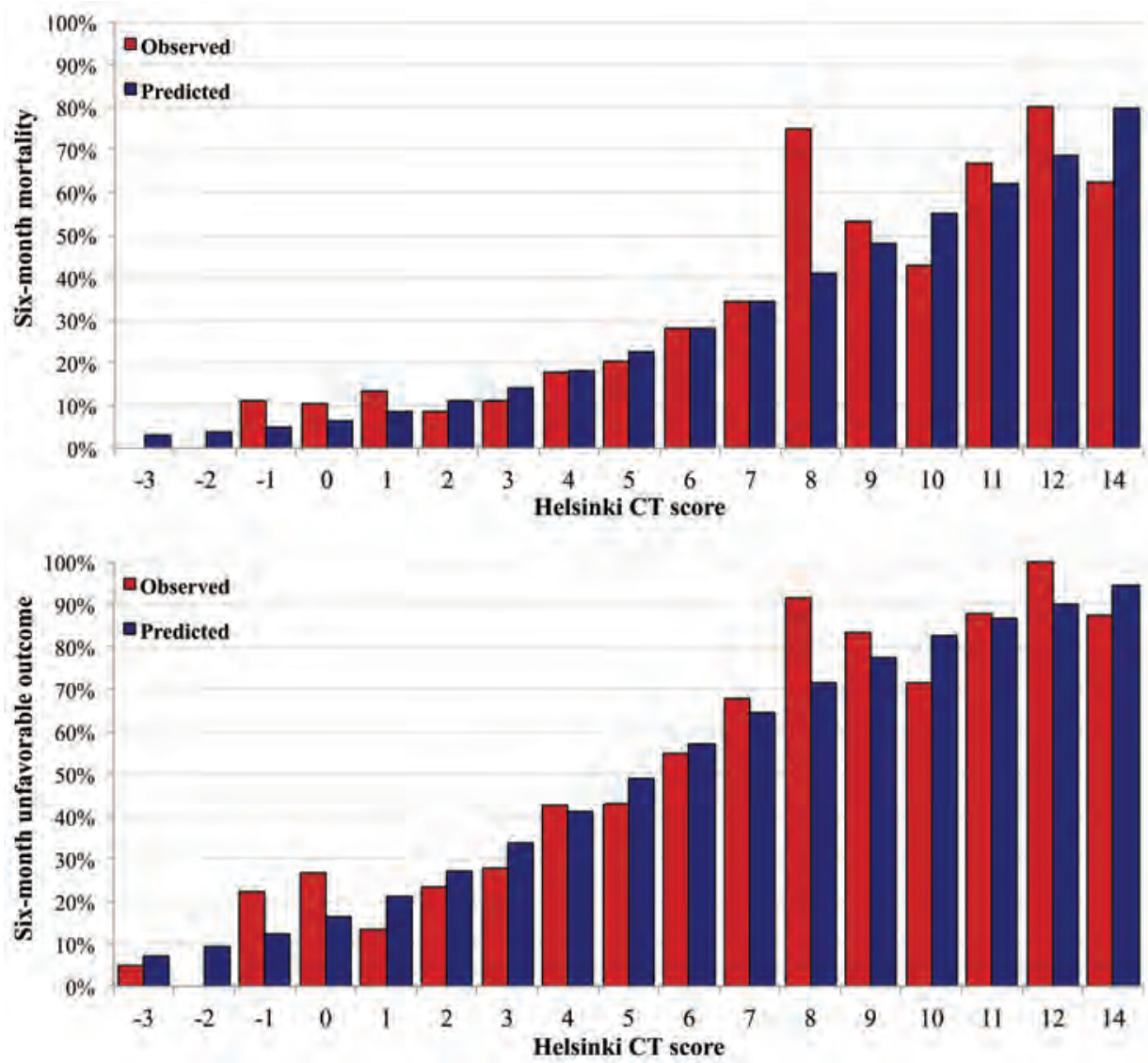

Figure 8: Concordance between predicted and observed outcome for the Helsinki CT score. Top panel: six-month mortality; lower panel: six-month unfavourable outcome. Overall concordance between predicted and observed outcome is excellent, with a slight under prediction for patients with a Helsinki CT score of 8. These patients often had large subdural hematomas, intracerebral hemorrhages and intraventricular hemorrhages. The Helsinki CT score is unable to account for multiple large mass lesions, which may explain the underprediction noted

Table 20: The Helsinki CT score chart

\begin{tabular}{|ll|}
\hline Variable & Score \\
\hline Mass lesion $\geq 25 \mathrm{~cm}^{3}$ & 2 \\
Subdural hematoma & 2 \\
Epidural hematoma & -3 \\
Intracerebral hemorrhage & 2 \\
Intraventricular hemorrhage & 3 \\
Suprasellar cisterns & \\
Normal & 0 \\
Compressed & 1 \\
Obliterated & 5 \\
Sumscore & $-3-14$ \\
\hline
\end{tabular}

Variables and their associated scores included in the Helsinki CT score. The Helsinki CT score ranges from a minimum of -3 to a maximum of 14 . The probability of 6 -month outcome is defined as $1 /\left(1+\mathrm{e}^{\mathrm{-LP}}\right)$, where $\mathrm{LP}_{\text {Mortality }}=-2.666+0.287 *$ Helsinki CT score

$\mathrm{LP}_{\text {Unfavorable }}=-1.636+0.319 *$ Helsinki CT score 


\subsubsection{Modified Intensive Care Scoring Systems}

The modified intensive care scoring systems include customized versions of APACHE II and SAPS II, an adjusted SOFA score, and the reference model. APACHE II and SAPS II were originally developed for predicting risk of in-hospital mortality in the general ICU population. These two models were specifically customized for six-month outcome prediction in patients with TBI treated in the ICU (Figure 9). The risks of sixmonth mortality (Pmort) using the APACHE II and SAPS II models are calculated as follows:

- Pmort $_{\text {APACHE II }}=1 /\left(1+\mathrm{e}^{-(-5.183}+\right.$ APACHE II score * ${ }^{0.193)}$ )

- Pmort $_{\text {SAPS II }}=1 /\left(1+\mathrm{e}^{-\left(-4.967+\text { SAPS II score }{ }^{*} 0.092\right)}\right)$

The risk of six-month unfavorable neurological outcome (Pneuro) using APACHE II is calculated as follows:

- Pneuro $_{\text {APACHE II }}=1 /\left(1+\mathrm{e}^{-(-3.335+\text { APACHE II score * }}\right.$ ${ }^{0.170}$ )

The original SOFA showed poor performance for predicting outcome in patients with moderate to severe TBI (AUC 0.68). Thus, it was modified to suit the TBI population. Accordingly, the adjusted SOFA is a modified version of the original SOFA designed specifically for patients with moderate to severe TBI. In the adjusted SOFA, GCS is included as a separate variable to give it more influence. Like GCS, age is similarly included as a separate variable, which significantly increased the predictive ability of (adjusted) SOFA to match APACHE II (AUC 0.79 vs. $0.79, \mathrm{p}=0.920$ ) and SAPS II (AUC 0.79 vs. $0.80, \mathrm{p}=0.745$ ).

The reference model is a simple prognostic model based solely on patient age and worst measured GCS during the first 24 hours in the ICU. Age was categorized into ten-year intervals and GCS was dichotomized based on the median, as this combination was found to give the highest performance. The reference model showed good discrimination (AUC 0.77, 95\% CI 0.74-0.80) and calibration (H-L p-value 0.086). It is notable that there were no significant differences in discrimination, calibration, or precision between the reference model and APACHE II (AUC -0.02, $\mathrm{p}=0.425$ ), or between the reference model and SAPS II (AUC -0.03, $\mathrm{p}=0.218$ ).

To test further the effect of age and GCS on outcome, patients from Study II and IV were pooled into a total study population of 2,430 patients with moderate and severe TBI (GCS 3-13, N=805 from II and $\mathrm{N}=1,625$ from IV). The combined six-month mortality rate was $30 \%$ (II: $24 \%$, IV: $33 \%$ ), the median age 56 years (IQR 41-67, II: 58 years [IQR 45-68], IV: 55 years [IQR 38-66]), and the median GCS 7 (IQR 4-77, II: 9 [IQR 4-11], IV: 6 [IQR 4-10]). In this large set of pooled data, age and GCS were used as continuous variables to minimize loss of information. The risk of six-month mortality was calculated using the following equation:

- Pmort $_{\text {age }+\mathrm{GCS}}=1 /\left(1+\mathrm{e}^{-(-0.801+0.037 * \text { AGE }+(-0.309)}\right.$ $\left.{ }^{*} \mathrm{GCS}\right)$

The apparent AUC of the new combined model was 0.79 (95\% CI 0.77-0.81) with good calibration (H-L p-value=0.410). The model was internally validated in Study II with an AUC of 0.81 (95\% CI 0.77-0.84) and in Study IV with an AUC of 0.78 (95\% CI 0.0.75-0.80). Calibration was good in both datasets (II: $\mathrm{H}-\mathrm{L}$ p-value $=0.088$; IV: H-L p-value $=0.142$, Figure 10). Bootstrap validation of the model revealed close to no optimism with an AUC of 0.787 (and an optimism corrected Nagelkerke $\mathrm{R}^{2}$ of 0.29 ). A comparison of the calibration between the intensive care scoring systems from study IV is shown in Figure 11. 


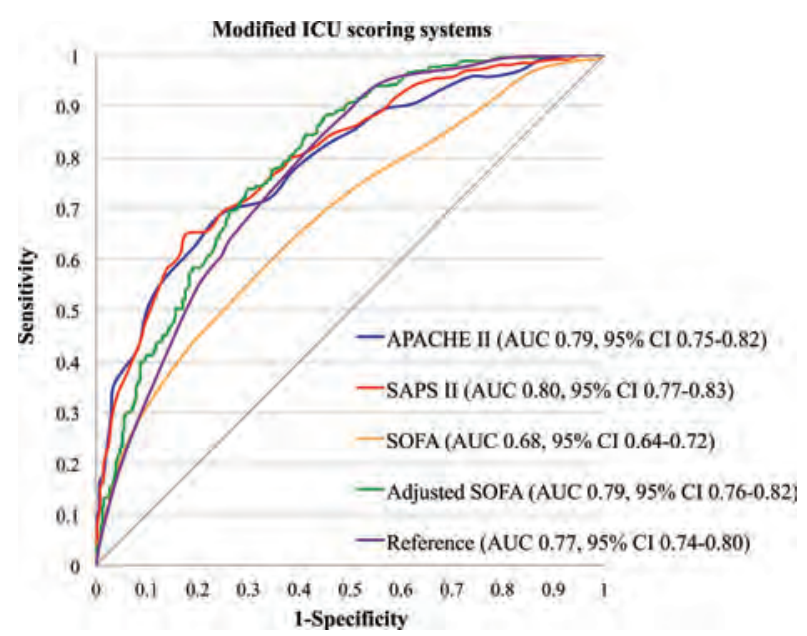

Figure 9: Comparison of area under the curve between the three ICU scoring systems (APACHE II, SAPS II, SOFA) and the new ICU models (reference model, adjusted SOFA). No significant differences $(p<0.05)$ in AUC between the ICU scoring systems and the new models were found

STUDY ॥

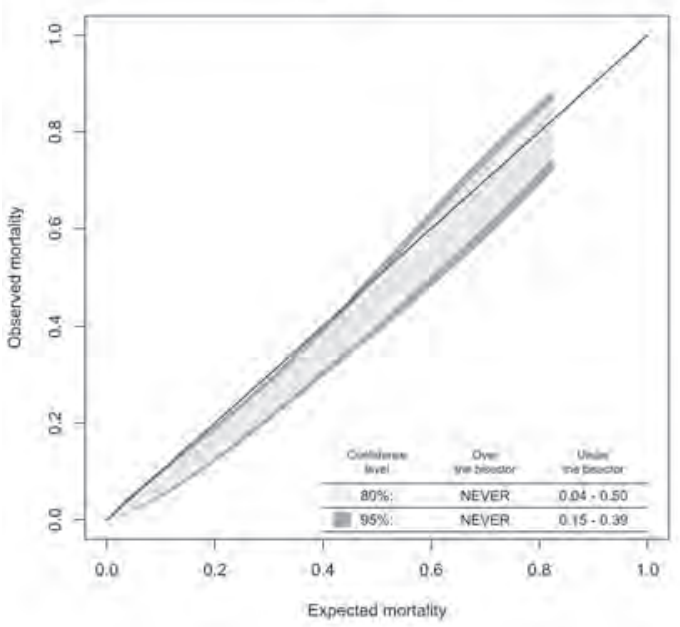

STUDY IV

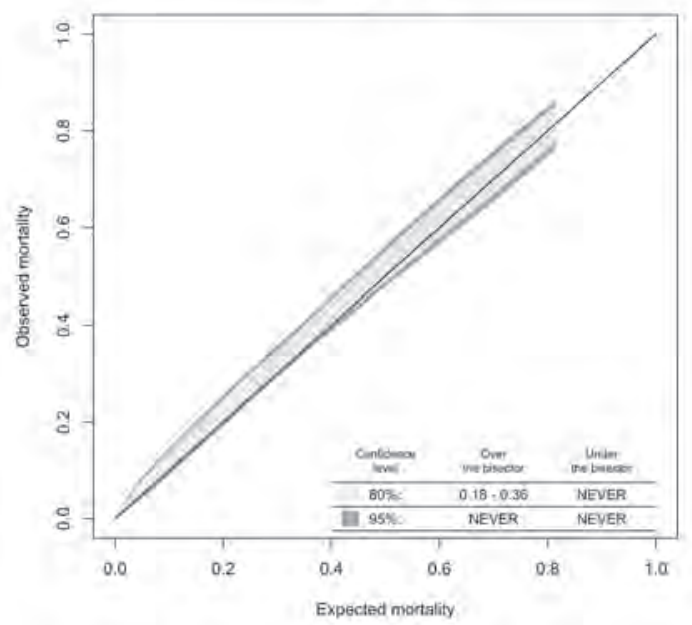

Figure 10: Calibration belt (GiViTI) of the simple model based on only age and GCS from the pooled data from studies II and IV. The pooled age + GCS models showed good calibration on both datasets according to the H-L test (Study II p-value=0.088, Study IV p-value=0.142). A closer look at the GiViTI calibration belt shows significant overprediction (higher expected than observed mortality) in for patients in Study II with a risk of 15 -39\%, while the belt does not cross the diagonal bisector line for patients in Study IV, indicating near perfect agreement between predicted and observed outcome 
Figure 11: Calibration of the customized intensive care scoring systems for six-month mortality. Left panel: $H-L$ calibration plot interconnected by a locally weighted scatterplot smoothing curve; Right panel: GiViTI calibration belt. The diagonal bisector line indicates perfect calibration. P-values $<0.05$ are considered poor calibration (significant deviation between observed and predicted outcome). Values above the bisector line indicate model underprediction (more patients die than predicted) and values under the bisector line indicate model overprediction (fewer patients die than predicted). From the figure one can see that all models exhibited good calibration $(p>0.05)$
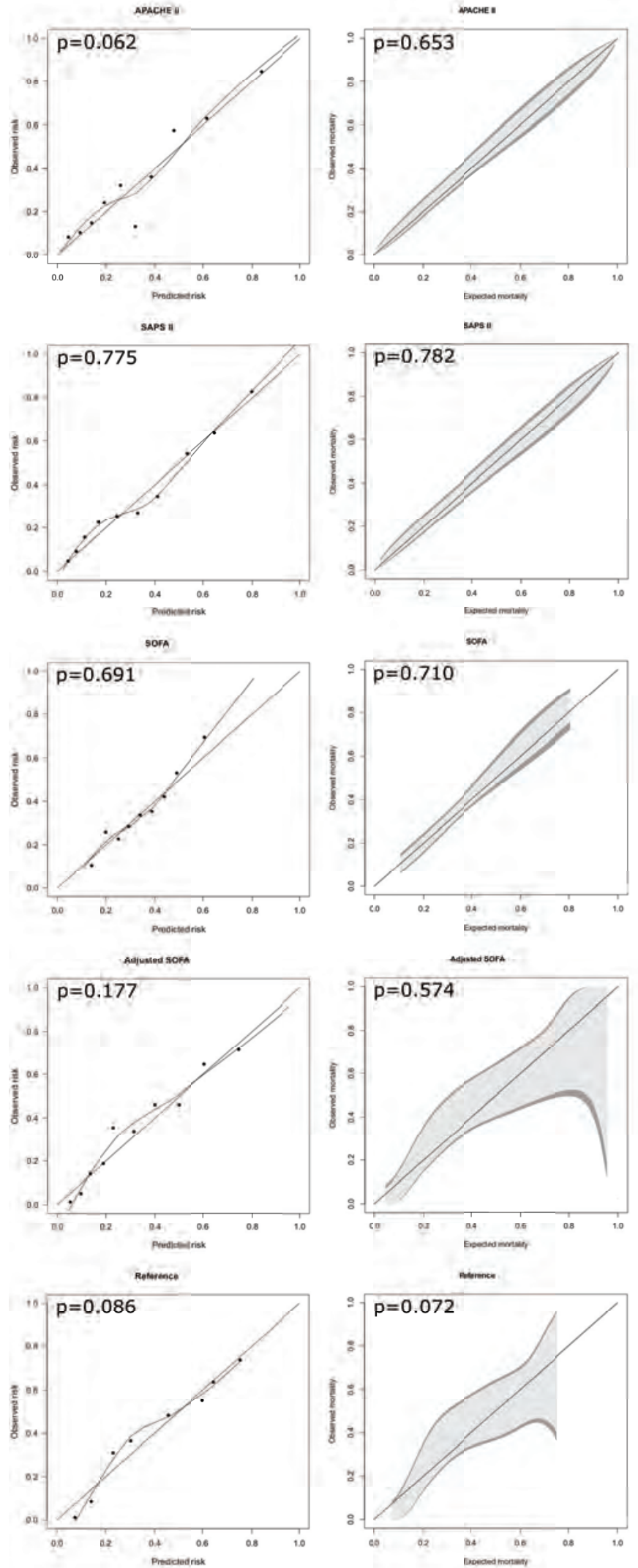


\section{Discussion}

\subsection{Key Findings}

This study examines three TBI specific models, two CT scoring systems, three intensive care scoring systems, and one trauma scoring system for outcome prediction in patients with TBI. In terms of long-term mortality prediction, the intensive care scoring systems were roughly comparable to the TBI models. The TBI models were, however, significantly superior in terms of long-term neurological outcome prediction. Moreover, the complex intensive care scoring systems did not show any additional prognostic value compared to a simple prognostic model based on only age and worst day one GCS. The general trauma scoring system was of limited value in patients with TBI. The CT scoring systems were, in isolation, of limited value for longterm outcome prediction. However, by combining the CT scoring systems with basic clinical features, superior performance was achieved. Several novel prediction models with improved performance over previous models were created, although these lack external validation.

\subsubsection{Traumatic Brain Injury Models}

This study found the TBI specific IMPACT models superior to the trauma and intensive care scoring systems for outcome prediction in patients with TBI. IMPACT demonstrated good discrimination in all studies (I-III), while calibration depended upon the level of complexity: the core and extended models exhibited suboptimal calibration while the laboratory model showed good calibration. Good calibration was, however, achieved for all levels of complexity following customization. Customization using all individual variables (type 2 second level) yielded the highest statistical performance and should be preferred over other customization strategies, assuming sufficiently large sample size, to enable future reevaluation of both the variables and their associated scores.

In should be noted that there are two major TBI models at present: IMPACT $^{9}$ and CRASH. ${ }^{10}$ Both models are based on a large number of patients from multiple settings and have been robustly validated. However, that does not provide any guidance on which one should be used. In this study IMPACT was chosen for several reasons. First, IMPACT is based on pooled data from eight RCTs and three observational studies while CRASH is developed on patients from a lone RCT. RCTs generally have much stricter inclusion criteria than observational studies (excluding patients with the worst prognosis not likely to benefit from treatment), making CRASH less applicable to register-based data like the present study. Second, because CRASH is based on a lone RCT (that ended in 2004), it is unlikely to undergo continual updating in the future. In contrast, the IMPACT study group regularly adds data from new studies, making the IMPACT database larger and larger and the IMPACT model more robust. ${ }^{18}$ Third, several previous studies have shown similar predictive ability of IMPACT and CRASH. ${ }^{9,10,164,165}$ Thus, it is highly presumable that CRASH and IMPACT would have equaled in predictive value in the present datasets as well. Fourth, CRASH was not designed to predict 6-month mortality, which may limit its use in observational studies where the possibility of assessing neurological outcome is often limited.

There are, however, two main advantages of CRASH over IMPACT that merit noting. First, CRASH is valid for patients with mild to severe TBI (GCS 3-14), while IMPACT only applies to patients with moderate to severe TBI (GCS 3-12). However, studies II-III confirmed IMPACT's validity for patients with complicated mild TBI (GCS 13-15 requiring ICU admission), diminishing this apparent advantage of CRASH. Second, 
CRASH is valid for patients from both lowto-middle income countries and from highincome countries, while the IMPACT models are based on studies conducted mainly in high-income countries. However, with the continual addition of new data to the IMPACT database, this advantage for CRASH seems certain to decline over time.

Prognostic models should, however, never be seen as complete and forthcoming continual updating of IMPACT is crucial. Inclusion of markers of coagulation and possible biomarkers for enhanced performance is something future studies should consider. In Europe, two large international collaborative projects, that have both received major funding from the European Commission, are about to start: the Collaborative European NeuroTrauma Effectiveness Research in TBI (CENTER-TBI, Project Number: 602150) and the Collaborative Research on Acute Traumatic Brain Injury in Intensive Care Medicine in Europe project (CREACTIVE, Project Number 602714). Similarly in the U.S., the Transforming Research and Clinical Knowledge in TBI (TRACK-TBI, ClinicalTrials.gov Identifier: NCT01565551) is underway. Data from these projects will certainly lead to a better understanding of the current epidemiology of TBI, improved characterization of TBI, improved outcome prediction, and better prognostic models.

\subsubsection{Intensive Care Scoring Systems}

The role of the intensive care scoring systems in TBI research will likely diminish in the future, because of the introduction of IMPACT and CRASH. Nonetheless, both APACHE II and SAPS II displayed good discrimination and good calibration (following customization), and are viable options in the absence of these TBI specific models (IV). In fact, APACHE II even matched IMPACT in terms of six-month mortality prediction (II). These findings are of importance for existing ICU databases already collecting intensive care scores, as these may now be used as reliable tools for case-mix adjustment for the TBI population.

In contrast to APACHE II and SAPS II, the SOFA scores showed poor predictive performance for TBI patients. However, after adding age and assigning more weight to the GCS component, the adjusted SOFA's performance improved to match both SAPS II and APACHE II, and thus probably IMPACT as well (original SOFA AUC 0.68 [IV], updated SOFA AUC 0.79 [IV], APACHE II and SAPS II AUC 0.79-0.80 [IV], IMPACT AUC 0.81-0.85 [I, II]).

In line with the improved performance of SOFA, after the addition of age and GCS, a simple model including only age and GCS (worst day one) exhibited similar performance to the more complex APACHE II and SAPS II scoring systems, suggesting that age and GCS are the main predictors of outcome after TBI and that adjusting for these factors is probably enough when more sophisticated prognostic models are unavailable. It is, however, important to note that the reference model uses the worst measured GCS in the first 24 hours in the ICU, as opposed to IMPACT which uses admission GCS. In Study IV, GCS was dichotomized based on the median value between survivors and non-survivors and categorized by age into ten-year intervals, as this approach was found to yield the best performance. However, categorization of variables that are not linear in nature may lead to loss of information and reduced statistical power. ${ }^{216}$ Accordingly, data from studies II and IV were pooled to create another (previously unpublished) model using age and GCS as linear predictors. This model was internally validated in both datasets and by bootstrapping, confirming good performance. 
There are several limitations of the intensive care scores that may limit their use in TBI research. First, it takes a minimum of 24 hours to estimate patient risk using the ICU models, and thus, initial risk stratification for clinical trial inclusion is usually not possible. Second, although modern computer science has made it possible to collect data automatically, it is still more resource- and time- consuming than models that include only admission characteristics. Third, any score that uses data collected from the first 24 hours is affected by the quality of care provided, so that high scores may be the result of either poor care or high severity of illness or both. ${ }^{19,217}$ It should, however, be noted that there are ICU models based on ICU admission variables that do not require 24-hour data collection which were not investigated in the present study, such as the $\mathrm{MPM}_{0}-\mathrm{II}^{218}$ and the MPM $\mathrm{M}_{0} \mathrm{III}^{219}$ models.

\subsubsection{Trauma Scoring Systems}

The RISC was of limited value for patients with moderate to severe TBI. In a subgroup of patients with isolated TBI, AUC was 'only' 0.76. Generally, values over 0.75 are considered sufficient. ${ }^{119}$ However, the predictive ability was only examined for 30-day hospital mortality, an outcome measure known to underestimate mortality rates after TBI significantly. ${ }^{29}$ Furthermore, external validation studies of IMPACT have shown AUC values up to 0.90 for predicting six-month mortality. ${ }^{161}$ Accordingly, discrimination of the RISC was considered to be only modest for isolated TBI patients.

RISC calibration was notably poor in every subgroup of TBI patients. Calibration was measured by the H-L $\hat{C}$-statistic, which may falsely generate $\mathrm{p}$-values $<0.05$ for large sample sizes, indicating poor calibration even when calibration in fact is good. ${ }^{125}$ The RISC gave an H-L $\chi^{2}$ of $382(\mathrm{p}<0.001)$ with a study population of 9,106 (TR-DGU), indicating poor calibration. In comparison, the development of APACHE IV included 110,558 patients and gave an $\mathrm{H}-\mathrm{L} \chi^{2}$ of 17 and an associated p-value of 0.08 , showing that good calibration is achievable even is large sample sizes, if the model is good. ${ }^{185}$ Moreover, concordance between predicted and observed mortality for the RISC was deficient, especially for the higher risk intervals (V: Figure 3). Thus, although the $\mathrm{H}-\mathrm{L}$ test in Study $\mathrm{V}$ is affected by the large sample size, poor calibration was prominent.

The RISC has routinely been used as a benchmarking tool in one of Europe's largest trauma databases, the TR-DGU. Because TBI is the leading cause of death in trauma it is crucial for correct benchmarking that the prognostic model used provide accurate outcome predictions in TBI. ${ }^{220}$ For accurate benchmarking in the future, the RISC ought to be updated to account better for patients with TBI. In fact, the importance of TBI has been acknowledged in the new, updated RISC II, which has now replaced the 'old' RISC. ${ }^{221}$

Most existing scoring systems like the RISC and TRISS are based largely on the anatomical injury severity scoring system AIS, often through the ISS or the NISS. The AIS is seldom calculated upon hospital admission, as it often requires primary, secondary, and tertiary patient surveys to assess all injuries completely. Thus, the trauma models cannot often be used as a tool for early baseline risk adjustment for study enrollment, one of the main purposes of prediction models in TBI research. Furthermore, the effect of extracranial injury on outcome was found to be negligible in the present study, which further questions the role of the general trauma scoring systems in TBI research.

\subsubsection{IMPACT-APACHE II}

Both IMPACT and APACHE II showed good predictive ability in TBI patients (II). Nevertheless, adjusting only for baseline 
prognostic risk by using IMPACT, later aspects of care are ignored, such as the quality of intensive care. Inter-center differences in process and quality of care are a confounding factor in most multi-center studies. For example, closer investigation of the IMPACT and the CRASH studies found large intercenter differences in outcome, even among European centers. ${ }^{222,223}$ On the other hand, adjusting only for abnormalities measured in the first 24 hours of ICU admission ignores initial injury severity. To overcome these difficulties, the IMPACT-APACHE II models were created as a combination of IMPACT and APACHE II with increasing levels of complexity (core, extended, and laboratory versions). The models account for both baseline injury severity (by IMPACT) and for early physiological abnormalities measured in the ICU (by APACHE II). Moreover, patient co-morbidity is taken into account as well (by APACHE II), which is nowadays a crucial aspect of the aging TBI population. ${ }^{37}$ Given the factors outlined, it came as no surprise that IMPACT-APACHE II showed superior predictive performance to the individual IMPACT models and APACHE II for outcome prediction. Thus, the novel IMPACT-APACHE II models offer a way to adjust for not only for baseline risk, but also for early aspects of intensive care and patient co-morbidities, and might come to serve as a powerful tool in increasing design and statistical power of forthcoming studies.

\subsubsection{Helsinki CT Score}

The Helsinki CT score ranges from -3 points (isolated small EDH) to a maximum of 14 points. In addition to the CT characteristics, patient age, GCS motor score, and pupillary reactivity can be added for increased performance. The Helsinki CT score was shown to be superior to both the Marshall CT classification and the Rotterdam CT score for outcome prediction. However, some valuable features of the Marshall and Rotterdam CT scores must be recognized.

The Marshall CT classification was not developed as a prediction tool and its usefulness lies in its descriptive value, which the Helsinki CT score does not replace. The Rotterdam CT score, on the other hand, was designed to predict outcome. However, at the cost of predictive performance the Rotterdam CT score was designed to range from 1 to 6, mimicking the GCS motor score. Thus, the Rotterdam CT score could be argued to be easier to interpret than the Helsinki CT score. However, the Helsinki CT score is also presented in a user-friendly score chart and the probabilities can easily be calculated using a publically available Microsoft Office Excel $^{\oplus}$ worksheet (http://links.lww.com/NEU/ A676). It should, however, be noted that the Rotterdam CT score was designed to predict six-month mortality, whereas the Helsinki CT score was designed to predict six-month unfavorable outcome. The differences between the Helsinki CT and Rotterdam CT scores reinforce the point that the same variables cannot be expected to predict both mortality and neurological outcome. In summary, the Helsinki CT score probably is probably advantageous over the Rotterdam CT score for predictive purposes, although external validation studies are needed to confirm this.

\subsection{Early Predictors of Outcome after TBI}

\subsubsection{Markers of Coagulation}

One in three patients with TBI has evidence of coagulopathy during the treatment course. ${ }^{83}$ The presence of coagulopathy significantly increases risk of hemorrhagic and ischemic lesion progression and consequently risk for unfavorable outcome and even death. . $2,83,224,225^{2}$ Results from the IMPACT study suggest that abnormalities in admission INR may be an important predictor of long-term outcome 
after TBI. ${ }^{78}$ Study I confirmed the association between INR and outcome. The fact that INR significantly increased the AUC of the IMPACT laboratory model (by +0.02 ) indicates a very strong association with mortality. Moreover, the explanatory variation of INR was similar to that of glucose, which is a known strong predictor of outcome. ${ }^{77,78}$ In contrast, no significant relationship between INR and long-term neurological outcome could be established by any of logistic regression, AUC, or NRI testing, showing that one cannot expect the same predictors to predict neurological outcome and mortality. Study I further showed that platelet count was not an independent predictor of outcome in TBI patients, supporting the hypothesis that platelet function rather than platelet count is the determining factor of platelet associated coagulopathy. ${ }^{226}$

\subsubsection{Major Extra-Cranial Injury}

Major extra-cranial injury (MEI) is present in about $23 \%$ to $41 \%$ of patients with TBI, depending on the population and definition of TBI and MEI. ${ }^{10,227}$ The role of MEI on outcome in patients with TBI is, however, debated. Some studies suggest that outcome after TBI is mainly dependent upon severity of brain injury and that coexisting MEI plays little part, whereas other studies advocate that presence of concomitant MEI significantly increases the likelihood of poor outcome. . $1066,67,227,228$

A meta-analysis including roughly 40,000 patients from the IMPACT, CRASH, and TARN databases found MEI (defined as AIS 3 or higher or an injury requiring hospital admission on its own) to be a strong predictor of outcome after TBI. ${ }^{65}$ However, the strength of the effect was inversely related to the degree of brain injury, so that the more severe the brain injury, the lesser the effect of MEI.
A likely reason why previous studies have yielded conflicting results is that no clear definition of MEI exists. ${ }^{229}$ A commonly used definition of MEI is ISS $>15$, although ISS cut-off points up to $>25$ have also been used. ${ }^{177,230}$ In Study I, MEI was defined as ISS $>15$ and $>25$, whereas in Study V, MEI was defined as a head-AIS of $\geq 3$, plus at least one other body part at AIS $\geq 2$. Both studies (I, V) systematically found MEI to remain an insignificant predictor of outcome, after adjusting for other markers of injury. In fact, in Study V patients with TBI and concomitant MEI (polytrauma TBI) had a slightly lower risk of mortality than TBI patients without MEI (isolated TBI). This finding, however, is probably explained by the fact that patients with isolated TBI had a more severe TBI (by head-AIS) than polytrauma TBI patients. Thus, the findings support the hypothesis that severity of brain injury is the major determinant of outcome in patients with TBI.

A recent international consensus meeting proposed a new definition of MEI: at least two injuries with AIS $\geq 3$, plus at least one of the following physiological derangements: hypotension, decreased level of consciousness, acidosis, or coagulopathy. ${ }^{231}$ This definition has, however, been neither investigated nor validated in the TBI population, and thus, the role of MEI on outcome after TBI remains controversial. Standardized data collection and uniform definitions are advocated for appropriate prognostic research, so that the best treatment for TBI patients with associated injuries can be determined.

\subsubsection{Early Computerized Tomography Characteristics}

The admission CT characteristics associated with poor outcome irrespective of patient age, GCS motor score, or pupillary light reactivity were: mass lesion volume $\geq 25 \mathrm{~cm}^{3}$, type of mass lesion (SDH, ICH, EDH), tSAH in basal cisterns, presence of IVH, abnormal 
fourth ventricle, absent suprasellar cisterns, absent ambiens cisterns, and bilateral cortical sulci effacement. Still, only six of these were independently associated with outcome: mass lesion volume $\geq 25 \mathrm{~cm}^{3}$, type of mass lesion (SDH, ICH, EDH), presence of IVH, and status of suprasellar cisterns (the variables together constituting the Helsinki CT score).

Several previous studies have suggested degree of midline shift and presence of $\mathrm{tSAH}$ to be the strongest predictors (detected by CT imaging) of poor outcome after TBI. ${ }^{10,68,69,167,232,233}$ In spite of this, both midline shift and tSAH were found to be insignificant and consequently omitted from the Helsinki CT score (III). The reasons for these different results remain uncertain, but they should certainly be noted.

Midline shift, when measured on admission, is often the result of a spaceoccupying mass lesion, and thus, highly amendable to correction through mass lesion evacuation. In contrast, day one or postoperative midline shift is probably a much more informative predictor than admission or pre-operative midline shift, which might explain the weak association between midline shift and outcome in the present study.

Traumatic SAH was previously thought as one of the strongest predictors of poor outcome in TBI. ${ }^{68,69,233-236}$ In the IMPACT study, the presence of tSAH independently doubled the odds of poor outcome., ${ }^{9,68}$ Likewise, in the CRASH trial, presence of tSAH was strongly associated with poor outcome. ${ }^{10}$ In contrast, in the present study, $\mathrm{tSAH}$ was insignificant in multivariate analysis (I-III). Lack of statistical power might be one reason why tSAH was insignificant. In fact, most patients had $\mathrm{tSAH}$ (presence of tSAH in Study I: 67\%, II: 57\%, III: 58\%) and the difference in incidence between those with good vs. poor outcome might have been too small to make any difference. Another reason might be that $\mathrm{tSAH}$ and
IVH were differentiated in this study. The presence of IVH and $\mathrm{tSAH}$ strongly correlates with the risk of developing posttraumatic hydrocephalus, which is strongly associated with poor outcome. ${ }^{237,238} \mathrm{Up}$ to $40 \%$ of patients with moderate to severe TBI develop post-traumatic hydrocephalus and the presence of $\mathrm{tSAH}$, and especially IVH, increases the risk. ${ }^{237,238}$ Thus, separating tSAH and IVH might explain why $\mathrm{tSAH}$ was found to be insignificant when adjusting for IVH. ${ }^{238}$

The Rotterdam CT and Marshall CT scoring systems were both of limited value for long-term outcome prediction (III). However, the addition of age, motor score, and pupils significantly improved discrimination drastically, with AUCs rising from 0.63-0.75 to $0.81-0.84$ and explanatory variation values rising from $9-16 \%$ to $38-39 \%$. This shows that early CT findings should not be used in isolation to establish patient prognosis, but should always be combined with relevant clinical features. It is notable that even after combining patient clinical characteristics with CT features, approximately $40 \%$ of the actual outcome was explained.

\subsection{Statistical Considerations}

Good discrimination does not necessarily mean good calibration and vice versa. In fact, perfectly calibrated models cannot achieve the theoretical AUC maximum of 1. ${ }^{121}$ Discrimination was measured in all studies using the AUC. The AUC is highly dependent on the underlying case-mix; a heterogeneous population increases AUC while a homogenous population decreases AUC. Studies I, II, and III included patients with mild, moderate, and severe TBI (GCS 3-15, all requiring ICU admission), whereas studies IV and V only included patients with moderate and severe TBI (GCS 3-13 in IV and AIS-head $\geq 3$ in V). Thus, studies I, II and III may be considered more heterogeneous than studies IV and V, which could affect the 
AUC reported. To avoid such bias, a case-mix adjusted AUC has been proposed. ${ }^{239}$

We used three types of calibration tests: the H-L test (I, II, IV, V), the calibration slope (III), and the GiViTI calibration belt (II, IV). The H-L test and the calibration slope have been extensively used in the past. Studies II and IV are, however, among the first to assess and compare the H-L and GiViTI calibration tests. ${ }^{240}$ The main advantage of the GiViTI calibration belt over the H-L test and the calibration slope is the possibility of estimating 95\% confidence intervals over the whole risk spectrum. Thus, the calibration belt provides valuable information about the degree and direction of miscalibration, such as whether it affects only a specific risk interval or if the overall calibration is poor. This is valuable not only for external validation of prognostic models but also for evaluating and comparing the quality of care at individual centers.

We found the H-L and the GiViTI tests to produce similar results for external validation studies (II, IV). Thus, for overall calibration testing, the $\mathrm{H}-\mathrm{L}$ test is probably sufficient. However, when the H-L test indicates poor calibration $(\mathrm{p}<0.05)$ one may utilize the GiViTI calibration belt to assess the significance of miscalibration and pinpoint risk intervals of either under- or overprediction. ${ }^{126,211,241}$ Future studies are necessary to gain a better understanding of the benefits and possible pitfalls of using the GiViTI calibration belt.

\subsection{Patient Outcome after Traumatic Brain Injury}

Overall six-month mortality rate ranged between $23 \%$ and $33 \%$ and six-month unfavorable outcome was between $47 \%$ and $57 \%$ (I-IV). For patients with severe TBI (GCS $\leq 8)$ the weighted six-month mortality rate was $40 \%$ and unfavorable outcome rate
63\%. These numbers are somewhat higher compared to some previous observational studies (Table 21, a non-systematic review of outcome in observational studies). It should, however, be noted that in the present study, median patient age was just below 60 years, whereas in previous studies it has generally been below 40 years (Figure 12). It is widely known that age is one of the strongest predictors of outcome after TBI. ${ }^{29,49-53}$ The relationship between older age and poor outcome has been suggested to be linear. ${ }^{49}$ Thus, the increasing age of TBI patients is most likely a primary reason why poor outcome was more frequently noted in the present study. This deduction also supports the theory of stagnated improvements in outcome after TBI because of the epidemiologic shift previously proposed. ${ }^{37,92}$

The importance of long-term follow-up in TBI patients cannot be overemphasized. Studies using hospital mortality as the primary outcome measure are severely biased for two main reasons. First, discharge policies vary among hospitals, biasing follow-up time. ${ }^{142,143}$ Second, a substantial number of TBI patients die following hospital discharge, biasing outcome rates. ${ }^{29,50-52}$ Supporting these concerns, Study II showed a 14-day mortality rate of $11 \%$, compared to a $33 \%$ six-month mortality rate in Study IV, for a staggering $200 \%$ increase. Thus, hospital mortality severely underestimates mortality rates after TBI and should be discouraged as a primary outcome measure in TBI research. Furthermore, it was found that mortality rates steadily increased over the entire follow-up period, suggesting that even a six-month outcome may be too short to evaluate the full effects of TBI on patient outcome, especially in terms of functional outcome, neurological outcome, and quality of life. 
Table 21: Non-systematic review of trends in outcome and age over time in observational studies

\begin{tabular}{|c|c|c|c|c|c|c|c|}
\hline Study & Year of study & $\mathbf{N}$ & Setting & $\begin{array}{l}\text { Clinical } \\
\text { severity }\end{array}$ & Age $^{*}$ & Mortality & Unfavorable \\
\hline \multicolumn{8}{|l|}{ Prior to 1990} \\
\hline Jennett et al. $1977^{242}$ & $1968-1975$ & 700 & $\mathrm{UK} / \mathrm{NL} / \mathrm{US}$ & Coma $>6 h$ & 36 & $51 \%$ & $62 \%$ \\
\hline Foulkes et al. $1991^{243}$ & 1984-1987 & 746 & US & GCS $<9$ & 30 & $39 \%$ & $58 \%$ \\
\hline Murray et al. $1999^{244}$ & 1986-1988 & 988 & US & GCS $<9$ & 34 & $39 \%$ & $57 \%$ \\
\hline Weighted average & & & & & 33 & $42 \%$ & $59 \%$ \\
\hline \multicolumn{8}{|l|}{$1990-2000$} \\
\hline Patel et al. 2002 (91-93) ${ }^{97}$ & $1991-1993$ & 53 & UK & GCS $<9$ & 34 & $28 \%$ & $60 \%$ \\
\hline Patel et al. $2002(94-97)^{97}$ & 1994-1997 & 129 & UK & GCS $<9$ & 34 & $22 \%$ & $40 \%$ \\
\hline Murray et al. $1999^{245}$ & 1995 & 481 & $\mathrm{EU}$ & GCS $<9$ & 41 & $40 \%$ & $60 \%$ \\
\hline Fakhry et al. $2004^{93}$ & $1991-2000$ & 830 & US & GCS $<9$ & 35 & $16 \%$ & $45 \%$ \\
\hline $\begin{array}{l}\text { Clayton et al. } 2004^{95} \\
1992-2000\end{array}$ & & 843 & UK & GCS $<9$ & 30 & $23 \%$ & NA \\
\hline Patel et al. $2005^{220}$ & $1989-2003$ & 6921 & UK & GCS $<9$ & 30 & $29 \%$ & NA \\
\hline Arabi et al. $2010^{94}$ & $1999-2001$ & 72 & Saudi Arabia & GCS $<9$ & 32 & $28 \%$ & NA \\
\hline Weighted average & & & & & 31 & $27 \%$ & $50 \%$ \\
\hline \multicolumn{8}{|l|}{ 2000-2005 } \\
\hline Rusnak et al. $2007^{246}$ & 1999-2004 & 492 & Aus & GCS $<9$ & 49 & $38 \%$ & $51 \%$ \\
\hline Myburgh et al. $2008^{29}$ & 2000 & 363 & Aus-NZ & GCS $<9$ & 39 & $32 \%$ & $55 \%$ \\
\hline $\mathrm{Ng}$ et al. $2006^{247}$ & 1999-2004 & 672 & Singapore & GCS $<9$ & 43 & $36 \%$ & $51 \%$ \\
\hline Arabi et al. $2010^{94}$ & 2001-2006 & 362 & Saudi Arabia & GCS $<9$ & 30 & $19 \%$ & NA \\
\hline Weighted average & & & & & 39 & $27 \%$ & $52 \%$ \\
\hline \multicolumn{8}{|l|}{ After 2005} \\
\hline Andriessen et al. $2011^{248}$ & 2008-2009 & 339 & NL & GCS $<9$ & 46 & $46 \%$ & $60 \%$ \\
\hline Weighted average & & & & & 40 & $32 \%$ & $40 \%$ \\
\hline \multicolumn{8}{|l|}{ Present study } \\
\hline Raj et al. 2014 (II) & 2009-2012 & 379 & FIN & GCS $<9$ & 53 & $36 \%$ & $63 \%$ \\
\hline Raj et al. 2014 (IV) & 2003-2012 & 1067 & FIN & GCS $<9$ & 52 & $42 \%$ & NA \\
\hline Weighted average & & & & & 52 & $40 \%$ & $63 \%$ \\
\hline
\end{tabular}

Table showing a non-systematic review of trends in outcome and patient age in observational studies from prior to 1990 to after 2005 plus data from studies II and IV. As seen in the table after 1990, mortality rates have been around $30 \%$ and rate of unfavorable outcome around $50 \%$. Studies II and IV indicate a slightly higher mortality (40\%) and unfavorable outcome (63\%) rates than previous studies. However, patient median/mean age was notably higher in studies II and IV than in previous studies (52 vs. 33-40 years). This is a likely explanation of the poorer outcome noticed, as age was shown to be one of the strongest predictors of outcome (III, IV) and has a linear relationship with outcome. ${ }^{49}{ }^{\star}$ Mean or median age, depending on what was reported 
$70 \%$

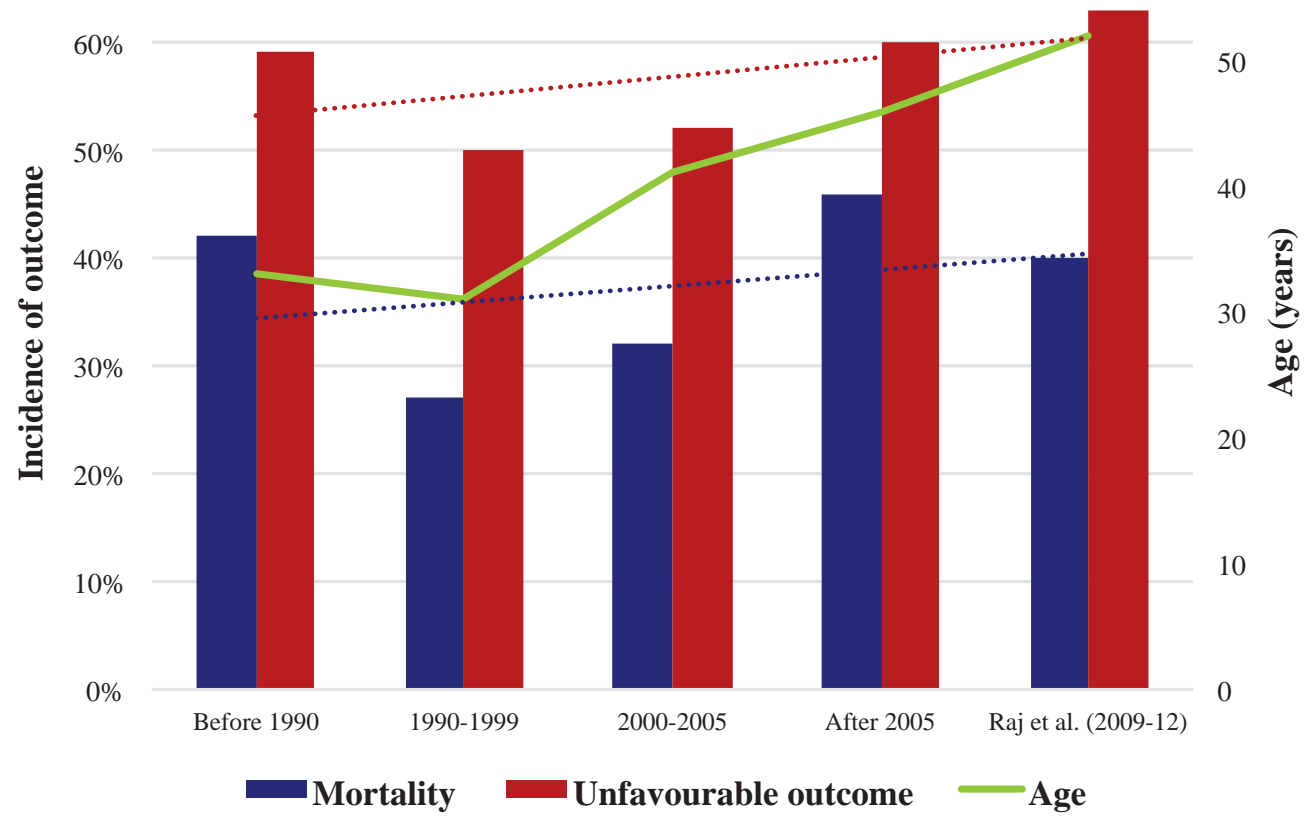

Figure 12: Non-systematic overview of trends in outcome and age over time in observational studies. $Y$-axis to the left shows the incidence of the outcome (\%) and secondary y-axis to the right shows patient age (years). The green line represents the trend in mean/median age from observational studies conducted prior to 1990 to after 2005 plus data from the present study. A slight increase in rates of mortality and unfavourable outcome is noticed for the present study (far right) compared to the other time epochs. However, patient age was also notably higher in the present study compared to previous studies (as indicated by the rising green line.

\subsubsection{Outcome Assessment After TBI}

The increasing age of TBI patients presents another important problem, namely how to assess outcome in the elderly. The majority of TBI clinical trials assess outcome by mortality and by dichotomization of the (extended) GOS to favorable or unfavorable outcome. Mortality is a robust outcome measure with little (in fact, no) room for interpretation; the patient is or is not dead at a given time-point. In contrast, neurological outcome involves a much broader spectrum, with substantial room for interpretation. Generally, neurological outcome is assessed using the GOS and dichotomized based on self-dependence to favorable and unfavorable outcome, as it was in this study. However, with the increasing age of TBI patients, more and more patients will be classified as dependent prior to injury, and by definition remain dependent after the injury, regardless of their actual recovery rate. Thus, preinjury health status is an important aspect of outcome prediction that is often ignored in TBI research and should be considered in forthcoming studies. Furthermore, the GOS might be considered too insensitive to measure the full outcome extent after TBI, ignoring factors such as quality of life, cognitive function, physical function, and neuropsychological performance. Although new statistical approaches to outcome analysis (sliding dichotomy and proportional 
odds analysis ${ }^{26}$ might improve studies' statistical power, multidimensional outcome analysis is crucial in forthcoming studies. Furthermore, the effect of genetic variations on outcome and complications after TBI (e.g. hydrocephalus, epilepsy, neurological deficits) are other areas of key interest for future research.

\subsection{Limitations of the Study}

There are some limitations of the present study that must be acknowledged. First, the main limitation of the study is that few of the newly proposed models were externally validated. Although all models were internally validated, external validation in independent datasets is essential to demonstrate model generalizability. Thus, before application, proposed models such as IMPACT-APACHE II and the Helsinki CT score should be externally validated in independent datasets. Second, due to the retrospective nature of studies I-III, neurological outcome was assessed retrospectively according to the simple $\mathrm{GOS}^{205}$ and not to the more sensitive extended GOS. ${ }^{249}$ Third, all studies were register-based, and as in all register studies, the quality of data and data completeness should be considered. However, missing data were not a significant problem in any of the studies and when there were missing data, these patients were excluded instead of using the more sophisticated statistical techniques, such as multiple imputation. ${ }^{250}$ Fourth, the performance of the RISC for long-term outcome prediction could not be assessed. Thus, the 'true' predictive ability of the RISC in patients with TBI could not be established. Fifth, variable interaction and transformation techniques were not exploited in the present study. Further studies should aim at investigating inter-variable interactions and look at the possibility of variable transformation, as this might increase model performance.

\subsection{Future Implications}

\subsubsection{Which Model To Use And For What?}

Based on this study's results, the choice among TBI models, intensive care scoring systems, and trauma scoring systems is the TBI models wherever possible. IMPACT exhibited the best overall performance in the present study and is thus considered the most robust model in patients with TBI. Aside from superior statistical performance, accurate prognoses assessable directly upon hospital admission is an obvious advantage of IMPACT over other investigated models. However, if IMPACT is unavailable, customization of some of the intensive care scores is probably a valid substitute. Although the prognostic models provide seemly accurate estimations of patient prognosis, there are numerous factors that simply cannot be accounted for by standardized models. As indicated by the explanatory variation, about $40 \%$ at best of patient outcome was explained by IMPACT. That means that about $60 \%$ of the outcome remains to be explained. Thus, using prognostic models in the individual patient should be approached with due caution; current models are not accurate enough to provide individual prognoses and the role of current prognostic models is mainly for research purposes.

\subsubsection{External Validation of the Proposed Models}

Future external validations studies of IMPACT-APACHE II and Helsinki CT score are essential to show model generalizability. Furthermore, the APACHE or intensive care component of IMPACT-APACHE II models should be modified to include more neurointensive specific variables, such as ICP, CPP, $\mathrm{P}_{b t} \mathrm{O}_{2}$, and possibly biomarkers (e.g. S100B peaks ${ }^{251}$ ) and brain microdialysis markers. In addition, the individual scores included in the Helsinki CT score should 
be externally validated and evaluated in independent datasets, as it is possible that the regression coefficients and their associated scores might differ in other settings.

\subsection{Practical Examples of Prognostic Models in TBI Research}

Prognostic model research in itself does not lead anywhere if the prognostic models remain underutilized. Below are descriptions of two examples of how different types of prognostic models can be used in TBI research.

The role of hyperoxemia in the setting of TBI is a controversial topic. ${ }^{252,253}$ To investigate this a national ICU database (FICC) was used to assess the independent effect of hyperoxemia on long-term mortality in patients with moderate to severe TBI. Because the FICC lacks some of the essential data necessary to use IMPACT, a customized version of APACHE II was used to adjust for differences in severity of illness among TBI patients. The APACHE II was customized using the total score (level one customization), which resulted in good model discrimination and calibration (AUC 0.80 , H-L p-value $=0.10$ ). This customized APACHE II thus provided an excellent tool for injury severity adjustment in multivariate analysis. Subsequently, hyperoxemia was found not to be an independent predictor of outcome in patients with moderate to severe TBI treated in the ICU. ${ }^{50}$

Up to half of all TBI patients are alcohol intoxicated at the time of injury. ${ }^{4}$ The effect of acute alcohol intoxication on outcome after TBI is, however, a debated subject. $^{254}$ Because high levels of blood alcohol concentration (BAC) are known to decrease level of consciousness, alcohol intoxicated patients may be wrongly classified as having a more severe TBI than they really have. ${ }^{255}$ Thus, adjusting for IMPACT may be insufficient, as admission GCS is one of the most important predictors. The APACHE II, on the other hand, includes the worst day one GCS and thus enables identification of patients with low initial GCS due to alcohol intoxication instead of brain injury. Thus, IMPACT-APACHE II provides an excellent tool to adjust for TBI severity with alcohol intoxication as a confounding factor. Subsequently, after adjusting for potential confounding factors, including IMPACTAPACHE II and the Rotterdam CT scores, low admission BAC $(<2.3 \%)$ were found to significantly decrease the risk of six-month mortality compared to no BAC $(0 \%)$ or high BAC $(\geq 2.3 \%$ ) (no BAC as reference; low BAC OR 0.41, 95\% CI 0.19-0.88, p=0.021; high BAC OR 0.58, 95\% CI 0.29-1.15, $\mathrm{p}=0.120) .{ }^{256}$ 


\section{Conclusions}

1. The TBI specific IMPACT models displayed superior overall performance compared to the intensive care and trauma scoring systems, showing that patients with TBI are a highly specific population in the trauma and intensive care unit environment. Thus, the use of a TBI specific prognostic model, undergoing continual updating, is advocated $(\mathrm{I}-\mathrm{V})$.

2. Three novel models were developed: the TBI-ICU combination model (IMPACTAPACHE), the Helsinki CT score, and the reference model (age + GCS). The TBIICU model showed superior performance over the TBI and intensive care scoring system when used in isolation, and may be used to adjust for patient baseline prognostic risk and inter-center differences in quality of early intensive care (II). The Helsinki CT score may be used for early objective prediction of long-term outcome and for describing and comparing patient series (III). The reference model, based on only age and GCS, showed similar performance to the more complex intensive care scoring systems (which are also roughly comparable to IMPACT), showing that adjusting for these factors may provide adequate case-mix adjustment. This is of great importance for forthcoming epidemiological studies lacking the necessary data for more complex prognostications (IV). External validation studies of the newly proposed models are required to show generalizability. 


\section{Acknowledgements}

This study was carried out at the Department of Neurosurgery and the Department of Anesthesiology and Intensive Care, Helsinki University Central Hospital from 2012 to 2014. The thesis is part of the Clinical Research Program of Faculty of Medicine and Doctoral School of Health Science (Dissertationes Scholae Doctoralis Ad Sanitatem Investigandam Universitatis Helsinkiensis).

I begin by presenting my deepest gratitude to my supervisors Jari Siironen and Markus Skrifvars. Jari, you were the first to introduce me to the world of neurotrauma. Thank you for taking me in as a young inexperienced medical student and guiding me in the right direction. You have been my role model, both inside and outside the hospital, since we first started this project. Markus, you truly are the best supervisor one could wish for. You taught me everything from scientific writing to complex statistical analyses, and so much more. Without you none of this work would have been even remotely possible, and I am truly grateful to you.

I also wish to give my sincerest gratitude to Riku Kivisaari for the countless hours spent analyzing radiological images (even on your free time!). Although not serving as my official supervisor, you always acted like one.

I express my sincere gratitude to my custos, Professor Juha Hernesniemi, the head, and mentor for the whole Department of Neurosurgery in Helsinki. His skills as a surgeon and compassion as a leader inspire not only me, but also a whole generation of future neurosurgeons.

My special thanks go to Juha Öhman and Patrik Finne, the official reviewers of this thesis. Thank you for your advice and constructive criticism that so improved the final product.

I am deeply ful to thank Professor Andrew Maas for accepting the role of being my opponent and for sharing his visionary views and immense knowledge of neurotrauma on this special day.

I am grateful to Jaakko Lappalainen for all his critical revisions and excellent comments on my manuscripts thoughout the years. My deepest appreciation also goes to Matti Reinikainen for all the constructive comments, statistical advice, and clinical knowledge.

I thank all my co-authors, Tuomas Brinck, Lauri Handolin, Päivi Tanskanen, Stepani Bendel, Rolf Lefering, and Tuomas Selander, for making the studies in this dissertation possible.

My heartfelt thanks go to all the Anesthesiologists and Neurosurgeons at the Department of Neurosurgery at Töölö Hospital. Thank you for your patience, instruction, and guidance the last two summers.

To my boys, Era Mikkonen, Gustav Strömberg, Walter Federolf, Erik Wahlström, and Rasmus Löfman: thank you for your support and patience over the years, but most of all, thank you for your friendship, which I hold so dear. I also wish to acknowledge the members of "Rahuls 
klinikgrupp" (you know who you are) and the amazing journey through medical school that we have shared.

Also, to my boys back home, Daniel Fellman, David Nyman, Jonas Grönholm, Kristoffer Knuts, Martin Kjellman, Linus Korkea-Aho, and Robin Julin. Having known me for nearly 20 years, you are my oldest friends and know me better than anyone. Thank you for all the adventures we have enjoyed and will continue to en joy together.

To my beautiful sisters Richika Raj and Rimmi Raj (or, as I like to say, Timon and Pumba): although it was not always the easiest task, thank you for your support and love.

Sara Johansson, my soul mate, and the love of my life. Not only being the sole woman, besides my mother, capable of putting up with me, you make my life worth living. Without you, none of this matters.

I dedicated this book to my mother (Renu Raj) and father (Bharat Raj). Mamma, my love for you is beyond words, and I cannot describe how proud I am of being your son. Pappa, coming from a tiny village in the mountains of Himalaya (Budhesu, India) to another tiny village in Finland (Jakobstad, Finland), your journey through life cannot be matched. I am truly grateful for everything you have given me. I stumble on my words, but you must know that you are my biggest inspiration in life.

The research and the writing of this book were financially supported by grants from Finska Läkaresällskapet, Maire Taponen Foundation, Medicinska Understödsföreningen Liv och Hälsa, Svensk-Österbottniska Samfundet r.f., the Maud Kuistila Memorial Foundation, the Viktor Fagerström Foundation of the Finnish Medical Society Duodecim, and a Helsinki University Central Hospital EVO grant.

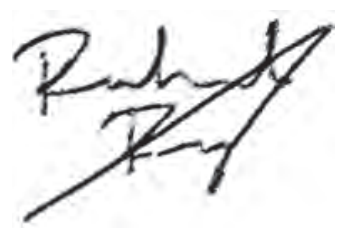

Helsinki, November 2014 


\section{References}

1. Jennett B. Epidemiology of head injury. J Neurol Neurosurg Psychiatr 1996;60:362-9.

2. Lu JJ, Marmarou AA, Choi SS, Maas AA, Murray GG, Steyerberg EWE. Mortality from traumatic brain injury. Acta Neurochir Suppl 2004;95:281-5.

3. Langlois JA, Rutland-Brown W, Wald MM. The epidemiology and impact of traumatic brain injury: a brief overview. J Head Trauma Rehabil 2006;21:375-8.

4. Tagliaferri F, Compagnone C, Korsic M, Servadei F, Kraus J. A systematic review of brain injury epidemiology in Europe. Acta Neurochir (Wien) 2006;148:255-68.

5. Faul M, Wald MM, Rutland-Brown W, Sullivent EE, Sattin RW. Using a cost-benefit analysis to estimate outcomes of a clinical treatment guideline: testing the Brain Trauma Foundation guidelines for the treatment of severe traumatic brain injury. J Trauma 2007;63:1271-8.

6. Olesen J, Gustavsson A, Svensson M, Wittchen H-U, Jönsson B, CDBE2010 study group, et al. The economic cost of brain disorders in Europe. Eur J Neurol 2012;19:155-62.

7. Maas AIR, Stocchetti N, Bullock R. Moderate and severe traumatic brain injury in adults. Lancet Neurology 2008;7:728-41.

8. Coronado VG, McGuire LC, Sarmiento K, Bell J, Lionbarger MR, Jones CD, et al. Trends in Traumatic Brain Injury in the U.S. and the public health response: 1995-2009. J Safety Res 2012;43:299-307.

9. Steyerberg EW, Mushkudiani N, Perel P, Butcher I, Lu J, McHugh GS, et al. Predicting outcome after traumatic brain injury: development and international validation of prognostic scores based on admission characteristics. PLoS Med 2008;5:e165.

10. MRC CRASH Trial Collaborators, Perel P, Arango M, Clayton T, Edwards P, Komolafe E, et al. Predicting outcome after traumatic brain injury: practical prognostic models based on large cohort of international patients. BMJ 2008;336:425-9.

11. Hukkelhoven CWPM, Rampen AJJ, Maas AIR, Farace E, Habbema JDF, Marmarou A, et al. Some prognostic models for traumatic brain injury were not valid. J Clin Epidemiol 2006;59:132-43.

12. Perel P, Edwards P, Wentz R, Roberts I. Systematic review of prognostic models in traumatic brain injury. BMC Med Inform Decis Mak 2006;6:38.

13. Hemingway H, Croft P, Perel P, Hayden JA, Abrams K, Timmis A, et al. Prognosis research strategy (PROGRESS) 1: a framework for researching clinical outcomes. BMJ 2013;346:e5595.

14. Riley RD, Hayden JA, Steyerberg EW, Moons KGM, Abrams K, Kyzas PA, et al. Prognosis Research Strategy (PROGRESS) 2: prognostic factor research. PLoS Med 2013;10:e1001380.
Steyerberg EW, Moons KGM, van der Windt DA, Hayden JA, Perel P, Schroter S, et al. Prognosis Research Strategy (PROGRESS) 3: prognostic model research. PLoS Med 2013;10:e1001381.

16. Hingorani AD, Windt DAVD, Riley RD, Abrams K, Moons KGM, Steyerberg EW, et al. Prognosis research strategy (PROGRESS) 4: stratified medicine research. BMJ 2013;346:e5793.

17. Lingsma HF, Roozenbeek B, Steyerberg EW, Murray GD, Maas AIR. Early prognosis in traumatic brain injury: from prophecies to predictions. Lancet Neurology 2010;9:543-54.

18. Maas AIR, Murray GD, Roozenbeek B, Lingsma HF, Butcher I, McHugh GS, et al. Advancing care for traumatic brain injury: findings from the IMPACT studies and perspectives on future research. Lancet Neurology 2013;12:1200-10.

19. Selker HP. Systems for comparing actual and predicted mortality rates: characteristics to promote cooperation in improving hospital care. Ann Intern Med 1993;118:820-2.

20. Champion HR, Copes WS, Sacco WJ, Lawnick MM, Keast SL, Bain LW, et al. The Major Trauma Outcome Study: establishing national norms for trauma care. J Trauma 1990;30:1356-65.

21. Knaus WA, Wagner DP, Zimmerman JE, Draper EA. Variations in mortality and length of stay in intensive care units. Ann Intern Med 1993;118:753-61.

22. Le Gall J-R. The use of severity scores in the intensive care unit. Intensive Care Medicine 2005;31:1618-23.

23. Breslow MJ, Badawi O. Severity scoring in the critically ill: Part 1: Interpretation and accuracy of outcome prediction scoring systems. Chest 2012;141:245-52.

24. Breslow MJ, Badawi O. Severity scoring in the critically ill: Part 2: Maximizing value from outcome prediction scoring systems. Chest 2012;141:51827.

25. Maas AIR, Menon DK, Lingsma HF, Pineda JA, Sandel ME, Manley GT. Re-orientation of clinical research in traumatic brain injury: report of an international workshop on comparative effectiveness research. J Neurotrauma 2012;29:32-46.

26. Maas AIR, Steyerberg EW, Marmarou A, McHugh GS, Lingsma HF, Butcher I, et al. IMPACT recommendations for improving the design and analysis of clinical trials in moderate to severe traumatic brain injury. Neurotherapeutics 2010;7:127-34.

27. Vincent J-L, Moreno R. Clinical review: scoring systems in the critically ill. Crit Care 2010;14:207.

28. Champion HR. Trauma scoring. Scand J Surg 2002;91:12-22.

29. Myburgh JA, Cooper DJ, Finfer SR, Venkatesh $\mathrm{B}$, Jones D, Higgins A, et al. Epidemiology and 12-month outcomes from traumatic brain injury in Australia and New Zealand. J Trauma 2008;64:854-62. 
30. Menon DK, Schwab K, Wright DW, Maas AI, Demographics and Clinical Assessment Working Group of the International and Interagency Initiative toward Common Data Elements for Research on Traumatic Brain Injury and Psychological Health. Position statement: definition of traumatic brain injury. Arch Phys Med Rehabil 2010;91:1637-40.

31. Olesen J, Leonardi M. The burden of brain diseases in Europe. Eur J Neurol 2003;10:471-7.

32. Kay A, Teasdale G. Head injury in the United Kingdom. World J Surg 2001;25:1210-20.

33. Feigin VL, Theadom A, Barker-Collo S, Starkey NJ, McPherson K, Kahan M, et al. Incidence of traumatic brain injury in New Zealand: a population-based study. Lancet Neurology 2013;12:5364.

34. Centers for Disease Control and Prevention (CDC). CDC grand rounds: reducing severe traumatic brain injury in the United States. MMWR Morb Mortal Wkly Rep 2013;62:549-52.

35. Koskinen S, Alaranta H. Traumatic brain injury in Finland 1991-2005: a nationwide register study of hospitalized and fatal TBI. Brain Inj 2008;22:20514.

36.

Coronado VG, Xu L, Basavaraju SV, McGuire LC, Wald MM, Faul MD, et al. Surveillance for traumatic brain injury-related deaths--United States, 1997-2007. MMWR Surveill Summ 2011;60:1-32.

37. Roozenbeek B, Maas AIR, Menon DK. Changing patterns in the epidemiology of traumatic brain injury. Nat Rev Neurol 2013;9:231-6.

38. Mathers CD, Loncar D. Projections of global mortality and burden of disease from 2002 to 2030. PLoS Med 2006;3:e442

39. Savola O, Niemelä O, Hillbom M. Alcohol intake and the pattern of trauma in young adults and working aged people admitted after trauma. Alcohol and Alcoholism 2005;40:269-73.

40. Sundstrøm T, Sollid S, Wentzel-Larsen T, Wester K. Head injury mortality in the Nordic countries. J Neurotrauma 2007;24:147-53.

41. Paljärvi T, Mäkelä P, Poikolainen K. Pattern of drinking and fatal injury: a population-based follow-up study of Finnish men. Addiction 2005;100:1851-9.

42.

Haddad SH, Arabi YM. Critical care management of severe traumatic brain injury in adults. Scand J Trauma Resusc Emerg Med 2012;20:12.

43. Rosenfeld JV, Maas AI, Bragge P, Morganti-Kossmann MC, Manley GT, Gruen RL. Early management of severe traumatic brain injury. Lancet 2012;380:1088-98.

44. Chesnut RM, Marshall LF, Klauber MR, Blunt BA, Baldwin N, Eisenberg HM, et al. The role of secondary brain injury in determining outcome from severe head injury. J Trauma 1993;34:216-22.
Unterberg AW, Stover J, Kress B, Kiening KL. Edema and brain trauma. Neuroscience 2004;129:1021-9.

46. Smith M. Critical care management of severe head injury. Anaesthesia \& Intensive Care Medicine 2014;15:164-7.

47. Brain Trauma Foundation, American Association of Neurological Surgeons, Congress of Neurological Surgeons. Guidelines for the management of severe traumatic brain injury. J. Neurotrauma2007;24 Suppl 1:S1-106.

48. Helmy AA, Vizcaychipi MM, Gupta AKA. Traumatic brain injury: intensive care management. $\mathrm{Br}$ J Anaesth 2007;99:32-42.

49. Hukkelhoven CWPM, Steyerberg EW, Rampen AJJ, Farace E, Habbema JDF, Marshall LF, et al. Patient age and outcome following severe traumatic brain injury: an analysis of 5600 patients. J Neurosurg 2003;99:666-73.

50. Raj R, Bendel S, Reinikainen M, Kivisaari R, Siironen J, Lång $\mathrm{M}$, et al. Hyperoxemia and long-term outcome after traumatic brain injury. Crit Care 2013;17:R177.

51. Roberts I, Yates D, Sandercock P, Farrell B, Wasserberg J, Lomas G, et al. Effect of intravenous corticosteroids on death within 14 days in 10008 adults with clinically significant head injury (MRC CRASH trial): randomised placebo-controlled trial. Lancet 2004;364:1321-8.

52. Edwards P, Arango M, Balica L, Cottingham R, El-Sayed H, Farrell B, et al. Final results of MRC CRASH, a randomised placebo-controlled trial of intravenous corticosteroid in adults with head injury-outcomes at 6 months. Lancet 2005;365:19579.

53. Mushkudiani NA, Engel DC, Steyerberg EW, Butcher I, Lu J, Marmarou A, et al. Prognostic value of demographic characteristics in traumatic brain injury: results from the IMPACT study. J Neurotrauma 2007;24:259-69.

54. Farace E, Alves WM. Do women fare worse: a metaanalysis of gender differences in traumatic brain injury outcome. J Neurosurg 2000;93:53945.

55. Groswasser Z, Cohen M, Keren O. Female TBI patients recover better than males. Brain Injury 1998;12:805-8.

56. Junpeng M, Huang S, Qin S. Progesterone for acute traumatic brain injury. Cochrane Database Syst Rev 2011;CD008409.

57. Teasdale G, Jennett B. Assessment of coma and impaired consciousness. A practical scale. Lancet $1974 ; 2: 81-4$

58. Mena JHJ, Sanchez AIA, Rubiano AMA, Peitzman ABA, Sperry JLJ, Gutierrez MIM, et al. Effect of the modified Glasgow Coma Scale score criteria for mild traumatic brain injury on mortality prediction: comparing classic and modified Glasgow Coma Scale score model scores of 13. J Trauma 2011;71:1185-93. 
59. Teasdale G, Maas A, Lecky F, Manley G, Stocchetti N, Murray G. The Glasgow Coma Scale at 40 years: standing the test of time. Lancet Neurology 2014;13:844-54.

60. Teasdale G, Jennett B. Assessment of coma and severity of brain damage. Anesthesiology 1978;49:225-6.

61. Marmarou A, Lu J, Butcher I, McHugh GS, Murray GD, Steyerberg EW, et al. Prognostic value of the Glasgow Coma Scale and pupil reactivity in traumatic brain injury assessed pre-hospital and on enrollment: an IMPACT analysis. J Neurotrauma 2007;24:270-80

62. Green SM. Cheerio, laddie! Bidding farewell to the Glasgow Coma Scale. Ann Emerg Med 2011;58:427-30.

63. Ritter AM, Muizelaar JP, Barnes T, Choi S, Fatouros P, Ward J, et al. Brain stem blood flow, pupillary response, and outcome in patients with severe head injuries. Neurosurgery 1999;44:941-8.

64. Ropper AH, Cole D, Louis DN. Clinicopathologic correlation in a case of pupillary dilation from cerebral hemorrhage. Arch Neurol 1991;48:1166-9.

65. van Leeuwen N, Lingsma HF, Perel P, Lecky F, Roozenbeek B, Lu J, et al. Prognostic value of major extracranial injury in traumatic brain injury: an individual patient data meta-analysis in 39,274 patients. Neurosurgery 2012;70:811-8.

66. Ho KM, Burrell M, Rao S. Extracranial injuries are important in determining mortality of neurotrauma. Crit Care Med 2010;38:1562-8.

67. Sarrafzadeh AS, Peltonen EE, Kaisers U, Küchler I, Lanksch WR, Unterberg AW. Secondary insults in severe head injury--do multiply injured patients do worse? Crit Care Med 2001;29:1116-23.

68. Maas AIR, Steyerberg EW, Butcher I, Dammers $\mathrm{R}, \mathrm{Lu}$ J, Marmarou A, et al. Prognostic value of computerized tomography scan characteristics in traumatic brain injury: results from the IMPACT study. J Neurotrauma 2007;24:303-14.

69. Maas AIR, Hukkelhoven CWPM, Marshall LF, Steyerberg EW. Prediction of outcome in traumatic brain injury with computed tomographic characteristics: a comparison between the computed tomographic classification and combinations of computed tomographic predictors. Neurosurgery 2005;57:1173-82.

70. Hulkower MB, Poliak DB, Rosenbaum SB, Zimmerman ME, Lipton ML. A decade of DTI in traumatic brain injury: 10 years and 100 articles later. AJNR Am J Neuroradiol 2013;34:2064-74.

71. Yuh EL, Cooper SR, Mukherjee P, Yue JK, Lingsma $\mathrm{H}$, Gordon W, et al. Diffusion Tensor Imaging for Outcome Prediction in Mild Traumatic Brain Injury: A TRACK-TBI Study. J Neurotrauma 2014;31:1457-77.

72.

Chesnut RM. Secondary brain insults after head injury: clinical perspectives. New Horiz 1995;3:366-75.
73. McHugh GS, Engel DC, Butcher I, Steyerberg EW, Lu J, Mushkudiani N, et al. Prognostic value of secondary insults in traumatic brain injury: results from the IMPACT study. J Neurotrauma 2007;24:287-93.

74. Manley G, Knudson MM, Morabito D, Damron S, Erickson V, Pitts L. Hypotension, hypoxia, and head injury: frequency, duration, and consequences. Arch Surg 2001;136:1118-23.

75. Stocchetti N, Furlan A, Volta F. Hypoxemia and arterial hypotension at the accident scene in head injury. J Trauma 1996;40:764-7.

76. Stocchetti N, Colombo A, Ortolano F, Videtta W, Marchesi R, Longhi L, et al. Time course of intracranial hypertension after traumatic brain injury. J Neurotrauma 2007;24:1339-46.

77. Salim A, Hadjizacharia P, DuBose J, Brown C, Inaba K, Chan LS, et al. Persistent hyperglycemia in severe traumatic brain injury: an independent predictor of outcome. Am Surg 2009;75:25-9.

78. Van Beek JGM, Mushkudiani NA, Steyerberg EW, Butcher I, McHugh GS, Lu J, et al. Prognostic value of admission laboratory parameters in traumatic brain injury: results from the IMPACT study. J Neurotrauma 2007;24:315-28.

79. LeRoux P. Haemoglobin management in acute brain injury. Curr Opin Crit Care 2013;19:83-91.

80. Laroche M, Kutcher ME, Huang MC, Cohen MJ, Manley GT. Coagulopathy after traumatic brain injury. Neurosurgery 2012;70:1334-45.

81. Maegele M. Coagulopathy after traumatic brain injury: incidence, pathogenesis, and treatment options. Transfusion 2013;53 Suppl 1:28S-37S.

82. Lustenberger T, Talving P, Kobayashi L, Inaba K, Lam L, Plurad D, et al. Time course of coagulopathy in isolated severe traumatic brain injury. Injury 2010;41:924-8.

83. Harhangi BS, Kompanje EJO, Leebeek FWG, Maas AIR. Coagulation disorders after traumatic brain injury. Acta Neurochir (Wien) 2008;150:165-75.

84. NICE-SUGAR Study Investigators, Finfer S, Chittock DR, Su SY-S, Blair D, Foster D, et al. Intensive versus conventional glucose control in critically ill patients. N Engl J Med 2009;360:1283-97.

85. Vespa PM, McArthur D, O’Phelan K, Glenn T. Persistently low extracellular glucose correlates with poor outcome 6 months after human traumatic brain injury despite a lack of increased lactate: a microdialysis study. J Cereb Blood Flow Metab 2003;23:865-77.

86. Holbein M, Béchir M, Ludwig S, Sommerfeld J, Cottini SR, Keel M, et al. Differential influence of arterial blood glucose on cerebral metabolism following severe traumatic brain injury. Crit Care 2009;13:R13. 
87. Schirmer-Mikalsen K, Vik A, Gisvold SE, Skandsen T, Hynne H, Klepstad P. Severe head injury: control of physiological variables, organ failure and complications in the intensive care unit. Acta anaesthesiologica Scandinavica 2007;51:1194-201.

88. Chamoun RB, Gopinath SP, Robertson CS. Biomarkers for Traumatic Brain Injury. European Critical Care \& Emergency Medicine 2009;1:4748.

89. Zetterberg H, Smith DH, Blennow K. Biomarkers of mild traumatic brain injury in cerebrospinal fluid and blood. Nat Rev Neurol 2013;9:201-10.

90. Czeiter E, Mondello S, Kovacs N, Sandor J, Gabrielli A, Schmid K, et al. Brain injury biomarkers may improve the predictive power of the IMPACT outcome calculator. J Neurotrauma 2012;29:17708.

91. Papa L, Ramia MM, Kelly JM, Burks SS, Pawlowicz A, Berger RP. Systematic review of clinical research on biomarkers for pediatric traumatic brain injury. J Neurotrauma 2013;30:324-38.

92. Stein SC, Georgoff P, Meghan S, Mizra K, Sonnad SS. 150 years of treating severe traumatic brain injury: a systematic review of progress in mortality. J Neurotrauma 2010;27:1343-53.

93. Fakhry SM, Trask AL, Waller MA, Watts DD, IRTC Neurotrauma Task Force. Management of brain-injured patients by an evidence-based medicine protocol improves outcomes and decreases hospital charges. J Trauma 2004;56:492-500.

94. Arabi YM, Haddad S, Tamim HM, Al-Dawood A, Al-Qahtani S, Ferayan A, et al. Mortality reduction after implementing a clinical practice guidelines-based management protocol for severe traumatic brain injury. J Crit Care 2010;25:190-5.

95. Clayton TJ, Nelson RJ, Manara AR. Reduction in mortality from severe head injury following introduction of a protocol for intensive care management. Br J Anaesth 2004;93:761-7.

96. Gerber LM, Chiu Y-L, Carney N, Hartl R, Ghajar J. Marked reduction in mortality in patients with severe traumatic brain injury. J Neurosurg 2013;119:1583-90.

97. Patel HC, Menon DK, Tebbs S, Hawker R, Hutchinson PJ, Kirkpatrick PJ. Specialist neurocritical care and outcome from head injury. Intensive Care Medicine 2002;28:547-53.

98. Bulger EM, Nathens AB, Rivara FP, Moore M, MacKenzie EJ, Jurkovich GJ, et al. Management of severe head injury: institutional variations in care and effect on outcome. Crit Care Med 2002;30:1870-6.

99. Mushkudiani NA, Hukkelhoven CWPM, Hernández AV, Murray GD, Choi SC, Maas AIR, et al. A systematic review finds methodological improvements necessary for prognostic models in determining traumatic brain injury outcomes. J Clin Epidemiol 2008;61:331-43.
100. Hukkelhoven CWPM, Steyerberg EW, Habbema JDF, Farace E, Marmarou A, Murray GD, et al. Predicting outcome after traumatic brain injury: development and validation of a prognostic score based on admission characteristics. J Neurotrauma 2005;22:1025-39.

101. David W Hosmer J, Lemeshow S, Sturdivant RX. Applied Logistic Regression. Hoboken, New Jersey: John Wiley \& Sons; 2013.

102. Choi SC, Muizelaar JP, Barnes TY, Marmarou A, Brooks DM, Young HF. Prediction tree for severely head-injured patients. J Neurosurg 1991;75:251-5.

103. Eftekhar B, Mohammad K, Ardebili HE, Ghodsi $\mathrm{M}$, Ketabchi E. Comparison of artificial neural network and logistic regression models for prediction of mortality in head trauma based on initial clinical data. BMC Med Inform Decis Mak 2005;5:3.

104. Sargent DJ. Comparison of artificial neural networks with other statistical approaches: results from medical data sets. Cancer 2001;91:1636-42.

105. Spackman KA. Combining logistic regression and neural networks to create predictive models. Proc Annu Symp Comput Appl Med Care 1992;:456-9.

106. Harrell FE, Lee KL, Califf RM, Pryor DB, Rosati RA. Regression modelling strategies for improved prognostic prediction. Statistics in medicine 1984;3:143-52.

107. Royston P, Moons KGM, Altman DG, Vergouwe Y. Prognosis and prognostic research: Developing a prognostic model. BMJ 2009;338:b604.

108. Steyerberg EW, Harrell FE, Borsboom GJ, Eijkemans MJ, Vergouwe Y, Habbema JD. Internal validation of predictive models: efficiency of some procedures for logistic regression analysis. J Clin Epidemiol 2001;54:774-81.

109. Picard RR, Berk KN. Data splitting. Am Statistician 1990;44:140-7.

110. Picard RR, Cook RD. Cross-Validation of Regression Models. Journal of the American Statistical Association 1984;79:575-83.

111. Efron B, Tibshirani R. An introduction to the bootstrap. CRC Press 1994;Monographs on Statistics \& Applied Probability.

112. Efron B, Tibshirani R. Improvements on cross-validation: the $632+$ bootstrap method. Journal of the American Statistical Association 1997;92:548-60.

113. Fox J. Bootstrapping regression models. 2002;Appendix to An R and S-PLUS Companion to Applied Regression.

114. Steyerberg EW. Clinical Prediction Models. New York: Springer Verlag; 2010.

115. Altman DG, Royston P. What do we mean by validating a prognostic model? Statistics in medicine 2000;19:453-73.

116. Justice AC, Covinsky KE, Berlin JA. Assessing the generalizability of prognostic information. Ann Intern Med 1999;130:515-24. 
117. Feldman Z, Contant CF, Robertson CS, Narayan RK, Grossman RG. Evaluation of the Leeds prognostic score for severe head injury. Lancet 1991;337:1451-3.

118. Bleeker SE, Moll HA, Steyerberg EW, Donders ART, Derksen-Lubsen G, Grobbee DE, et al. External validation is necessary in prediction research: a clinical example. J Clin Epidemiol 2003;56:826-32.

119. Hanley JA, McNeil BJ. The meaning and use of the area under a receiver operating characteristic (ROC) curve. Radiology 1982;143:29-36.

120. Steyerberg EW, Vickers AJ, Cook NR, Gerds T, Gonen M, Obuchowski N, et al. Assessing the performance of prediction models: a framework for traditional and novel measures. Epidemiology 2010;21:128-38.

121. Cook NR. Use and misuse of the receiver operating characteristic curve in risk prediction. Circulation 2007;115:928-35.

122. Vincent J-LJ, Sakr YY. SOFA so good for predicting long-term outcomes. Resuscitation 2012;83:537-8.

123. Lemeshow S, Hosmer DW. A review of goodness of fit statistics for use in the development of logistic regression models. Am J Epidemiol 1982;115:92-106.

124. Kramer AA, Zimmerman JE. Assessing the calibration of mortality benchmarks in critical care: The Hosmer-Lemeshow test revisited. Crit Care Med 2007;35:2052-6.

125. Bertolini G, D’Amico R, Nardi D, Tinazzi A, Apolone G. One model, several results: the paradox of the Hosmer-Lemeshow goodness-of-fit test for the logistic regression model. J Epidemiol Biostat 2000;5:251-3.

126. Finazzi S, Poole D, Luciani D, Cogo PE, Bertolini G. Calibration belt for quality-of-care assessment based on dichotomous outcomes. PLoS ONE 2011;6:e16110.

127. Miller ME, Langefeld CD, Tierney WM, Hui SL, McDonald CJ. Validation of probabilistic predictions. Med Decis Making 1993;13:49-58.

128. Miller ME, Hui SL, Tierney WM. Validation techniques for logistic regression models. Statistics in medicine 1991;10:1213-26.

129. Nagelkerke N. A note on a general definition of the coefficient of determination. Biometrika 1991;78:691-2.

130. Murray GD, Butcher I, McHugh GS, Lu J, Mushkudiani NA, Maas AIR, et al. Multivariable prognostic analysis in traumatic brain injury: results from the IMPACT study. J Neurotrauma 2007;24:329-37.

131. Pepe MS, Janes H, Longton G, Leisenring W, Newcomb P. Limitations of the odds ratio in gauging the performance of a diagnostic, prognostic, or screening marker. Am J Epidemiol 2004;159:88290.
132. Pencina MJ, D’Agostino RB, D’Agostino RB, Vasan RS. Evaluating the added predictive ability of a new marker: from area under the ROC curve to reclassification and beyond. Statistics in medicine 2008;27:157-72.

133. Zhu BP, Lemeshow S, Hosmer DW, Klar J, Avrunin J, Teres D. Factors affecting the performance of the models in the Mortality Probability Model II system and strategies of customization: a simulation study. Crit Care Med 1996;24:57-63.

134. Moreno R, Apolone G. Impact of different customization strategies in the performance of a general severity score. Crit Care Med 1997;25:2001-8.

135. Bakhshi-Raiez F, Peek N, Bosman RJ, de Jonge E, de Keizer NF. The impact of different prognostic models and their customization on institutional comparison of intensive care units. Crit Care Med 2007;35:2553-60.

136. Rothen HU, Takala J. Can outcome prediction data change patient outcomes and organizational outcomes? Curr Opin Crit Care 2008;14:513-9.

137. Woodhouse D, Berg M, van der Putten J, Houtepen J. Will benchmarking ICUs improve outcome? Curr Opin Crit Care 2009;15:450-5.

138. Hemmila MR, Nathens AB, Shafi S, Calland JF, Clark DE, Cryer HG, et al. The Trauma Quality Improvement Program: pilot study and initial demonstration of feasibility. J Trauma 2010;68:253-62.

139. Shafi S, Ahn C, Parks J, Nathens AB, Cryer HM, Gentilello LM, et al. Quality of Care Within a Trauma Center Is not Altered by Injury Type. J Trauma 2010;68:716-20.

140. Angus DC. Scoring system fatigue...and the search for a way forward. Crit Care Med 2000;28:2145-6.

141. Lemeshow S, Le Gall JR. Modeling the severity of illness of ICU patients. A systems update. JAMA 1994;272:1049-55.

142. Brinkman S, Abu-Hanna A, de Jonge E, de Keizer NF. Prediction of long-term mortality in ICU patients: model validation and assessing the effect of using in-hospital versus long-term mortality on benchmarking. Intensive Care Medicine 2013;39:1925-31.

143. Pouw ME, Peelen LM, Moons KGM, Kalkman CJ, Lingsma HF. Including post-discharge mortality in calculation of hospital standardised mortality ratios: retrospective analysis of hospital episode statistics. BMJ 2013;347:f5913.

144. Shafi S, Nathens AB, Parks J, Cryer HM, Fildes JJ, Gentilello LM. Trauma quality improvement using risk-adjusted outcomes. J Trauma 2008;64:599604.

145. Nathens AB, Xiong W, Shafi S. Ranking of trauma center performance: the bare essentials. J Trauma 2008;65:628-35. 
146. Lee KL, Pryor DB, Harrell FE, Califf RM, Behar VS, Floyd WL, et al. Predicting outcome in coronary disease. Statistical models versus expert clinicians. Am J Med 1986;80:553-60.

147. Barlow P, Teasdale G. Prediction of outcome and the management of severe head injuries: the attitudes of neurosurgeons. Neurosurgery 1986;19:989-91.

148. Perel P, Wasserberg J, Ravi RR, Shakur H, Edwards P, Roberts I. Prognosis following head injury: a survey of doctors from developing and developed countries. J Eval Clin Pract 2007;13:464-5.

149. Murray LS, Teasdale GM, Murray GD, Jennett B, Miller JD, Pickard JD, et al. Does prediction of outcome alter patient management? Lancet 1993;341:1487-91.

150. Maas AIR, Roozenbeek B, Manley GT. Clinical trials in traumatic brain injury: past experience and current developments. Neurotherapeutics 2010;7:115-26.

151. Roozenbeek B, Maas AIR, Lingsma HF, Butcher I, Lu J, Marmarou A, et al. Baseline characteristics and statistical power in randomized controlled trials: selection, prognostic targeting, or covariate adjustment? Crit Care Med 2009;37:2683-90.

152. Hernández AV, Steyerberg EW, Habbema JDF. Covariate adjustment in randomized controlled trials with dichotomous outcomes increases statistical power and reduces sample size requirements. J Clin Epidemiol 2004;57:454-60.

153. Murray GD, Barer D, Choi S, Fernandes H, Gregson B, Lees KR, et al. Design and analysis of phase III trials with ordered outcome scales: the concept of the sliding dichotomy. J Neurotrauma 2005;22:511-7.

154. Roozenbeek B, Lingsma HF, Perel P, Edwards P, Roberts I, Murray GD, et al. The added value of ordinal analysis in clinical trials: an example in traumatic brain injury. Crit Care 2011;15:R127.

155. Maas A, Menon D, Steyerberg E, Citerio G, Lecky F, Manley G, et al. Collaborative European NeuroTrauma Effectiveness Research in TBI (CENTER-TBI): A Prospective Longitudinal Observational Study. Neurosurgery 2014; In Press.

156. Prioritization COCER, Services BOHC, Institute of Medicine. Initial National Priorities for Comparative Effectiveness Research. Washington, DC: National Academies Press; 2009.

157. Maas AIR, Marmarou A, Murray GD, Teasdale SGM, Steyerberg EW. Prognosis and clinical trial design in traumatic brain injury: the IMPACT study. J Neurotrauma 2007;24:232-8.

158. Marmarou A, Lu J, Butcher I, McHugh GS, Mushkudiani NA, Murray GD, et al. IMPACT database of traumatic brain injury: design and description. J Neurotrauma 2007;24:239-50.
159. Roozenbeek B, Chiu Y-L, Lingsma HF, Gerber LM, Steyerberg EW, Ghajar J, et al. Predicting 14-day mortality after severe traumatic brain injury: application of the IMPACT models in the brain trauma foundation TBI-trac ${ }^{\circledR}$ New York State database. J Neurotrauma 2012;29:1306-12.

160. Roozenbeek B, Lingsma HF, Lecky FE, Lu J, Weir J, Butcher I, et al. Prediction of outcome after moderate and severe traumatic brain injury: external validation of the International Mission on Prognosis and Analysis of Clinical Trials (IMPACT) and Corticoid Randomisation After Significant Head injury (CRASH) prognostic models. Crit Care Med 2012;40:1609-17.

161. Lingsma H, Andriessen TMJC, Haitsema I, Horn J, van der Naalt J, Franschman G, et al. Prognosis in moderate and severe traumatic brain injury: External validation of the IMPACT models and the role of extracranial injuries. J Trauma Acute Care Surg 2013;74:639-46.

162. Panczykowski DM, Puccio AM, Scruggs BJ, Bauer JS, Hricik AJ, Beers SR, et al. Prospective independent validation of IMPACT modeling as a prognostic tool in severe traumatic brain injury. J Neurotrauma 2012;29:47-52.

163. MRC CRASH Trial Collaborators, Perel P, Arango M, Clayton T, Edwards P, Komolafe E, et al. Predicting outcome after traumatic brain injury: practical prognostic models based on large cohort of international patients. BMJ 2008;336:425-9.

164. Wong GKC, Teoh J, Yeung J, Chan E, Siu E, Woo P, et al. Outcomes of traumatic brain injury in Hong Kong: validation with the TRISS, CRASH, and IMPACT models. J Clin Neurosci 2013;20:1693-6.

165. Han J, King NKK, Neilson SJ, Gandhi MP, Ng I. External Validation of the CRASH and IMPACT Prognostic Models in Severe Traumatic Brain Injury. J Neurotrauma 2014;31:1146-52.

166. Honeybul S, Ho KM, Lind CRP, Gillett GR. Validation of the CRASH model in the prediction of 18-month mortality and unfavorable outcome in severe traumatic brain injury requiring decompressive craniectomy. J Neurosurg 2014;120:11317.

167. Marshall LF, Marshall SB, Klauber MR, Clark MB. A new classification of head injury based on computerized tomography. J Neurosurg 1991;75:S14S22.

168. Jacobs B, Beems T, van der Vliet TM, van Vugt $\mathrm{AB}$, Hoedemaekers C, Horn J, et al. Outcome prediction in moderate and severe traumatic brain injury: a focus on computed tomography variables. Neurocrit Care 2013;19:79-89.

169. Nelson DW, Nyström H, MacCallum RM, Thornquist B, Lilja A, Bellander B-M, et al. Extended analysis of early computed tomography scans of traumatic brain injured patients and relations to outcome. J Neurotrauma 2010;27:51-64. 
170. Huang Y-H, Deng Y-H, Lee T-C, Chen W-F. Rotterdam computed tomography score as a prognosticator in head-injured patients undergoing decompressive craniectomy. Neurosurgery 2012;71:80-5.

171. Mata-Mbemba D, Mugikura S, Nakagawa A, Murata T, Ishii K, Li L, et al. Early CT Findings to Predict Early Death in Patients with Traumatic Brain Injury: Marshall and Rotterdam CT Scoring Systems Compared in the Major Academic Tertiary Care Hospital in Northeastern Japan. Acad Radiol 2014;21:605-11.

172. Baker SP, O’Neill B, Haddon W, Long WB. The injury severity score: a method for describing patients with multiple injuries and evaluating emergency care. J Trauma 1974;14:187-96.

173. Osler T, Baker SP, Long W. A modification of the injury severity score that both improves accuracy and simplifies scoring. J Trauma 1997;43:922-5.

174. The abbreviated Injury Scale 2005 - Update 2008. Association for the Advancement of Automotive Medicine 2008; Des Plains, IL 60018.

175. Champion HR, Sacco WJ, Carnazzo AJ, Copes W, Fouty WJ. Trauma score. Crit Care Med 1981;9:672-6.

176. Champion HR, Sacco WJ, Copes WS, Gann DS, Gennarelli TA, Flanagan ME. A revision of the Trauma Score. J Trauma 1989;29:623-9.

177. Boyd CR, Tolson MA, Copes WS. Evaluating trauma care: the TRISS method. Trauma Score and the Injury Severity Score. J Trauma 1987;27:370-8.

178. Gabbe BJ, Cameron PA, Wolfe R. TRISS: does it get better than this? Academic Emergency Medicine 2004;11:181-6.

179. Demetriades D, Chan LS, Velmahos G, Berne TV, Cornwell EE, Belzberg H, et al. TRISS methodology in trauma: the need for alternatives. Br J Surg 1998;85:379-84.

180. Lefering R. Development and validation of the revised injury severity classification score for severely injured patients. European Journal of Trauma and Emergency Surgery 2009;35:437-47.

181. Knaus WA, Zimmerman JE, Wagner DP, Draper EA, Lawrence DE. APACHE-acute physiology and chronic health evaluation: a physiologically based classification system. Crit Care Med 1981;9:591-7.

182. Le Gall JR, Loirat P, Alperovitch A, Glaser P, Granthil C, Mathieu D, et al. A simplified acute physiology score for ICU patients. Crit Care Med 1984;12:975-7.

183. Knaus WA, Draper EA, Wagner DP, Zimmerman JE. APACHE II: a severity of disease classification system. Crit Care Med 1985;13:818-29.

184. Knaus WA, Wagner DP, Draper EA, Zimmerman JE, Bergner M, Bastos PG, et al. The APACHE III prognostic system. Risk prediction of hospital mortality for critically ill hospitalized adults. Chest 1991;100:1619-36.
185. Zimmerman JE, Kramer AA, McNair DS, Malila FM. Acute Physiology and Chronic Health Evaluation (APACHE) IV: hospital mortality assessment for today's critically ill patients. Crit Care Med 2006;34:1297-310.

186. Le Gall JRJ, Lemeshow SS, Saulnier FF. A new Simplified Acute Physiology Score (SAPS II) based on a European/North American multicenter study. JAMA 1993;270:2957-63.

187. Metnitz PGH, Moreno RP, Almeida E, Jordan B, Bauer P, Campos RA, et al. SAPS 3--From evaluation of the patient to evaluation of the intensive care unit. Part 1: Objectives, methods and cohort description. Intensive Care Medicine 2005;31:1336-44.

188. Moreno RP, Metnitz PGH, Almeida E, Jordan B, Bauer P, Campos RA, et al. SAPS 3--From evaluation of the patient to evaluation of the intensive care unit. Part 2: Development of a prognostic model for hospital mortality at ICU admission. Intensive Care Medicine 2005;31:1345-55.

189. Ferreira FLF, Bota DPD, Bross AA, Mélot CC, Vincent JLJ. Serial evaluation of the SOFA score to predict outcome in critically ill patients. JAMA 2001;286:1754-8.

190. Minne L, Abu-Hanna A, de Jonge E. Evaluation of SOFA-based models for predicting mortality in the ICU: A systematic review. Crit Care 2008;12:R161.

191. Pettilä V, Pettilä M, Sarna S, Voutilainen P, Takkunen O. Comparison of multiple organ dysfunction scores in the prediction of hospital mortality in the critically ill. Crit Care Med 2002;30:1705-11.

192. Menon DK, Zahed C. Prediction of outcome in severe traumatic brain injury. Curr Opin Crit Care 2009;15:437-41.

193. Hyam JA, Welch CA, Harrison DA, Menon DK. Case mix, outcomes and comparison of risk prediction models for admissions to adult, general and specialist critical care units for head injury: a secondary analysis of the ICNARC Case Mix Programme Database. Crit Care 2006;10 :S2.

194. Vassar MJ, Lewis FR, Chambers JA, Mullins RJ, O'Brien PE, Weigelt JA, et al. Prediction of outcome in intensive care unit trauma patients: a multicenter study of Acute Physiology and Chronic Health Evaluation (APACHE), Trauma and Injury Severity Score (TRISS), and a 24-hour intensive care unit (ICU) point system. J Trauma 1999;47:324-9.

195. Livingston BM, MacKirdy FN, Howie JC, Jones R, Norrie JD. Assessment of the performance of five intensive care scoring models within a large Scottish database. Crit Care Med 2000;28:1820-7.

196. Rocca B, Martin C, Viviand X, Bidet PF, SaintGilles HL, Chevalier A. Comparison of four severity scores in patients with head trauma. J Trauma 1989;29:299-305. 
197. Reiter A, Mauritz W, Jordan B, Lang T, Pölzl A, Pelinka L, et al. Improving risk adjustment in critically ill trauma patients: the TRISS-SAPS Score. J Trauma 2004;57:375-80.

198. Vincent JL, de Mendonça A, Cantraine F, Moreno $\mathrm{R}$, Takala J, Suter PM, et al. Use of the SOFA score to assess the incidence of organ dysfunction/failure in intensive care units: results of a multicenter, prospective study. Working group on "sepsis-related problems" of the European Society of Intensive Care Medicine. Crit Care Med 1998;26:1793-800.

199. Vincent JL, Ferreira F, Moreno R. Scoring systems for assessing organ dysfunction and survival. Critical Care Clinics 2000;16:353-66.

200. Reinikainen M, Mussalo P, Hovilehto S, Uusaro A, Varpula T, Kari A, et al. Association of automated data collection and data completeness with outcomes of intensive care. A new customised model for outcome prediction. Acta anaesthesiologica Scandinavica 2012;56:1114-22.

201. Ringdal KG, Coats TJ, Lefering R, Di Bartolomeo S, Steen PA, Røise O, et al. The Utstein template for uniform reporting of data following major trauma: a joint revision by SCANTEM, TARN, DGU-TR and RITG. Scand J Trauma Resusc Emerg Med 2008; $16: 7$.

202. Gunning K, Rowan K. ABC of intensive care: outcome data and scoring systems. BMJ 1999;319:241-4.

203. Gebel JM, Sila CA, Sloan MA, Granger CB, Weisenberger JP, Green CL, et al. Comparison of the $\mathrm{ABC} / 2$ estimation technique to computer-assisted volumetric analysis of intraparenchymal and subdural hematomas complicating the GUSTO-1 trial. Stroke 1998;29:1799-801.

204. Kothari RU, Brott T, Broderick JP, Barsan WG, Sauerbeck LR, Zuccarello M, et al. The ABCs of measuring intracerebral hemorrhage volumes. Stroke 1996;27:1304-5.

205. Jennett B, Bond M. Assessment of outcome after severe brain damage. Lancet 1975;1:480-4.

206. Vincent JL, Moreno R, Takala J, Willatts S, de Mendonça A, Bruining H, et al. The SOFA (Sepsis-related Organ Failure Assessment) score to describe organ dysfunction/failure. Intensive Care Medicine 1996;22:707-10.

207. Kundu S, Aulchenko YS, van Duijn CM, Janssens ACJW. PredictABEL: an R package for the assessment of risk prediction models. Eur J Epidemiol 2011;26:261-4.

208. Robin X, Turck N, Hainard A, Tiberti N, Lisacek F, Sanchez J-C, et al. pROC: an open-source package for R and S+ to analyze and compare ROC curves. BMC Bioinformatics 2011;12:77.

209. Harrell FE Jr. RMS: regression modeling strategies. R package version 2009
210. Hilden J, Habbema JD, Bjerregaard B. The measurement of performance in probabilistic diagnosis. III. Methods based on continuous functions of the diagnostic probabilities. Methods Inf Med 1978;17:238-46.

211. Nattino G, Finazzi S, Bertolini G. A new calibration test and a reappraisal of the calibration belt for the assessment of prediction models based on dichotomous outcomes. Statistics in medicine 2014;33:2390-407.

212. DeLong ER, DeLong DM, Clarke-Pearson DL. Comparing the areas under two or more correlated receiver operating characteristic curves: a nonparametric approach. Biometrics 1988;44:837-45.

213. Seshan VE, Gonen M, Begg CB. Comparing ROC curves derived from regression models. Statistics in medicine 2013;32:1483-93.

214. Freedman DA. Bootstrapping Regression Models. The Annals of Statistics 1981;9:1218-28.

215. Moons KGM, Harrell FE, Steyerberg EW. Should scoring rules be based on odds ratios or regression coefficients? J Clin Epidemiol 2002;55:1054-5.

216. Royston P, Altman DG, Sauerbrei W. Dichotomizing continuous predictors in multiple regression: a bad idea. Statistics in medicine 2006;25:127-41.

217. Boyd O, Grounds RM. Physiological scoring systems and audit. Lancet 1993;341:1573-4.

218. Lemeshow S, Teres D, Klar J, Avrunin JS, Gehlbach SH, Rapoport J. Mortality Probability Models (MPM II) based on an international cohort of intensive care unit patients. JAMA 1993;270:247886.

219. Higgins TL, Teres D, Copes WS, Nathanson BH, Stark M, Kramer AA. Assessing contemporary intensive care unit outcome: an updated Mortality Probability Admission Model (MPM0-III). Crit Care Med 2007;35:827-35.

220. Patel HC, Bouamra O, Woodford M, King AT, Yates DW, Lecky FE, et al. Trends in head injury outcome from 1989 to 2003 and the effect of neurosurgical care: an observational study. Lancet 2005;366:1538-44.

221. Lefering R, Huber-Wagner S, Nienaber U, Maegele $\mathrm{M}$, Bouillon B. Update of the trauma risk adjustment model of the TraumaRegister DGU ${ }^{\mathrm{m} x}$ : the Revised Injury Severity Classification, version II. Critical Care 2014;18.

222. Lingsma HF, Roozenbeek B, Li B, Lu J, Weir J, Butcher I, et al. Large between-center differences in outcome after moderate and severe traumatic brain injury in the international mission on prognosis and clinical trial design in traumatic brain injury (IMPACT) study. Neurosurgery 2011;68:601-7. 
223. De Silva MJ, Roberts I, Perel P, Edwards P, Kenward MG, Fernandes J, et al. Patient outcome after traumatic brain injury in high-, middleand low-income countries: analysis of data on 8927 patients in 46 countries. Int J Epidemiol 2009;38:452-8.

224. Allard CB, Scarpelini S, Rhind SG, Baker AJ, Shek $\mathrm{PN}$, Tien $\mathrm{H}$, et al. Abnormal coagulation tests are associated with progression of traumatic intracranial hemorrhage. J Trauma 2009;67:959-67.

225. Stein SC, Young GS, Talucci RC, Greenbaum BH, Ross SE. Delayed brain injury after head trauma: significance of coagulopathy. Neurosurgery 1992;30:160-5.

226. Nekludov M, Bellander B-M, Blombäck M, Wallen HN. Platelet dysfunction in patients with severe traumatic brain injury. J Neurotrauma 2007;24:1699-706.

227. Heinzelmann M, Platz A, Imhof HG. Outcome after acute extradural haematoma, influence of additional injuries and neurological complications in the ICU. Injury 1996;27:345-9.

228. Lefering R, Paffrath T, Linker R, Bouillon B, Neugebauer EAM, Deutsche Gesellschaft für Unfallchirurgie/German Society for Trauma Surgery. Head injury and outcome - what influence do concomitant injuries have? J Trauma 2008;65:1036-43.

229. Pape HC. Classification of patients with multiple injuries--is the polytrauma patient defined adequately in 2012? Injury 2012;43:127-8.

230. McLain RF. Functional outcomes after surgery for spinal fractures: return to work and activity. Spine 2004;29:470-7.

231. Butcher NE, Balogh ZJ. Update on the definition of polytrauma. European Journal of Trauma and Emergency Surgery 2014;40:107-11.

232. Jacobs B, Beems T, van der Vliet TM, Diaz-Arrastia RR, Borm GF, Vos PE. Computed tomography and outcome in moderate and severe traumatic brain injury: hematoma volume and midline shift revisited. J Neurotrauma 2011;28:203-15.

233. Mattioli C, Beretta L, Gerevini S, Veglia F, Citerio G, Cormio M, et al. Traumatic subarachnoid hemorrhage on the computerized tomography scan obtained at admission: a multicenter assessment of the accuracy of diagnosis and the potential impact on patient outcome. J Neurosurg 2003;98:37-42.

234. Wardlaw JM, Easton VJ, Statham P. Which CT features help predict outcome after head injury? J Neurol Neurosurg Psychiatr 2002;72:188-92.

235. Servadei F, Murray GD, Teasdale GM, Dearden M, Iannotti F, Lapierre F, et al. Traumatic subarachnoid hemorrhage: demographic and clinical study of 750 patients from the European brain injury consortium survey of head injuries. Neurosurgery 2002;50:261-7.
236. Servadei F, Murray GD, Penny K, Teasdale GM, Dearden M, Iannotti F, et al. The value of the "worst" computed tomographic scan in clinical studies of moderate and severe head injury. European Brain Injury Consortium. Neurosurgery 2000;46:70-5.

237. Poca MA, Sahuquillo J, Mataró M, Benejam B, Arikan F, Báguena M. Ventricular enlargement after moderate or severe head injury: a frequent and neglected problem. J Neurotrauma 2005;22:1303-10.

238. Tian H-L, Xu T, Hu J, Cui Y-H, Chen H, Zhou L-F. Risk factors related to hydrocephalus after traumatic subarachnoid hemorrhage. Surg Neurol 2008;69:241-6.

239. Vergouwe Y, Moons KGM, Steyerberg EW. External validity of risk models: Use of benchmark values to disentangle a case-mix effect from incorrect coefficients. Am J Epidemiol 2010;172:971-80

240. Serrano N. Calibration strategies to validate predictive models: is new always better? Intensive Care Medicine 2012;38:1246-8.

241. Nattino G, Finazzi S, Bertolini G. Comments on "Graphical assessment of internal and external calibration of logistic regression models by using loess smoothers" by Peter C. Austin and Ewout W. Steyerberg. Statistics in medicine 2014;33:2696-8.

242. Jennett B, Teasdale G, Galbraith S, Pickard J, Grant H, Braakman R, et al. Severe head injuries in three countries. J Neurol Neurosurg Psychiatr 1977;40:291-8.

243. Foulkes MA, Eisenberg HM, Jane JA, Marmarou A, Marshall LF, Group TTCDBR. The Traumatic Coma Data Bank: design, methods, and baseline characteristics. J Neurosurg 1991;75:S8-S13.

244. Murray LS, Teasdale GM, Murray GD, Miller DJ, Pickard JD, Shaw MD. Head injuries in four British neurosurgical centres. Br J Neurosurg 1999;13:564-9.

245. Murray GD, Teasdale GM, Braakman R, Cohadon F, Dearden M, Iannotti F, et al. The European Brain Injury Consortium survey of head injuries. Acta Neurochir (Wien) 1999;141:223-36.

246. Rusnak M, Janciak I, Majdan M, Wilbacher I, Mauritz W, Australian Severe TBI Study Investigators. Severe traumatic brain injury in Austria I: introduction to the study. Wien Klin Wochenschr 2007;119:23-8.

247. Ng I, Lee K-K, Lim JHG, Wong H-B, Yan X-Y. Investigating gender differences in outcome following severe traumatic brain injury in a predominantly Asian population. Br J Neurosurg 2006;20:73-8.

248. Andriessen TMJC, Horn J, Franschman G, van der Naalt J, Haitsma I, Jacobs B, et al. Epidemiology, severity classification, and outcome of moderate and severe traumatic brain injury: a prospective multicenter study. J Neurotrauma 2011;28:201931. 
249. Weir J, Steyerberg EW, Butcher I, Lu J, Lingsma HF, McHugh GS, et al. Does the extended Glasgow Outcome Scale add value to the conventional Glasgow Outcome Scale? J Neurotrauma 2012;29:53-8.

250. McHugh GS, Butcher I, Steyerberg EW, Lu J, Mushkudiani N, Marmarou A, et al. Statistical approaches to the univariate prognostic analysis of the IMPACT database on traumatic brain injury. J Neurotrauma 2007;24:251-8.

251. Thelin EP, Nelson DW, Bellander B-M. Secondary peaks of S100B in serum relate to subsequent radiological pathology in traumatic brain injury. Neurocrit Care 2014;20:217-29.

252. Fehlings MG, Baker A. Is there a role for hyperoxia in the management of severe traumatic brain injury? J Neurosurg 2007;106:525-5.
253. Kumaria A, Tolias CM. Normobaric hyperoxia therapy for traumatic brain injury and stroke: a review. Br J Neurosurg 2009;23:576-84.

254. Opreanu RC, Kuhn D, Basson MD. Influence of alcohol on mortality in traumatic brain injury. J Am Coll Surg 2010;210:997-1007.

255. Shahin H, Gopinath SP, Robertson CS. Influence of alcohol on early Glasgow Coma Scale in head-injured patients. J Trauma 2010;69:1176-81.

256. Raj R, Skrifvars MB, Kivisaari R, Hernesniemi J, Lappalainen J, Siironen J. Acute alcohol intoxication and long-term outcome in patients with traumatic brain injury. J Neurotrauma 2014; In Press. 